$$
\text { UNIVERSIDADE DE SÃO PAULO }
$$

FACULDADE DE ZOOTECNIA E ENGENHARIA DE ALIMENTOS

ANDRÉ MESQUITA

AÇÃO DO FENETIL ÉSTER DO ÁCIDO CAFEICO (CAPE) EM LEISHMANIA (LEISHMANIA) AMAZONENSIS 


\title{
ANDRÉ MESQUITA
}

\section{AÇÃO DO FENETIL ÉSTER DO ÁCIDO CAFEICO (CAPE) EM LEISHMANIA (LEISHMANIA) AMAZONENSIS}

\author{
VERSÃO CORRIGIDA
}

Dissertação apresentada à Faculdade de Zootecnia e Engenharia de Alimentos da Universidade de São Paulo, como parte dos requisitos para a obtenção do título de Mestre em Ciências do programa de Pós-graduação em Biociência Animal.

Área de Concentração: Bioagentes Patogênicos.

Orientador: Prof. Dr. Edson Roberto da Silva

Coorientadora: Profa. Dra. Claudia do Carmo Maquiaveli 
Ficha catalográfica elaborada pelo

Serviço de Biblioteca e Informação, FZEA/USP,

com os dados fornecidos pelo(a) autor(a)

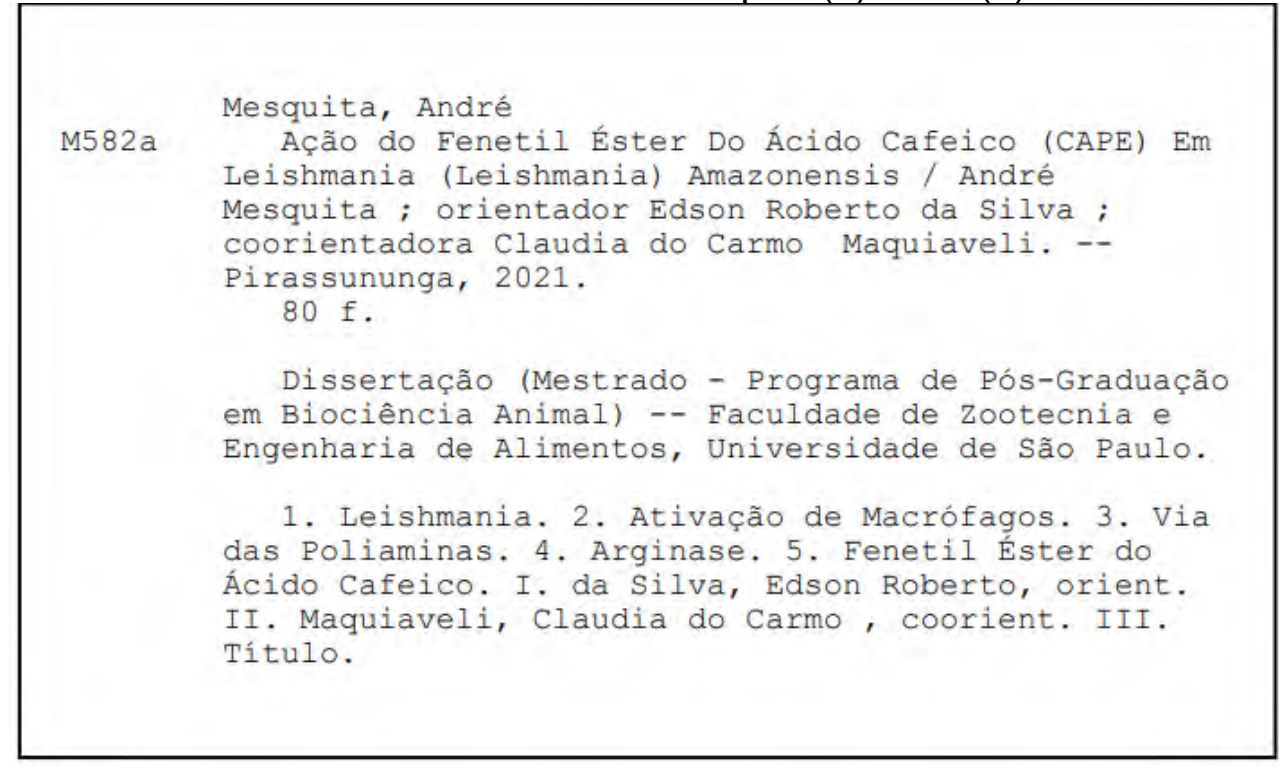

Permitida a cópia total ou parcial deste documento, desde que citada a fonte - o autor 


\section{AÇÃO DO FENETIL ÉSTER DO ÁCIDO CAFEICO (CAPE) EM LEISHMANIA}

(LEISHMANIA) AMAZONENSIS

Dissertação apresentada à Faculdade de Zootecnia e Engenharia de Alimentos da Universidade de São Paulo, como parte dos requisitos para a obtenção do título de Mestre em Ciências do programa de Pós-graduação em Biociência Animal.

Área de Concentração: Bioagentes Patogênicos.

Orientador: Prof. Dr. Edson Roberto da Silva

Coorientadora: Profa. Dra. Claudia do Carmo Maquiaveli

Data de aprovação:

BANCA EXAMINADORA

Prof. Dr. Antônio Augusto Mendes Maia

Instituição: Universidade São Paulo (Faculdade de Zootecnia e Engenharia de Alimentos)

Profa. Dra. Carolina Moura Costa Catta Preta Instituição:National Institute of Allergy and Infectious Diseases (NIAID), National Institutes of Health (NIH).

Profa. Dra. Trícia Maria Ferreira de Sousa Oliveira Instituição: Universidade São Paulo (Faculdade de Medicina Veterinária e Zootecnia) 


\section{AGRADECIMENTOS}

Primeiramente gostaria de agradecer a Deus por me guiar nestes anos, me dando forças para seguir em cada noite virada, me dando inspiração e atendendo minhas preces nos momentos mais difíceis. Também não posso deixar de agradecer meus pais, Maria Marcia Scherma Mesquita e João Maria Mesquita pelo apoio e conforto emocional, além do incentivo de nunca deixar abater nas adversidades. Ao meu namorado, Danilo Aparecido Meler, agradeço todo o carinho, paciência e ajuda prestada nestes anos, por mais que houve tropeços nestes tempos difíceis, tudo teria sido mais difícil sem você.

A Fundação de Amparo à Pesquisa do Estado de São Paulo (FAPESP) pelo financiamento da pesquisa através da bolsa $n^{\circ}$ 19/23769-4. Aos meus orientadores Dr. Edson Roberto da Silva e Dra. Claudia do Carmo Maquiaveli, pela grande oportunidade que me deram em ser orientado, no período que passei sob seus ensinamentos foram compartilhados muito além de saberes técnicos e científicos, mas valores humanos que vão além das páginas dos artigos e paredes do laboratório.

A Andressa Parca e Thaís Ribeiro Fadel por tudo que vivemos nas aulas, trabalhos, viagens e momentos de mútuo apoio foi graças a vocês que cheguei ao final com uma bagagem cheia de vivências e amadurecimento. A Tamiris Maganha, Amanda Murarolli Marinho e Camila Silveira Stanquini vocês também foram grandes companheiras de caminhada. Aos alunos Gabriel Santos, Gabriel Andrade e Bárbara Hild, nós ficamos muito tempo juntos, rimos e sofremos não somente nos resultados não alcançados, mas no nosso campo pessoal e sempre tentamos nos ajudar mesmo que em simples conselhos.

Aos membros técnicos Flávia Simone Munin, Luciana Machado, Márcia Ramos Monteiro da Silva, Julia Cristina Benassi e Marcelo Thomazini pelo acolhimento e no seus respectivos laboratórios, foram várias oportunidades de grande crescimento profissional para mim.

Um agradecimento especial aos docentes Dr. Heidge Fukumasu, Dr. Silvio Henrique de Freitas e Dr. Juliano Coelho da Silveira pelos sábios ensinamentos passados na disciplina Seminários em Biociência Animal, a Dra. Daniele dos Santos Martins pelos sábios ensinamentos passados na disciplina de Animais como 
Modelos experimentais e a Dra. Trícia Maria Ferreira de Sousa Oliveira pela participação na qualificação e defesa do mestrado.

E por último e não menos importante, a todas as professoras que fizeram parte do meu ciclo escolar, professora de Ciências Maria da Graças Dix, professora de Língua Portuguesa Naise Santos, a professora de História Audrey Roberta Hengstmann e professoras enfermeiras Melina Renata Blascke Barbiere, Mariana Alonso Carraro, Fernanda Gonçalves, Sandra Sueli Celano e Ana Paula Santos, vocês foram as agentes que me inspiraram, me embasaram nas minhas escolhas profissionais e acadêmicas. Tudo isso só foi possível por causa de vocês. 
Que ninguém te faça duvidar, cuida da tua "raridade" como a flor mais preciosa da tua árvore.

Tu és o sonho de todos os teus antepassados.

Bert Hellinger. 
RESUMO

MESQUITA, A. Ação do fenetil éster do ácido cafeico (CAPE) em Leishmania (Leishmania) Amazonensis. 2021, 80 p. Dissertação de mestrado. Faculdade de Zootecnia e Engenharia de Alimentos, Universidade de São Paulo, Pirassununga, 2021.

As leishmanioses são doenças causadas por parasitas intracelulares do gênero Leishmania e seu processo infeccioso é potencializado na presença da enzima arginase e na ativação de macrófagos pelo sistema Th2. Atualmente, são registrados casos de resistência parasitária à terapêutica e ao óxido nítrico. O fenetil éster do ácido cafeico (CAPE) é um polifenol encontrado em plantas e na própolis e possui uma diversidade de efeitos biológicos. O objetivo desta dissertação foi verificar se o CAPE possui potencial para eliminar cepas de Leishmania (Leishmania) amazonensis. A enzima arginase recombinante de $L$. (L.) amazonensis foi utilizada como alvo terapêutico para correlacionar com a ação sobre promastigotas e amastigotas intracelulares. Macrófagos infectados com o parasito foram ativados com LPS + IFN $-\gamma$ associados ou não com o CAPE para avaliação do índice de infectividade. Também foi realizado um ensaio de reversão da ação do CAPE em macrófagos infectados tratados com o composto associado ou não com Lornitina com o objetivo de verificar se a ação do composto era revertida após suplementação. Os resultados mostraram que o CAPE apresentou uma EC 50 de 1,9 $\mu \mathrm{M}$ com $95 \% \mathrm{Cl}$ de $1,4-2,6 \mu \mathrm{M}$ sob a enzima arginase do parasito, inibindo a enzima de forma não competitiva. $\mathrm{O}$ valor de $\mathrm{IC}_{50}$ nos promastigotas foi de $8,6 \mu \mathrm{M}$ com variação entre $7,2 \mu \mathrm{M}$ à $10,4 \mu \mathrm{M}$ (intervalo de confiança $(\mathrm{Cl})$ de $95 \%$ ). A concentração que reduziu em $50 \%$ o índice de infectividade foi de $16,3 \mu \mathrm{M}$ com variação entre $9,0 \mu \mathrm{M}$ a 31,5 $\mu \mathrm{M}(\mathrm{Cl} 95 \%)$. A suplementação com L-ornitina não reverteu a ação do CAPE evidenciando que o polifenol, embora seja um potente inibidor da enzima arginase do parasito, o seu efeito leishmanicida ocorre por mecanismo desconhecido. Conclusão: o CAPE é um composto que possui ação contra $L$. (L.) amazonensis, mas não deve agir através da inibição da arginase. A ação leishmanicida do CAPE contra as duas formas do parasito pode servir de ponto de partida para o desenvolvimento de um novo tratamento para a leishmaniose.

Palavras-chave: CAPE, arginase, poliaminas, Leishmania. 
MESQUITA, A. Action of caffeic acid phenethyl ester (CAPE) in Leishmania (Leishmania) Amazonensis. 2021, 80 p. M.Sc. Dissertation - Faculdade de Zootecnia e Engenharia de Alimentos, Universidade de São Paulo, Pirassununga, 2021.

Leishmaniasis are diseases caused by intracellular parasites of the Leishmania genus and its infectious process is potentiated in the presence of the arginase enzyme and the activation of macrophages by the Th2 system. Currently, cases of parasitic resistance to therapy and nitric oxide are reported. Caffeic acid phenethyl ester (CAPE) is a polyphenol found in plants and propolis and has a variety of biological effects. The objective of this dissertation was to verify if CAPE has the potential to eliminate Leishmania (Leishmania) amazonensis strains. The recombinant arginase enzyme from $L$. (L.) amazonensis was used as a therapeutic target to correlate with the action on intracellular promastigotes and amastigotes. Macrophages infected with the parasite were activated with LPS + IFN- $\gamma$ associated or not with CAPE to assess the infectivity index. A reversion test of the action of CAPE in infected macrophages treated with the compound associated or not with Lornithine was also carried out to verify if the action of the compound was reverted after supplementation. The results showed that CAPE had an $\mathrm{EC}_{50}$ of $1.9 \mu \mathrm{M}$ with a $95 \% \mathrm{Cl}$ of $1.4-2.6 \mu \mathrm{M}$ under the parasite arginase enzyme, inhibiting the enzyme in a non-competitive way. The $\mathrm{IC}_{50}$ value in promastigotes was $8.6 \mu \mathrm{M}$, ranging from $7.2 \mu \mathrm{M}$ to $10.4 \mu \mathrm{M}(95 \%$ confidence interval $(\mathrm{Cl})$. The concentration that reduced the infectivity index by $50 \%$ was $16.3 \mu \mathrm{M}$, ranging from $9.0 \mu \mathrm{M}$ to $31.5 \mu \mathrm{M}(95 \% \mathrm{Cl})$. Supplementation with L-ornithine did not reverse the action of CAPE, showing that polyphenol, although it is a potent inhibitor of the parasite's arginase enzyme, its leishmanicidal effect occurs through an unknown mechanism. Conclusion: CAPE is a compound that has an action against $L$. (L.) amazonensis, but should not act through arginase inhibition. CAPE's leishmanicidal action against both forms of the parasite may serve as a starting point for the development of a new treatment for leishmaniasis.

Key words: CAPE, arginase, poliamines, Leishmania. 


\section{LISTA DE ILUSTRAÇÕES}

Figura 1 - Formas Clínicas da Leishmaniose

Figura 2 - Casos de leishmaniose tegumentar ocorridos no Brasil de 1980 a 2020..24

Figura 3 - Casos de leishmaniose visceral ocorridos no Brasil de 1980 a 2020.......24

Figura 4 - Fluxograma do processo de metaciclogênese da leishmaniose

Figura 5 - Macrófagos peritoneais de Swiss infectados com amastigotas de L. (L.) amazonensis

Figura 6 - Polarização dos macrófagos, T-helper subsets e metabolismo da LArginina

Figura 7 - Vias bioquímicas das poliaminas 34

Figura 8 - Síntese da putrescina pela catálise da espermina e espermidina. .36

Figura 9 - Fármacos utilizados para terapêutica contra leishmaniose .43

Figura 10 - Molécula do fenetil éster do ácido cafeico (CAPE) 48

Figura 11 - Gráfico da curva dose versus resposta de inibição arginase após serem tratadas com diferentes concentrações do CAPE. .58

Figura 12 - Mecanismo de inibição da arginase .58

Figura 13 - Gráfico da curva dose versus resposta em promastigotas de L. (L) amazonensis após $72 \mathrm{~h}$ de tratamento com CAPE e anfotericina.

Figura 14 - Gráfico do índice de Infectividade de culturas de macrófagos peritoneais infectados com L. (L.) amazonensis.

Figura 15 - Gráfico do índice de Infectividade de culturas macrófagos peritoneais de Swiss infectados com L. (L.) amazonensis por um período de 72 horas.

Figura 16 - Concentração de nitrito no sobrenadante de cultura de macrófagos infectados (MØ I) com L. (L.) amazonensis tratados por um período de 72 horas com $0.1 \mu \mathrm{g} / \mathrm{mL} \quad$ INF- $\gamma+5 \mathrm{ng} / \mathrm{mL}$ LPS $\left(\right.$ IFN $-\gamma^{+}$LPS) e CAPE $20 \mu \mathrm{M}$ (CAPE) .62

Figura 17 - Concentração de nitrito no sobrenadante de cultura de macrófagos infectados (MØ I) com L. (L.) amazonensis tratados por um período de $72 \mathrm{~h}$ com 0.1 $\mu \mathrm{g} / \mathrm{mL}$ INF- $\gamma+5 \mathrm{ng} / \mathrm{mL}$ LPS (INF- $\gamma+$ LPS) associado ou não com CAPE $20 \mu \mathrm{M}$ (INF$Y+$ LPS + CAPE) e CAPE $20 \mu \mathrm{M}$ (CAPE)

Figura 18 - Gráfico da suplementação de L-ornitina de cultura de macrófagos infectados com L. (L.) amazonensis. 


\section{LISTA DE ABREVIATURAS, SÍGLAS E SIMBOLOS}

AdoMet

S-adenosilmetionina

AdoMetDC

S-adenosilmetionina descarboxilase

ADP

Adenosina difosfato

AKt/PKB

Proteína B quinase

APC's

Células apresentadoras de antígenos

APAO

Acetilpoliamina oxidase

ARG 1

Arginase 1

$\mathrm{BALB} / \mathrm{c}$

Camundondo Bagg Albino (Mus musculus)

cAMP

Adenosina 3',5'-monofosfato cíclico

$\mathrm{Ca}^{++}$

Cálcio

CAPA

Caffeic acid phenethyl amide

CAPE

Caffeic acid phenethyl ester

CD

Cluster of differentiation

CEPTOX

Centro de Pesquisa em Toxicologia Veterinária

CEUA

Comitê de Ética de Uso De Animais

cGMP

Monofosfato cíclico de guanosina

CHES

Ácido 2- (ciclohexilamino) etanossulfônico

Cl $95 \%$

Intervalo de confiança de $95 \%$

C-jun

Proteína transcriptora do fator C-jun

$\mathrm{Cm}$

Centímetros

$\mathrm{CO}_{2}$

Dióxido de carbono

$\mathrm{Co}^{2+}$

Íon de Cobalto

coX-1

Ciclo-oxigenase 1

coX-2

Ciclo-oxigenase 2

DMSO

Dimetilsulfóxido

DNA

Ácido desoxirribonucleico 


\begin{tabular}{|c|c|}
\hline DNDi & Drugs for Neglected Diseases Initiative \\
\hline$d N L$ & Drenagem de linfonodos poplíteos \\
\hline $\mathrm{EC}_{50}$ & Metade da concentração efetiva máxima \\
\hline EIF & Fator indutor do eritema sensível à tripsina \\
\hline EUA & Estados Unidos da América \\
\hline $\mathrm{Fe}^{2+}$ & Cátion de Ferro \\
\hline FVS & Fundação de Vigilância em Saúde \\
\hline GC/MS & $\begin{array}{l}\text { Cromatografia gasosa acoplada a espectrofotometria de } \\
\text { massa }\end{array}$ \\
\hline GIPLs & Fosfolipídios de glicoinositol \\
\hline GM-CSF & $\begin{array}{l}\text { Fator estimulador de colônias de granulócitos e } \\
\text { macrófagos }\end{array}$ \\
\hline $\mathrm{g} / \mathrm{mol}$ & Massa molar, gramas/mol \\
\hline gp & Glicoproteína \\
\hline gr & Grama \\
\hline GR & Glutationa/glutationa redutase \\
\hline GSH & Glutationa total \\
\hline $\mathrm{H}^{+}$ATPase & Membrana plasmática H +ATPase \\
\hline HBSS & Solução salina balanceada de Hank's \\
\hline HPLC & Cromatografia líquida de alta performance \\
\hline IF & Índice de infectividade \\
\hline IFN- $\gamma$ & Interferon gama \\
\hline IL-1 $\beta$ & Interleucina $-1 \beta$ \\
\hline IL-2 & Interleucina - 2 \\
\hline IL-4 & Interleucina - 4 \\
\hline IL-5 & Interleucina - 5 \\
\hline IL-6 & Interleucina - 6 \\
\hline IL-10 & Interleucina - 10 \\
\hline
\end{tabular}


IL-11

IL-12

IL-12 p40

IL-12 p70

IL-13

iNOS

IU

$\mathrm{kDa}$

$\mathrm{kg}$

Ki

K'i

lamp-1

lamp-2

L. aethiopica

La-arg-

La-WT

LC

L. (L.) amazonensis

L. infantum

L. (L.) infantum

L. major

L. mexicana

$\log \mathrm{EC}_{50}$

LOX

LPG

LPS
Interleucina - 11

Interleucina - 12

Interleucina - 12 p40

Interleucina - 12 p70

Interleucina - 13

Óxido nítrico sintase induzida

Unidades

QuiloDalton

Quilograma

Constante de inibição

Constante de dissociação do complexo Enzima/Inibidor e Substrato

Proteína 1 de membrana associada a lisossomos

Proteína 2 de membrana associada a lisossomos

Leishmania aethiopica

L. (L.) amazonensis arginase nocaute

L. (L.) amazonensis tipo selvagem

Leishmaniose cutânea

Leishmania (Leishmania) amazonensis

Leishmania infantum

Leishmania Leishmania infantum

Leishmania major

Leishmania mexicana

Log10 da concentração do fármaco que induz metade do efeito máximo

Lipoxigenase

Lipofosfoglicano

Lipopolisacarídeo 


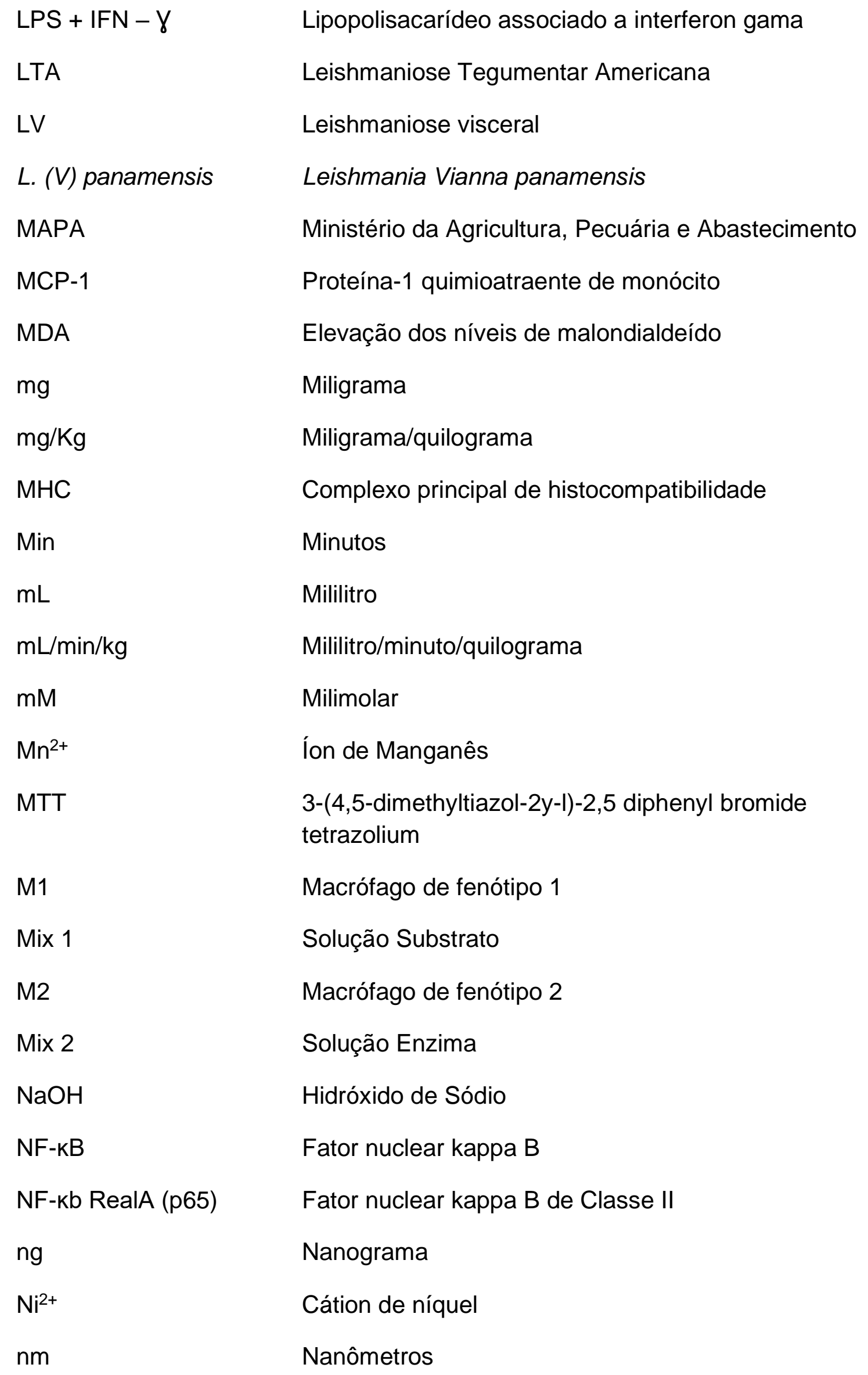


NO

NOS2

nor-NOHA

NUCL

ODC

OMS

OPS

PBS

$\mathrm{pH}$

PGE2

ROS

RNA

$\mathrm{Sb}^{5+}$

SD

SOD

SSAT

$\mathrm{TCD}^{+}$

Th1

Th2

TLR4

TNF- $\alpha$

TrxR

TO

UPLC-ESI-QTOF-MS $\stackrel{\circ}{ } \mathrm{C}$

$\mu \mathrm{g}$
Óxido nítrico

Óxido nítrico sintase 2

$\mathrm{N}$ - $\omega$-hidroxi-L-nor-arginina

Leishmaniose cutânea não ulcerada

Ornitina descarboxilase

Organização Mundial de Saúde

Organização Panamericana de Saúde

Phosphate buffered saline

Potencial hidrogeniônico

Prostaglandina $\mathrm{E}_{2}$

Espécies reativas de oxigênio

Ácido ribonucleico

Antimoniais pentavalente

Desvio padrão

Superoxidase dismutase

Espermina N1-acetiltransferase

Linfócitos T que expressam moléculas CD4 em sua superfície

Linfócito T helper 1

Linfócito T helper 2

Receptor tipo toll 4

Fatores de Necrose Tumoral Alfa

Tioredoxina/tioredoxina redutase

Tocantins

Cromatografia acoplada a espectrometria de massas

Graus Celsius

Micrograma 
$\mu \mathrm{L}$

$\mu \mathrm{M}$
Microlitro

Micromolar 


\section{ÍNDICE}

1. INTRODUÇÃO

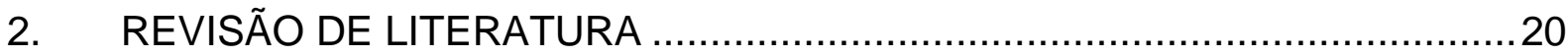

2.1 Aspectos Socioeconômicos e epidemiológicos das Leishmanioses ...............20

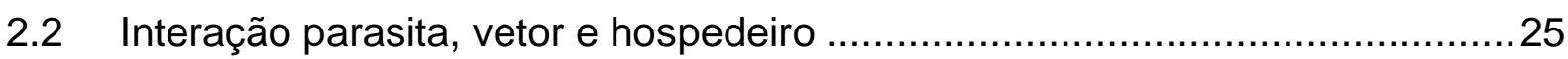

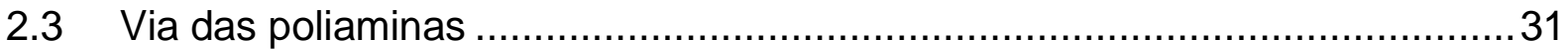

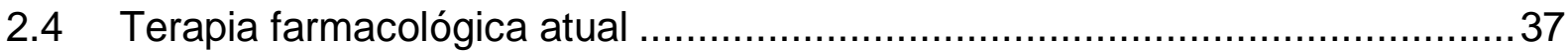

2.5 Fenetil éster do ácido cafeico (CAPE) ………....................................... 47

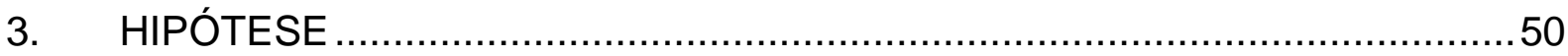

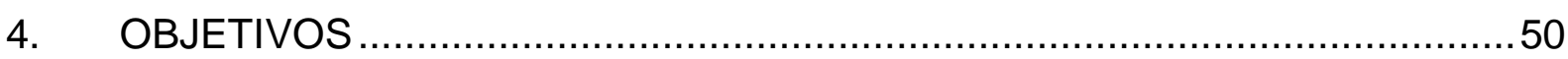

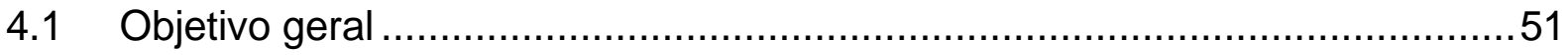

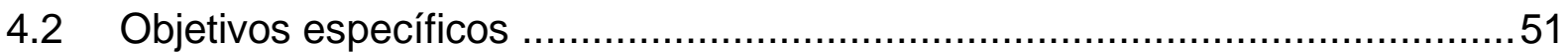

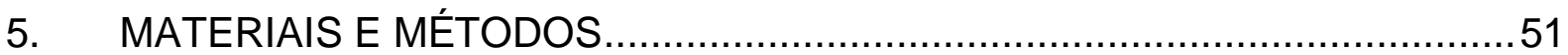

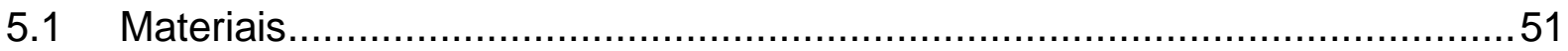

5.2 Aquisição de macrófagos peritoneais murino ……....................................51

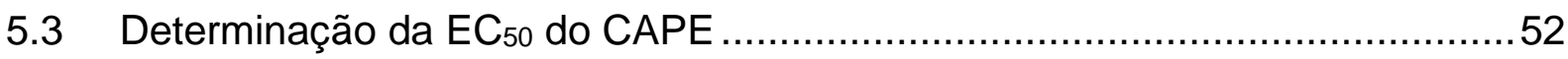

5.4 Determinações do mecanismo de inibição enzimática e elaboração das

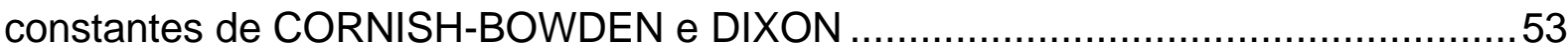

5.5 Determinação da $E_{50}$ do CAPE em meio de cultura com promastigotas de $L$.

(L.) amazonensis

5.6 Avaliação infecção dos macrófagos murinos pelos parasitos tratados com o CAPE......

5.7 Ativação dos macrófagos com LPS, IFN- $\gamma$ e tratados com CAPE .55

5.8 Concentração de nitrito na cultura macrófagos infectados com amastigotas de

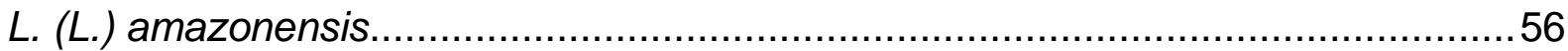

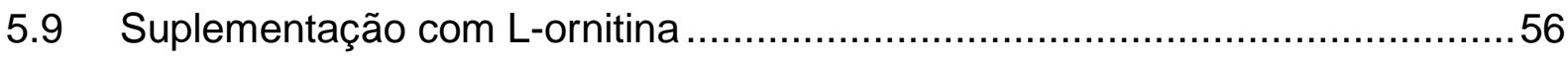

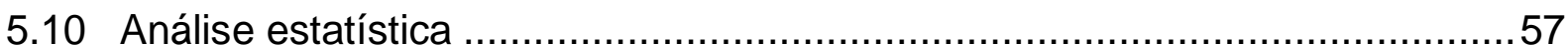

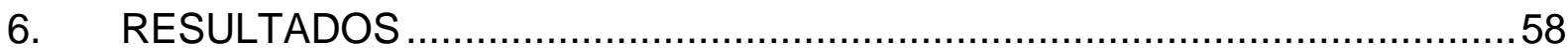

6.1 Determinação da $\mathrm{EC}_{50}$ de inibição da arginase pelo CAPE e mecanismo de

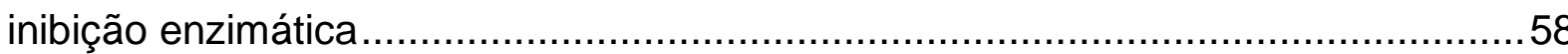

6.2 Determinação da $\mathrm{EC}_{50}$ do CAPE em promastigotas de L. amazonensis ........59

6.3 Avaliação do efeito do composto CAPE em macrófagos peritoneais de murino

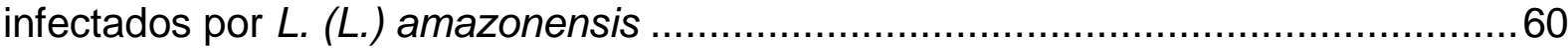

6.4 Efeito da CAPE em macrófagos ativados com LPS, IFN-Y..........................60 
6.5 Concentração de nitrito da cultura macrófagos infectados com amastigotas de

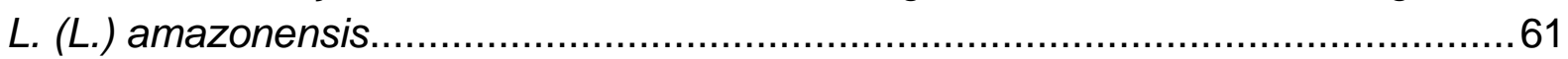

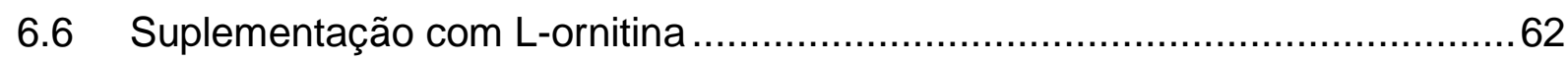

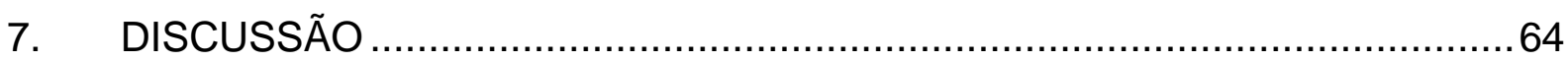

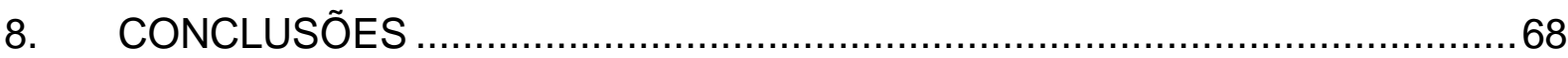

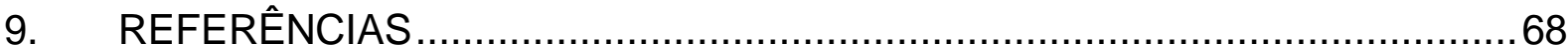




\section{INTRODUÇÃO}

As leishmanioses são doenças parasitárias causadas por protozoários flagelados que são transmitidos por vetores e que nos mamíferos se multiplicam dentro de células fagocitárias. Sua incidência ocorre nas regiões da África Oriental, países do Mediterrâneo, Sudeste asiático e América Latina (PACE, 2014; STEVERDING, 2017).

O medicamento de primeira escolha para tratar a leishmaniose é um antimonial descoberto pelo médico brasileiro Gaspar Vianna no início do século XX. Ao utilizar o tártaro emético, um composto já em desuso devido aos seus efeitos tóxicos, diluído na proporção inicial de 1:1000 e chegando até 1:100 foi administrada em pacientes portadores que apresentaram a cura desta moléstia (DEANE, 1985; REZENDE, 2008).

Apesar disto casos de resistência parasitária ao óxido nítrico são reportadas em várias partes do Mundo. Com isso, a busca de novos possíveis compostos para promover novas pesquisas e tratamentos é uma exigência. A via das poliaminas e a enzima arginase é um alvo terapêutico relevante a ser explorado no metabolismo das poliaminas que favorece a sobrevivência da Leishmania e sua inibição pode proporcionar possibilidades de encontrar fármacos mais acessíveis economicamente (ILARI et al. 2015).

Pesquisas já foram realizadas na busca de compostos que agem sobre a enzima, tais como epigalocatequina-3-O-galato, quercetina, o ácido clorogênico, o verbascosídeo e o fenetil amida do ácido cafeico (CAPA) (DOS REIS et al., 2013; DA SILVA, MAQUIAVELI E MAGALHÃES, 2012; DA SILVA et al., 2019; MAQUIAVELI et al., 2016; DA SILVA et al., 2020).

A partir disto, a busca de um novo composto com possibilidade de inibir a enzima arginase justifica este trabalho, que objetivou verificar se o CAPE, pode ser utilizado como candidato a agente terapêutico com alvo na enzima arginase. 


\section{REVISÃO DE LITERATURA}

\subsection{Aspectos Socioeconômicos e epidemiológicos das Leishmanioses}

A leishmaniose é uma infecção causada por protozoários do gênero Leishmania transmitida através da picada de fêmeas de flebotomíneos do gênero Phlebotomus e Lutzomyia infectadas (CDC, 2018; DE VRIES; REEDIJK; SCHALLIG, 2015). São considerados reservatórios das espécies de Leishmania: marsupiais, cingulatas (tatus), pilosas (bicho preguiça e tamanduás) roedores, carnívoros, primatas e morcegos (ROQUE E JANSEN, 2014).

No ambiente silvestre, roedores e canídeos selvagens são os reservatórios de Leishmania, contudo a infecção humana e canina é acidental, podendo ocorrer quando há a inserção destes em regiões enzoóticas relacionado a urbanização de áreas florestais, ou quando há contato com os reservatórios naturais, associada a presença do vetor flebotomíneo que além disto, pode se adaptar aos animais peridomésticos (DANTAS-TORRES, 2007; LAINSON; SHAW, 1978; NEUBER, 2008).

Em um levantamento realizado em 2014 na Guiana Francesa (MEDKOUR et al., 2019), foram capturados e analisados o baço de 33 morcegos da espécie Carollia perspicillata: 1 animal foi diagnosticado com infecção por Leishmania infantum, apresentado 55,6 parasitas/g de tecido coletado embora não apresentassem lesões macroscópicas.

É intitulado de zoonose reversa ou antropozoonose, quando ocorre a infecção de animais de forma esporádica a partir de humanos infectados, neste caso esta é a terminologia aplicada quando um humano é reservatório de alguma infecção e ela é transmitida para outros vertebrados (KUMAR, 2019), como exemplo nos casos de infecção $L$. donovani que ocorrem no Oriente Médio e no Norte da África (TABBABI, 2019).

A infecção possui as seguintes formas clínicas em humanos: leishmaniose cutânea, mucocutânea, visceral, ou calazar, a leishmaniose dérmica pós-calazar e a forma atípica (RUIZ-POSTIGO et al., 2021; SANDOVAL et al., 2021), estas estão demonstradas na figura 1. 
a

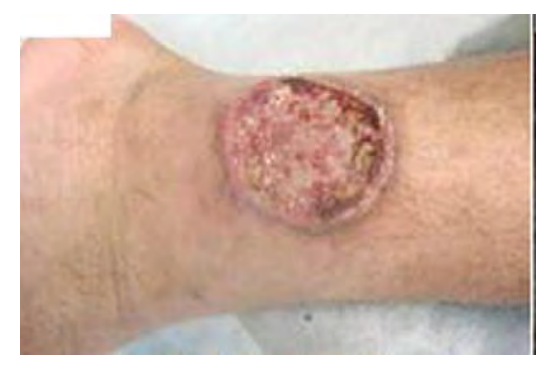

C

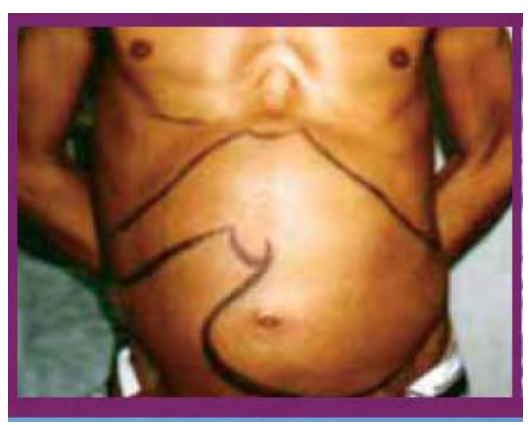

b

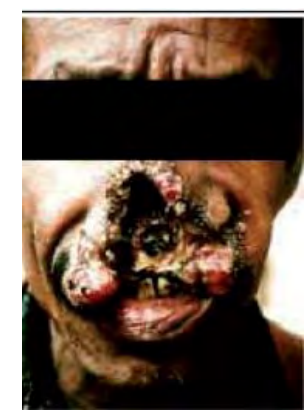

d

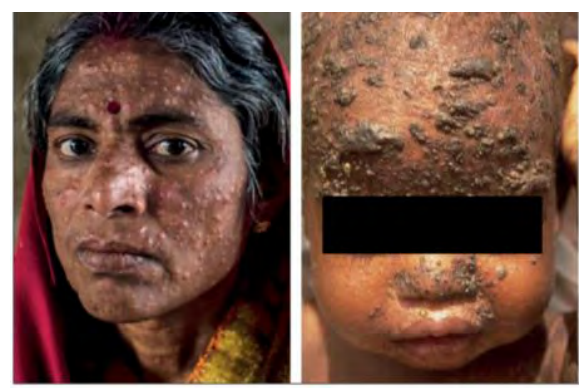

e

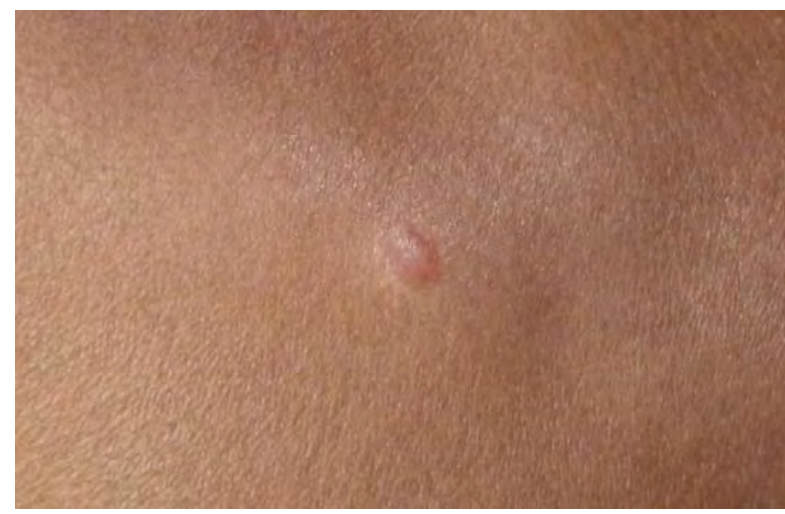

Figura 1. Formas clínicas da leishmaniose. Forma cutânea (a), forma mucocutânea (b), forma visceral (c), forma dérmica pós-calazar (d) e forma não ulcerada atípica (e). Fonte: Goto \& Lauletta Lindoso (2012) p. 296; Mcgwire \& Satoskar (2014), p. 8; WHO (2015); Burza et al. (2018), p.956;

Sandoval et al. (2021) p. 3.

No ano de 2008 no Oriente Médio, Norte da África e nações de fronteiras foram registrados 100.000 casos de leishmaniose. No Sudão e na Somália foram registrados 4.108 casos da forma visceral e 583 casos da forma tegumentar (TABBABI, 2019).

Em 2020, a Organização Mundial de Saúde (OMS) afirmou que foi notificada sobre casos de leishmaniose por 200 nações, sendo que em 89 (45\%) dos casos foram classificados como endêmicos para a leishmaniose cutânea e em 79 (40\%) nações os casos foram endêmicos para a leishmaniose visceral (RUIZ-POSTIGO et 
al., 2021). Anualmente estima-se a ocorrência de cerca de 1 milhão de novos casos de leishmaniose cutânea e 30.000 de leishmaniose visceral (WHO, 2021).

A Organização Panamericana de Saúde (OPS, 2013) considerou as leishmanioses como um importante problema de saúde pública nas Américas, devido a sua ampla distribuição, elevadas prevalências, seus principais fatores de risco, resultantes dos processos sociais, econômicos e ambientais que favorecem sua transmissão e dificultam seu controle.

Cerca de 1.028 .054 casos foram registrados de leishmaniose cutânea e mucosa e a leishmaniose visceral foram registrados 65.934 em 17 das 18 nações onde as doenças são endêmicas no período de 2001 a 2019 (OPAS, 2020).

É possível correlacionar o aspecto nutricional com a intensidade da afecção parasitária, pois a desnutrição pode tornar indivíduos mais suscetíveis a infecção, afetando o sistema imunológico de um possível hospedeiro (NWEZE; NWEZE; ONOJA, 2020). Malafaia (2010), afirmou que tanto a leishmaniose visceral quanto a desnutrição calórico proteica são adversidades para a saúde pública.

Em um estudo retrospectivo com 55 pacientes que foram a óbito devido a leishmaniose visceral, realizado no período de janeiro de 2003 a dezembro de 2008 , em alguns serviços hospitalares de Campo Grande, Mato Grosso do Sul, constatouse que a comorbidade mais presente nestes pacientes, na admissão do serviço hospitalar, foi a desnutrição, prevalente em 32,7\% dos pacientes (OLIVEIRA et al., 2010). No noroeste da Etiópia, um estudo realizado com 403 indivíduos, de ambos os sexos, entre julho e setembro de 2012, a desnutrição foi um dos principais fatores de risco associado ao desenvolvimento da leishmaniose visceral (MENGESHA et al., 2014).

A soro prevalência de leishmaniose visceral por Leishmania donovani realizado em seis vilas de Trishal, um distrito de Bangladesh, comparando um total de 103 cães, sendo 68 cães de rua e 35 de posse, no período de outubro de 2013 a março de 2014, constatou que os animais não saudáveis eram 13 vezes mais prevalentes para Leishmania donovani do que o grupo de cães saudáveis (ISLAM et al., 2017).

O cão possui um papel relevante na transmissão da L. (L.) infantum. Para a espécie Leishmania (Vianna) braziliensis o cão é considerado como uma fonte insignificante de transmissão, a não ser, em situações em que há foco de infecção doméstica e peridoméstica, ele irá atrair os vetores, mas não necessariamente será 
reservatório; os reservatórios são os outros animais sinantrópicos e domésticos ali presentes (DANTAS-TORRES, 2007).

Outro agravante observado no Brasil é a alteração do perfil da leishmaniose visceral, visto que até a década de 1980 era classificada como uma endemia rural, porém devido aos processos sociais da desocupação ou ocupação do espaço, como o êxodo rural ocorrido principalmente nesta década, a doença passou por uma gradativa urbanização da parasitose (NETO; WERNECK; COSTA, 2009).

Um estudo realizado no município de Araguaína - TO, no período de 2007 2012, constatou que houve disseminação da leishmaniose visceral nas regiões centrais e periurbanas do município, sendo relacionado a baixas condições de vida com a incidência da patologia (TOLEDO et al., 2017).

Os hábitos contemporâneos, tais como viagens e imigração, somadas às mudanças climáticas, guerras e a pandemia do HIV, possibilitou o avanço da patologia às regiões não endêmicas, favorecendo assim um novo ramo de mercado para o desenvolvimento de fármacos e vacinas que precisarão atender, além das populações endêmicas, as comunidades rurais e pobres (OKWOR; UZONNA, 2016).

Devido ao aumento da prevalência da doença em áreas não endêmicas, nas últimas décadas, organizações internacionais, como a "Drugs for Neglected Diseases Initiative" (DNDi) tem incentivado a busca por novos agentes farmacológicos para o tratamento das leishmanioses (SUNDAR; SINGH, 2018).

As leishmanioses são endêmicas no Brasil: cerca de $90 \%$ dos casos de leishmaniose visceral que foram registrados em todas as Américas estavam presentes em nosso país (ALBUQUERQUE et al., 2009). Nos anos de 2001 a 2017 as regiões centro-oeste, sudeste e nordeste foram a que apresentaram o maior risco de transmissão e que também foram as mais afetadas pela leishmaniose visceral (DE AZEVEDO; LORENZ; CHIARAVALLOTI-NETO, 2019).

No ano de 2019 o país que mais notificou foi o Brasil a forma cutânea e mucocutânea, cerca de 15.484 casos e a forma visceral foram 2.529 casos, correspondendo cerca de 97\% do total de casos notificados (OPAS, 2020).

$\mathrm{Na}$ figura 2 está apresentado o gráfico com os números de casos de leishmaniose tegumentar e a figura 3 o gráfico com os números de casos leishmaniose visceral, ocorridas no Brasil no período entre 1980 e 2020. 
Casos de leishmaniose tegumentar. Brasil, 1980 a 2020

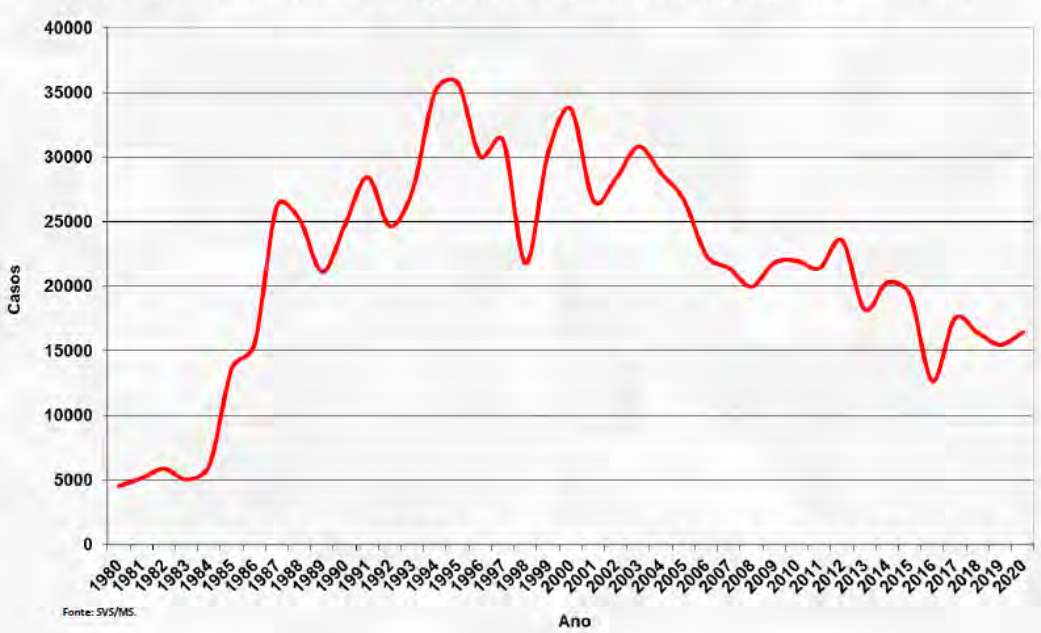

Figura 2. Casos de leishmaniose tegumentar ocorridos no Brasil de 1980 a 2020. Fonte: Ministério da Saúde (2021).

\section{Casos de leishmaniose visceral. Brasil, 1980 a 2020}

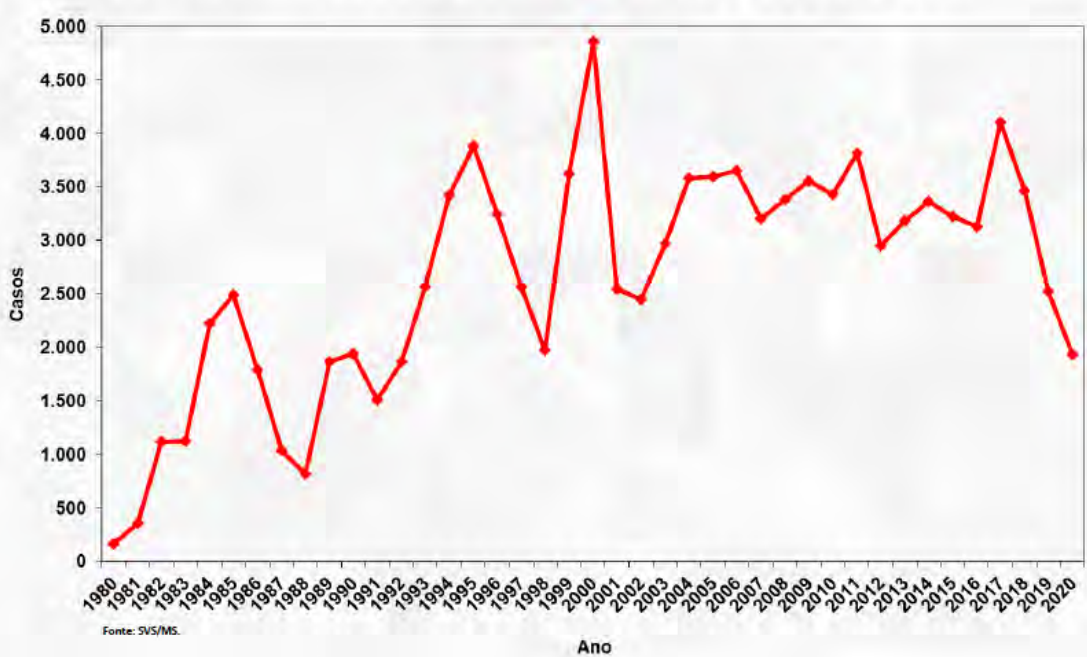

Figura 3. Casos de leishmaniose visceral ocorridos no Brasil de 1980 a 2020. Fonte: Ministério da Saúde (2021).

Observou-se no Brasil, que no ano de 1995 houve o maior número de casos registrados de leishmaniose cutânea seguido de uma diminuição com o passar dos anos (figura 2). Já a forma visceral teve seu pico de casos no ano de 2000 após isso houve uma oscilação no número de casos e somente uma queda que se iniciou no ano de 2017 (Figura 3).

A partir do banco de dados da Fundação de Vigilância em Saúde (FVS) do estado do Amazonas, levantou-se o perfil dos portadores de LTA no período de 2001 a 2010. Dos 21.942 casos registrados, cerca de $76,2 \%$ (16.372) dos pacientes 
eram do sexo masculino, o grupo etário de maior registro foi entre 21 a 30 anos com cerca de 26,6\% (5.711) (GUERRA et al., 2015).

A prevalência da LTA em indivíduos do sexo masculino foi correlacionada ao fato deste grupo possuir vínculo trabalhista com atividades extrativistas $43.7 \%$ (9.394), tais como caça, pesca, agricultura e silvicultura, expondo-se mais ao risco de contrair a infecção (GUERRA et al., 2015).

Teles, Fonseca e Gonçalves (2019) buscaram identificar o perfil da leishmaniose tegumentar americana no estado do Amazonas, no período de 2010 a 2014. Com um total de 8.384 participantes em todas as idades, foi observado que mais de $95 \%$ de casos eram da forma cutânea, sendo indivíduos do sexo masculino os que foram mais afetados.

Os adultos tiveram a maior incidência, principalmente nas idades de 20 a 40 anos, sendo uma característica deste grupo a baixa escolaridade e diversidade de etnias. A infecção estava presente em ambientes rurais e urbanos, sendo classificada como autóctones, estando presente em $75-80 \%$ dos casos (TELES; FONSECA; GONÇALVES, 2019).

Contudo, quando no que se refere ao gênero, não é somente os fatores comportamentais que predispõem a população masculina a infecção, há ensaios que demonstram que o sexo masculino pode ser mais suscetível a infecção, como demonstrado em ensaio realizado por ensaio de Lezama-Davila et al. (2007).

Os autores verificaram que em um grupo de 90 moradores, sendo 81 homens e 9 mulheres portadores da úlcera chiclero, um termo popular local para leishmaniose cutânea do munícipio Campeche, no México, uma região endêmica de leishmaniose causada por Leishmania mexicana, e através de sua análise evidenciou que as pacientes do sexo feminino eram mais resistentes a infecção devido elevação sérica do fator estimulador de colônias de granulócitos e macrófagos (GM-CSF) (LEZAMA-DAVILA et al., 2007).

Outro fator relevante a infecção entre os gêneros são os hormônios sexuais, como andrógenos, estrógenos e progestagênios, atuam de forma direta na resistência ou suscetibilidade ao processo infeccioso da leishmaniose (SNIDER et al., 2009).

\subsection{Interação parasita, vetor e hospedeiro}


As fêmeas de flebotomíneos são os vetores da doença e sua classificação taxonômica pertence à ordem Diptera e família Psychodidae. As espécies presentes no Novo Mundo são do gênero Lutzomyia e no Velho Mundo o gênero Phlebotomus (ANVERSA et al., 2018).

Inicialmente, o macho da espécie Lutzomyia longipalpis atrai a fêmea através de sinalização por feromônio e emissão sonora para o ato de acasalamento. $\mathrm{Na}$ busca pelo seu alimento, a fêmea tem hábitos no período crepuscular e noturno, ingere sangue dos hospedeiros vertebrados e se infecta com o parasita $L$. infantum (SOUSA-PAULA; OTRANTO; DANTAS-TORRES, 2020).

Cada espécie de protozoário é transmitida por uma espécie de flebotomíneo diferente, além de que para manter ciclo dos parasitas o reservatório animais são de suma importância, um exemplo é a espécie Lutzomyia flaviscutellata, ela é um dos vetores de Leishmania (Leishmania) amazonensis e tem como hospedeiro roedores da floresta Proechimys spp. (BATES, 2007).

A postura de seus ovos ocorre sob matéria orgânica em decomposição, tais como fezes, solo e matéria vegetal em decomposição. Os ovos eclodem as larvas que evoluem por 4 estágios, se tornam pupas até total amadurecimento dos flebótomos iniciando assim um novo ciclo reprodutivo do artrópode (SOUSA-PAULA; OTRANTO; DANTAS-TORRES, 2020).

Ao picar o hospedeiro intermediário, o flebotomíneo se contamina com a forma aflagelada, amastigota que posteriormente, se desenvolve na forma flagelada, promastigota, na luz do aparelho digestivo do artrópode (PISCOPO, AZZOPARDI, 2007; KAYE; SCOTT, 2011). Este processo é intitulado de metaciclogênese da leishmaniose (Figura 4). Ao se alimentar, os protozoários flagelados que estão no estágio metacíclico migram pela válvula estomodeal e por regurgitação são inoculados no local da picada (KAYE; SCOTT, 2011).

O que torna o protozoário no estágio metacíclico mais infectante é a presença de interações moleculares de proteínas de superfície de membrana com 0 hospedeiro: a lipofosfoglicano (LPG), os fosfolipídios de glicoinositol (GIPLs) e a glicoproteína de 63 kDa (gp23) (MOODY, 1993).

Outro fator relevante para infecção é a saliva do inseto, que ao entrar em contato com os tecidos e com o sangue do mamífero possui composto relevantes para a infecção, sendo eles, o fator indutor do eritema sensível à tripsina (na língua inglesa, EIF) e que produz um eritema sem prurido, devido a sua sensibilidade para 
tripsina, e o neuropeptídeo calcitonina generalizada, com ação vasodilatadora (RIBEIRO et al., 1989).

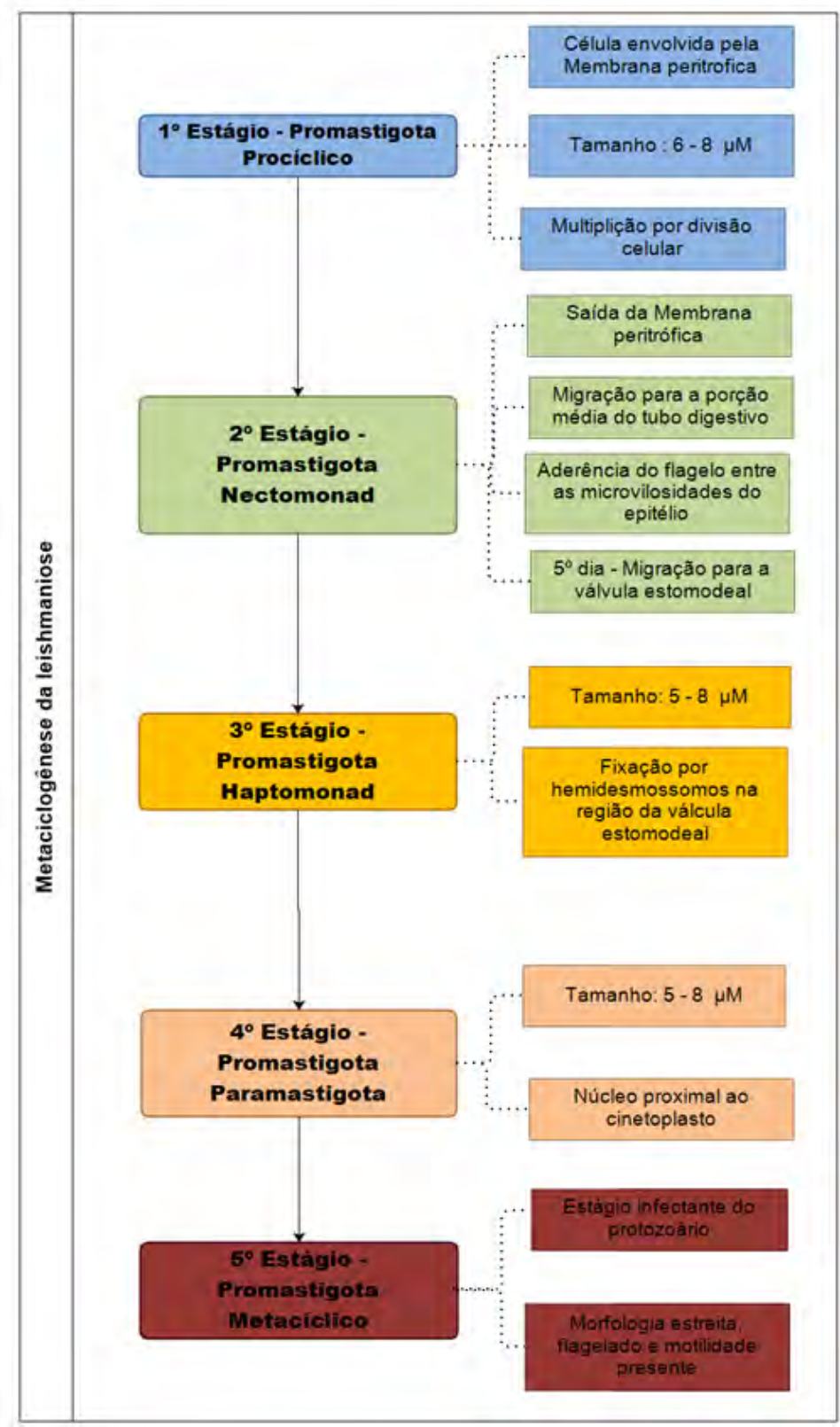

Figura 4. Fluxograma do processo de metaciclogênese da leishmaniose. Fonte: Bates (1994).

Ribeiro, Rossignol e Spielman (1986) concluiu que o homogeneizado das glândulas salivares de fêmeas de Lutzomyia longipalpis possui ação antiplaquetária induzida pelo colágeno e ADP, substâncias indutoras de eritema e a enzima apirase, que utiliza o íon $\mathrm{Ca}^{++} \mathrm{em} \mathrm{pH} 8.0$ para ação antitrombótica.

Samuelson et al. (1991), realizou um ensaio utilizando camundongos BALB/c para verificar se em inóculos de L. braziliensis associada ou não a um lisado de glândula salivar de L. longipalpis havia uma potencialização do estabelecimento do 
processo infeccioso através da avaliação do tamanho da lesão, da carga parasitária e o tempo de regressão da ferida.

Como resultados, o inóculo parasitário com o lisado evoluiu com lesões após 3 semanas e na avaliação da carga parasitária, após 8 semanas, a lesão possuía a carga parasitária de $20 \pm 7$ milhões (média $\pm S D$ ). Em contrapartida, o inóculo sem a presença do lisado apresentou lesões com rápida regressão e na avaliação carga parasitária era de < 100 após 8 semanas (SAMUELSON et al., 1991).

No local da picada os promastigotas precisam transpassar pela matriz extracelular para que possam ser fagocitados. Mcgwire, Chang e Engman (2003) demonstraram em seu experimento in vitro que a Leishmania faz a expressão da metaloprotease gp63 para que ocorra a migração das formas promastigotas através da matriz extracelular.

Em um experimento in vitro com cultivo tridimensional de colágeno I, os promastigotas de L. (L.) amazonensis aderiram ao colágeno I, degradaram estas fibras utilizando metalo-cisteína proteases e a protease Gp23 (PETRÓPOLIS et al. 2014).

Após transpassar pela matriz extracelular, os parasitas entraram em contato com monócitos, macrófagos e células de Langherans pertencentes ao sistema retículo endotelial (NEUBER, 2008). Foi observado que os promastigotas foram fagocitados pelos macrófagos e em seu interior diferenciam-se em amastigotas (PISCOPO; AZZOPARDI, 2007).

Os protozoários que foram internalizados multiplicaram-se dentro dos vacúolos nos fagolisossomos dos fagócitos (MOUGNEAU; BIHL; GLAICHENHAUS, 2011), (Figura 5). 


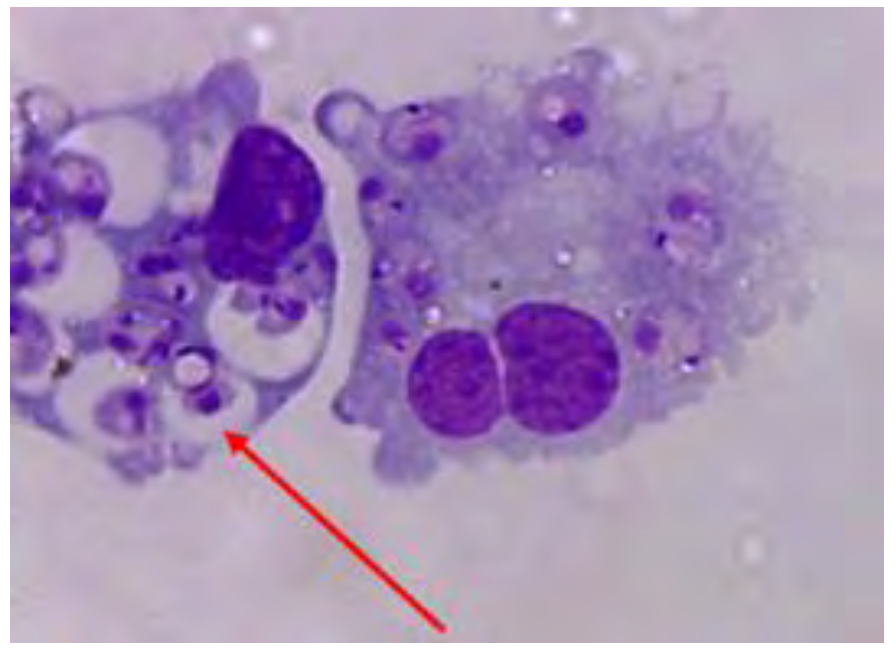

Figura 5 - Macrófagos peritoneais de Swiss infectados com amastigotas de L. (L.) amazonensis apontados com a seta vermelha. Células coradas com Giemsa, registradas em microscopia em aumento de 100x. Imagens registradas pelo próprio autor (2021).

No interior de fagolisossomos há um ambiente acidificado pela presença de enzimas lisossomais e seu interior é rodeada por uma membrana enriquecida com endossomo tardio, proteínas lisossomais macrosialina, lamp-1, lamp2, ab7p e $\mathrm{H}+$ ATPase vacuolar e com moléculas do maquinário de ante expressão gênica (MHC classe II e moléculas $\mathrm{H}-2 \mathrm{M}$ ) nos macrófagos ativados com IFN-y (COURRET, et al., 2002).

Em relação a ativação dos macrófagos, eles são classicamente descritos em M1 e M2 (figura 04), mas há variações para os macrófagos do tipo 2, sendo elas, M2a, M2b e M2c. Os M1 são ativados na presença das LPS bacterianos e/ou interferon gama (IFN-y) produzido por linfócitos TCD4+ (MARTINEZ et al., 2008).

Durante as respostas alergênicas, celulares e humorais, causadas por parasitas, se induz a ativação alternativa dos macrófagos pela resposta do tipo Th2 após secreção das IL-4 e IL-13. Especificamente a IL-4, que é do grupo de citocina do tipo 1 pleiotrópica, tendo como células sintetizadoras os basófilos, mastócitos e as células TCD4+, ou Th2 (VARIN; GORDON, 2009).

A ativação dos macrófagos é essencial para as respostas imunitárias em diversas patologias, incluindo as leishmanioses. A ativação é alcançada no momento que os receptores das células hospedeiras constatam os componentes microbianos e ou sinais de estresse (LIMA-JUNIOR et al., 2013).

Em análise imuno-histoquímica de biópsia cutânea de pacientes moradores dos municípios de Amapala e Orocuina (Honduras), portadores de leishmaniose 
cutânea não ulcerada (NUCL) causada por L. infantum chagasi mostrou que o material apresentava macrófagos (CD68 $\left.{ }^{+}\right) \mathrm{NK}\left(\mathrm{CD} 56^{+}\right)$, linfócitos T $\left(\mathrm{CD} 4^{+}\right.$e TCD8 $\left.{ }^{+}\right)$ e linfócitos $B\left(\mathrm{CD}^{2} \mathrm{O}^{+}\right)$(SANDOVAL et al., 2021).

Durante o processo de convalescência, em um modelo experimental murino de leishmaniose cutânea, as células Th1 predominaram, porém na progressão da infecção foi observado a predominância de células Th2 (LOCKSLEY et al., 1987).

Pela interação entre macrófagos e neutrófilos foi que ocorreu a eliminação da L. braziliensis, através do mecanismo de produção de moléculas superóxidos, após estímulo do (TNF- $\alpha$ ) (MOUGNEAU; BIHL; GLAICHENHAUS, 2011).

Após a estimulação in vitro pelos antígenos de Leishmania uma gama variada de perfis de citocinas de Th1 e Th2 foi encontrada em lesões de leishmaniose cutânea, sendo que a IL-10 e IL-13 foram correlacionadas com lesões crônicas (WHO, 2010).

Gabriel et al. (2019) também seguiram esta linha de pensamento, pois em sua exposição do processo fisiopatológico, a leishmaniose cutânea evolui dependendo da forma que os mecanismos de defesa foram ativados, pois após serem inoculados os promastigotas foram fagocitados, seus antígenos foram demonstrados pelas APC's e a IL-12 foi sintetizada pelas células dendríticas, ativando os linfócitos e secretando suas respectivas citocinas.

Assim, quando foi secretado a IL-4, IL-5, IL-13, juntamente com a diferenciação dos linfócitos Th17, ocorreu a replicação parasitária e lesão tecidual. Quando secretada a IL-12 pelas células dendríticas e/ou durante a apresentação dos antígenos do protozoário, houve a secreção das citocinas IL-2, IFN- $\gamma$ e TNF- $\alpha$, consequentemente os macrófagos foram ativados e assim ocorreu a inativação dos protozoários pelo seu efeito microbicida (GABRIEL et al., 2019).

Foi relatado por Mougneau, Bihl e Glaichenhaus (2011) que em modelos murinos suscetíveis para infecção de Leishmania a resposta imunológica prevalente das células $T$ é a Th2 devido ao fato delas secretarem a IL-4, IL-5 e /ou IL-13. Porém, para a eliminação do parasita a diferenciação das células T CD4+ devem ser polarizadas para Th1, através da secreção do IFN- $\gamma$ e/ou TNF- $\alpha$ e ativação de macrófagos, pois é este mecanismo imunológico que produz NO a partir de Larginina pela enzima iNOS (óxido nítrico sintase induzida).

Santos-Pereira et al. (2019) em seu ensaio buscou verificar se ao adicionar IL4 , IFN- $\gamma$ e LPS em macrófagos peritoneais de lavado murino de camundongos 
$\mathrm{BALB} / \mathrm{c}$ e $\mathrm{C} 3 \mathrm{H} / \mathrm{He}$ infectados com L. amazonensis. Como resultados, os macrófagos tratados com IL-4 em ambas as linhagens de macrófagos apresentaram um estímulo a proliferação parasitária, e o oposto ocorreu quando foram tratadas com IFN- $\mathrm{\gamma}$ e LPS, elas apresentaram resistência a infecção.

A resposta imunológica contra patógenos mediados pelos linfócitos Th1 os fatores de transcrição da família NF-kB são primordiais e a deficiência no NF-kb RealA (p65) ocasiona a inativação de enzimas que produzem mediadores inflamatórios como a iNOS e parasitas da espécie Leishmania podem interferir nessa via de sinalização (REINHARD et al., 2012).

Na figura 06 está ilustrado o processo de ativação das respostas Th1 e Th2 e seus papéis na eliminação ou proliferação dos parasitas, como descrito por Holzmuller et al., 2018:

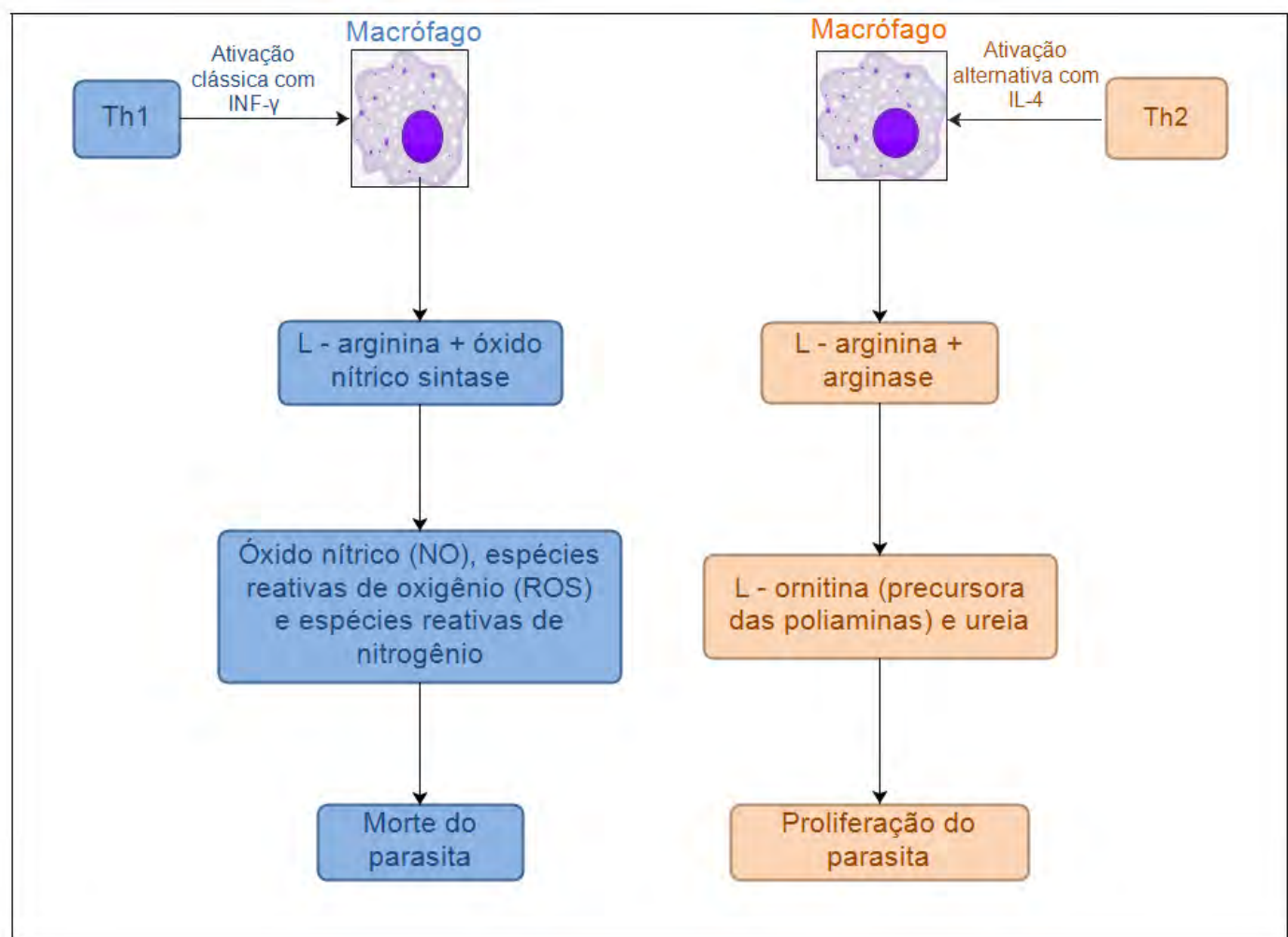

Figura 06 - Polarização dos macrófagos, T-helper subsets e metabolismo da L- Arginina. Fonte: Adaptado de Holzmuller et al. (2018, p.05).

\subsection{Via das poliaminas}

Classificadas como cátions alifáticos, as poliaminas putrescina, espermidina e espermina, quando carregadas em $\mathrm{pH}$ fisiológico possuem de duas até quatro 
cargas positivas, estando prontamente ligadas às membranas, ribossomos, RNA e DNA (DAVIS, 1990).

Munder (2009) afirmou que elas são pequenas moléculas catiônicas que estão envolvidas em uma variedade de funções celulares fundamentais, tais como transporte de membrana celular e proliferação. As primeiras destas moléculas a serem descobertas foram a espermidina e a espermina por Antonie van Leeuwenhoek em 1678 (WALLACE, 2009).

Com a finalidade de elucidar suas funções e envolvimento fisiológico, estas moléculas mais a putrescina foram alvo de intensivas pesquisas (NADÈGE MINOIS; DIDAC CARMONA-GUTIERREZ; FRANK MADEO, 2011), fato este atribuído devido aos efeitos destes complexos pleiotrópicos que dificultam a compreensão dos efeitos fisiológicos e os fisiopatológicos da perturbação do conteúdo das poliaminas (PEGG; CASERO, 2011).

Pegg (2009) afirmou que a produção científica sobre as poliaminas foram bastante ativas, possuindo considerável número de pesquisas nas áreas de bioquímica, genética e fisiologia dos organismos tais como, plantas, mamíferos, protozoários parasitas e microrganismos englobando os termófilos, sendo que estes portam uma maior variedade destas substâncias.

As poliaminas podem interferir nos processos fisiológicos do ciclo celular, sinalização celular, autofagia, morte celular, atividade nos canais iônicos, expressão gênica, reparação tecidual, células imunitárias, processos oncológicos, metabolismo e envelhecimento (BAE et al., 2018).

A putrescina, espermidina e espermina integram partes muito bem reguladas das vias metabólicas da via das poliaminas, quando alteradas foram correlacionadas com diversas patologias devido ao mau funcionamento celular, como a proliferação celular desordenada nas neoplasias, a morte celular descontrolada, agregação de componentes insolúveis e o aumento exponencial de patógenos nos casos de doenças infecto-parasitárias (NADÈGE MINOIS; DIDAC CARMONA-GUTIERREZ; FRANK MADEO, 2011).

Estas substâncias foram correlacionadas à replicação celular, todavia caso ocorra desequilíbrio na manutenção de sua concentração o resultado é a interrupção da transformação, do ciclo celular e da morte celular, como ocorre em células neoplásicas, elas têm um aumento da concentração dos compostos (WALLACE; FRASER; HUGHES, 2003). 
A arginase tem como função no organismo catalisar a reação da hidrólise da Larginina em L-ornitina e ureia (CHAUDHURI, 1927; VAN DEN BERG; MEURS; GOSENS, 2018). A ureia é uma pequena molécula, rica em nitrogênio e altamente hidrossolúvel e está presente em uma variedade de organismos no espectro evolucionário tais como, leveduras, bactérias, plantas invertebrados e vertebrados (JENKINSON; GRODY; CEDERBAUM, 1996).

$\mathrm{Na}$ cadeia de reação bioquímica, a L-arginina sofre a ação da enzima arginase e seus produtos são a ureia e a L-ornitina, este segundo produto sofre uma descarboxilação pela enzima ornitina descarboxilase (ODC), liberando $\mathrm{CO}_{2} \mathrm{e}$ putrescina (figura 7b). Paralelamente, a molécula S-adenosilmetionina (AdoMet) sofre uma descarboxilação da S-adenosilmetionina descarboxilase (AdoMetDC) gerando S-adenosilmetionina descarboxilada (figura 7a) (PHILLIPS, 2018).

A partir desta última reação, um grupo aminopropil é cedido pela aminopropil transferase (WALLACE; FRASER; HUGHES, 2003) à molécula de putrescina e a partir da catálise das enzimas espermidina sintase ou espermina sintase são sintetizadas as moléculas espermidina e espermina, respectivamente, transferindo este grupo aminopropil para os produtos da reação (figura 7c) (URDIALES; MEDINA; SÁNCHEZ-JIMÉNEZ, 2001).

Utilizando como substratos as poliaminas, a metionina e a glutamina a Leishmania obtém a tripanotiona, um agente antioxidante dos sistemas glutationa/glutationa redutase (GR) e tioredoxina/tioredoxina redutase (TrxR) necessária para a sua sobrevivência na célula hospedeira (GOGOI et al., 2016; PERDEH et al., 2019; KRAUTH-SIEGEL; MEIERING; SCHMIDT, 2003; MEDEIROS et al., 2020; COLOTTI; ILARI, 2011).

Outra via bioquímica capaz de converter a arginina em putrescina é a via da agmatina. A L-arginina sofre a ação da arginina descarboxilase sendo convertida a agmatina, esta sofre ação da enzima agmatina amidohidrolase resultando em $\mathrm{N}$ carbamoil putrescina, substrato da enzima $\mathrm{N}$-carbamoil-putrescina amidohidrolase, que produz putrescina (FUELL et al., 2010).

Esta via está presente não somente no metabolismo celular das plantas, mas também em tecidos dos mamíferos, como nas fendas sinápticas dos neurônios do sistema nervoso (ALCÁZAR, TUBURCIO, 2018; COLEMAN, HU, PEGG, 2004; HALARIS, PLIETZ, 2007).

Na figura 07 está ilustrada as vias bioquímicas das poliaminas: 
a

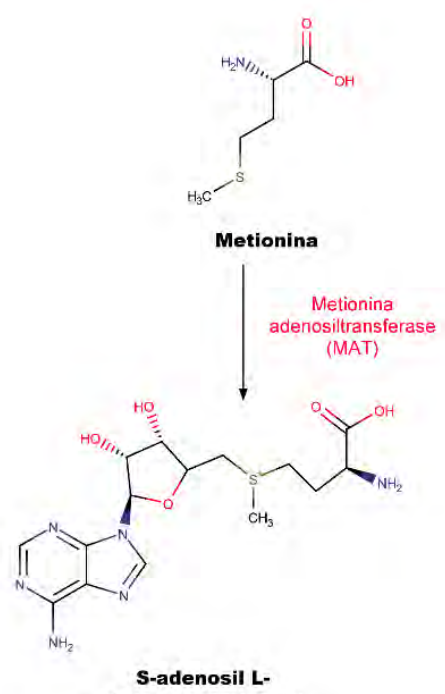

Metionina (AdoMet)

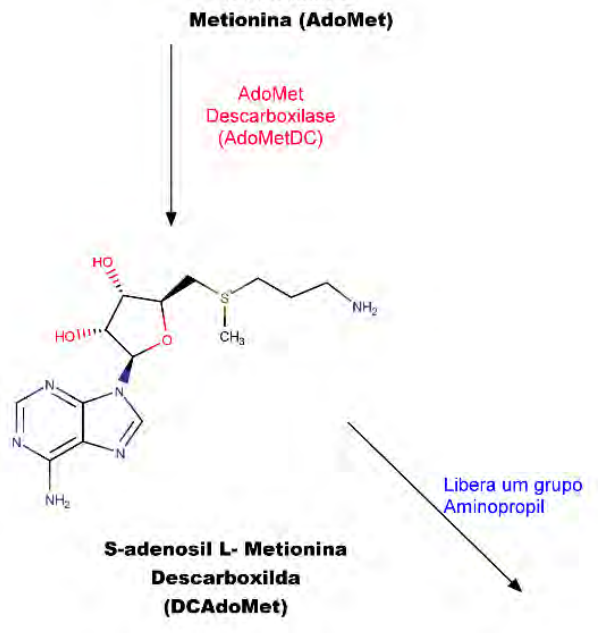

b
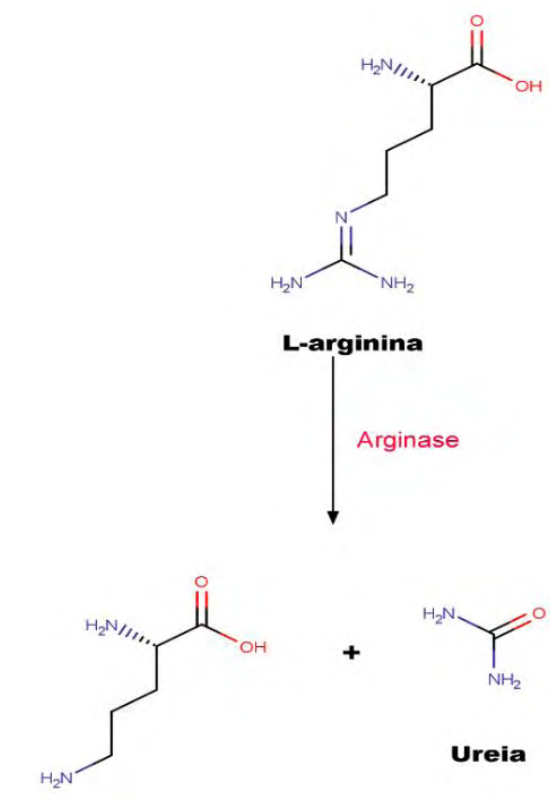

$\underbrace{\mathrm{H} N}_{\mathrm{NH}_{2}}$

Ureia

C
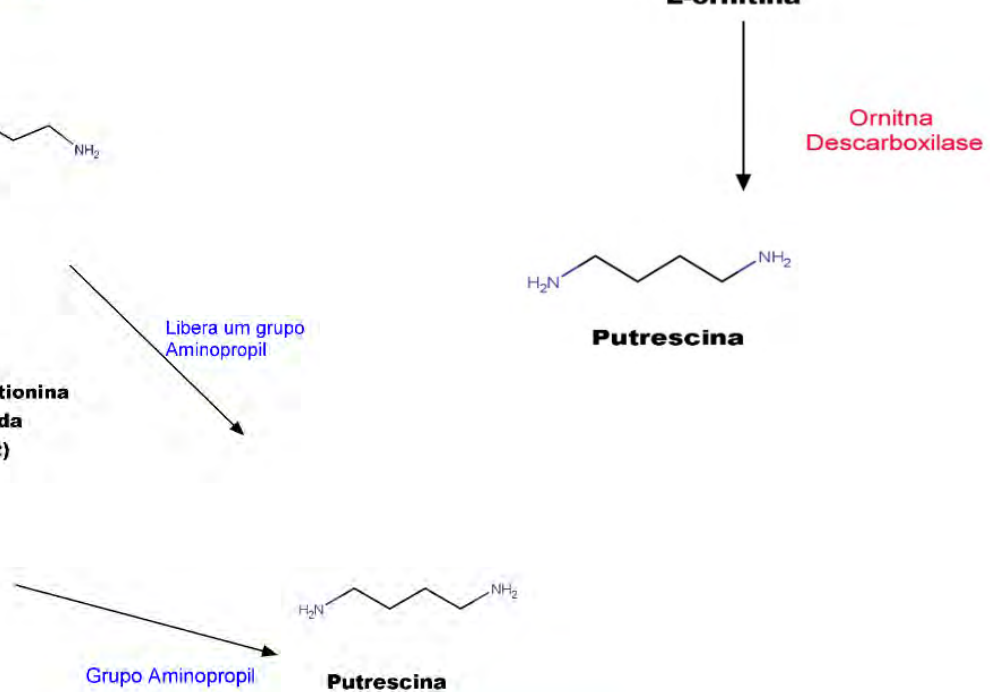

L-ornitina

Putrescina

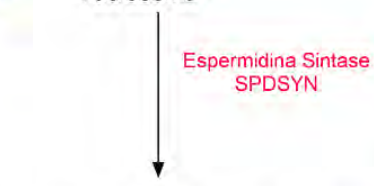

Tripanotiona Sintase

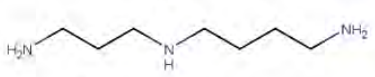

Espermidina

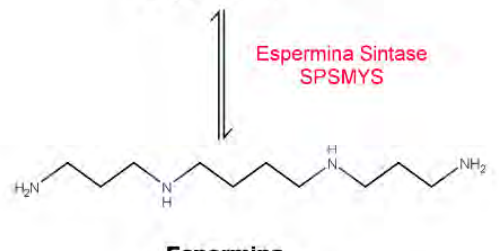

Espermina

Figura 07 - Vias bioquímicas das poliaminas. Fonte: Adaptado de Nadège Minois; Didac CarmonaGutierrez; Frank Madeo (2011, p.04) e Perdeh et al. (2019, p.03). 
A arginina é um aminoácido semi-essencial nos humanos, considerado um dos mais versáteis aminoácidos, desempenha o papel de precursor da síntese de ureia, óxido nítrico, poliaminas, prolina, glutamato, creatinina e agmatina (MORRIS $J R, 2018)$.

A arginase (L-arginina amidinohidrolase - EC 3.5.3.1) hidrolisa a L-arginina em L-ornitina e ureia. Uma característica comum de todos os estudos com a substância foram é que foram exigidos para sua atividade cátions divalentes (RECZKOWSKI; $\mathrm{ASH}, 1992$ ), tais como $\mathrm{Co}^{2+}, \mathrm{Ni}^{2+}$ ou $\mathrm{Mn}^{2+}$, bem como $\mathrm{Fe}^{2+}$ (HELLERMAN; PERKINS, 1935).

Nos mamíferos as arginase I e II requer um centro binuclear de manganês intacto para realizar a hidrólise da L-arginina e gerar L-ornitina e ureia (RECZKOWSKI; ASH, 1992). A arginase 1 é expressa pelos hepatócitos e se localiza no citoplasma, enquanto a arginase 2 é sintetizada na mitocôndria dos tecidos renais (CALDWELL et al., 2015), prostático, do intestino delgado e glândulas mamárias na lactação (MUNDER, 2009).

A arginase I participa da última etapa do ciclo da ureia, necessário para a eliminação da amônia nos mamíferos, gerando ureia e L-ornitina. A L-ornitina possui papel central em várias vias metabólicas relevantes como a produção da putrescina, espermidina e espermina junto da ODC (ornitina descarboxilase) (MUNDER, 2009).

A putrescina também pode ser sintetizada através do catabolismo da espermidina e espermina (figura 8) pelas enzimas espermidina e espermina N1acetiltransferase (SSAT) que adicionam um grupo acetil nos compostos possuem como produtos a $\mathrm{N} 1$-acetil espermidina e $\mathrm{N} 1$-acetil espermina, respectivamente (PEGG, 2008).

Os produtos por sua vez são novamente catalisados pela acetilpoliamina oxidase, que converte a N1-acetilespermina em espermidina e a N1acetilespermidina em putrescina. No caso da espermina, ela sofre novamente a ação da enzima SSAT a convertendo em N1-acetil espermidina e a partir desta reação ocorre a continuidade da reação catabólica (BAE et al., 2018).

A arginase II regula a biossíntese de L-ornitina em tecidos não hepáticos e ambas as formas os resíduos de seu ativo são idênticas e consequentemente precisam de um cluster binuclear $\mathrm{Mn}^{2+}$ (CLEMENTE et al., 2020). Wu e Morris Jr. (1998) referiram que as arginases têm atraído interesses devido ao fato delas possuírem o papel de sintetizar NO, prolina, glutamato, poliaminas e agmatina. 


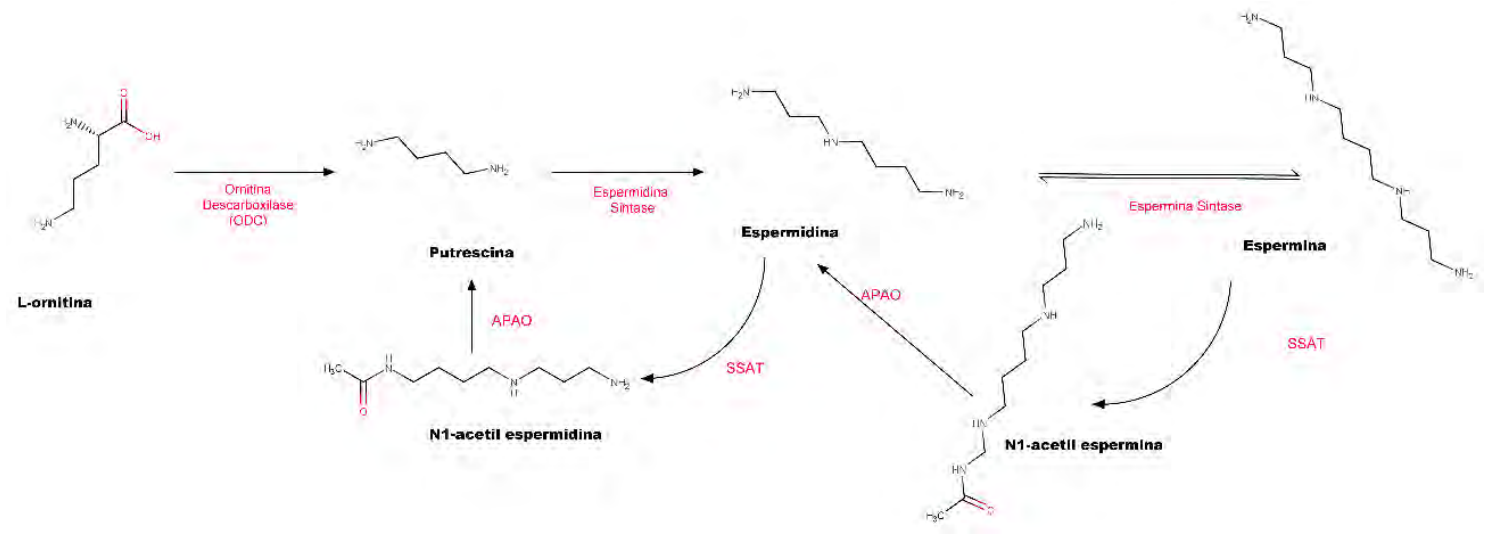

Figura 8 - Síntese da putrescina pela catálise da espermina e espermidina. SSAT (espermidina/ espermina N1-acetiltransferase) e APAO (acetilpoliamina oxidase). Fonte: Pegg, 2008 e Bae et al. (2018).

Em situações fisiológicas, os macrófagos com fenótipo M2 induzem a síntese das poliaminas, após hidrolisar a arginina pela arginase, desta reação tem como produtos ornitina e ureia e tem como objetivo a reparação tecidual, proliferação celular e biossíntese de colágeno (GABRIEL et al., 2019).

Abebe et al. (2012) correlacionou o agravamento da infecção por Leishmania com os níveis elevados da arginase por meio de seu ensaio realizado na Etiópia: a avaliação de amostras de biópsia de pacientes com lesão causada por L. aethiopica evidenciou um aumento do nível da arginase das amostras ao compará-las com biópsias de pele íntegra e em células sanguíneas.

Nahidi et al. (2020) também demonstrou essa correlação: ao administrar o inibidor da arginase nor-NOHA ( $\mathrm{N}$ - $\omega$-hidroxi-L-nor-arginina), em fêmeas de Balb/c com as patas infectadas com Leishmania tropica constatou que o grupo infectado com tratada com nor-NOHA, apresentou uma diminuição da proliferação parasitária nos linfonodos $(0,41 \pm 0,08$ parasito/dLN) ao ser comparado com o grupo controle que recebeu como tratamento PBS $(1,38 \pm 0,43$ parasite/dLN) após três meses de tratamento.

Quando a célula hospedeira está infectada pela Leishmania a L-arginina é substrato tanto para a ARG1 quanto para o NOS2. O NOS2 resultante de macrófagos com fenótipo M1, sintetiza a citrulina e o NO, estes compostos favorecem a eliminação parasitária, enquanto a ARG1 sintetizada pela ativação de macrófagos fenotipados M2 estimula a replicação parasitária (MUXEL et al., 2018; PESSENDA; DA SILVA, 2020). 
A via das poliaminas pode ser utilizada para elaboração de estratégias terapêuticas sintetizando fármacos para quimioprevenção e tratar patologias neoplásicas e tratamentos de doenças parasitárias (COLEMAN; HU; PEGG, 2004), pois as poliaminas são primordiais para o crescimento da Leishmania (MUXEL et al., 2018).

Com a finalidade de promover a síntese de poliaminas, a arginase possui relevância para o desenvolvimento da Leishmania e contribui para sua infectividade. Fato este comprovado por Aoki et al. (2017) após realizar em seu ensaio a infecção de macrófagos derivados de medula óssea de camundongos com amastigotas de $L$. (L.) amazonensis tipo selvagem ( $L a-W T$ ) contra $L$. (L.) amazonensis arginase nocaute ( $\mathrm{La}$-arg-) demonstrou que ambos os protozoários foram capazes de infectar os macrófagos, porém La-arg- ocasionaram um menor índice de infecção quando comparado com o outro grupo.

\subsection{Terapia farmacológica atual}

Atualmente a terapêutica da leishmaniose em humanos utiliza os seguintes fármacos: antimoniais, pentamidina, anfotericina $B$, miltefosina (BRINDHA; BALAMURALI; CHANDA, 2021); antifúngicos derivados do "azol" (ARONSON et al., 2017) e a paromomicina (ULIANA; TRINCONI; COELHO, 2018).

Os antimoniais orgânicos foram desenvolvidos há mais de 100 anos, sendo que a primeira forma foi o antimonial trivalente, seguido pelo desenvolvimento do antimonial pentavalente (LOISEAU; BORIES, 2006). Seu uso foi introduzido após pesquisas realizadas no século XX por Gaspar Vianna, pois uma vez que nesse período já se era de ciência à ação antiparasitária dessas substâncias, Vianna administrou em pacientes o composto e obteve a cura, com isso ele foi consagrado como o responsável pela cura da leishmaniose (REZENDE, 2008).

Os compostos o estibogluconato de sódio e antimoniato de meglumina são antimoniais pentavalente $\left(\mathrm{Sb}^{5+}\right)$. Ambos utilizados como agentes terapêuticos da LV (leishmaniose visceral) e LC (leishmaniose cutânea) e são fármacos de primeira escolha para a quimioterapia da leishmaniose (GHORBANI; FARHOUDI, 2018).

A comercialização do antimoniato de meglumina é feita pelo nome comercial Glucantime em ampolas de $5 \mathrm{~mL}$ contendo $1.5 \mathrm{~g}$ da droga equivalente a $405 \mathrm{mg}$ de 
antimônio pentavalente e sua administração é exclusivamente intramuscular (MARSDEN, 1985; MINISTÉRIO DA SAÚDE, 2017). A administração deve ser diária, em uma dosagem de $20 \mathrm{mg}$ de $\mathrm{Sb} / \mathrm{kg} / \mathrm{dia}$ e tem duração de 20 a 30 dias (FRÉZARD; DEMICHELI; RIBEIRO, 2009).

Seu mecanismo de ação não está esclarecido, porém o composto necessita passar três membranas da célula hospedeira até adentrar no fagolisossomos e agir sob os amastigotas, acredita-se que a forma pentavalente é convertida para a forma trivalente, contudo o seu mecanismo de conversão também não está esclarecido (LOISEAU; BORIES, 2006).

Capela, Moreira e Lopes (2019) afirmam que o uso do Glucantime e do pentosan inibem a tripanotiona redutase, uma substância essencial para a sobrevivência parasitária dentro do macrófago, pois ela usa o sistema triparedoxina/triparedoxina peroxidase (TXN/TXNPx) para neutralizar as espécies reativas de oxigênio (ROS).

Os efeitos colaterais ao uso do medicamento são dor no local da aplicação, náusea, êmese, astenia, mialgia, diarreia, cólica abdominal, rashs cutâneos (FRÉZARD; DEMICHELI; RIBEIRO, 2009), arritmia cardíaca e pancreatite aguda, trazendo a sua terapêutica risco à vida do cliente (CHAPPUIS et al., 2007).

Outros efeitos colaterais deste medicamento relacionados a alterações do ritmo e função cardíaca são o prolongamento do intervalo QT, taquicardia ventricular, fibrilação ventricular, torsades de pointes e batimentos ventriculares prematuros (SUNDAR; SINGH, 2018).

Seu uso possui limitações, devido a resistência parasitária ocorridas no Nepal e Índia, alta toxicidade, variáveis em sua eficácia contra a forma cutânea e visceral, além da sua forma de administração que exige uso parenteral por 28 dias (ALVAR; CROFT; OLLIARO, 2006), além de ser contraindicado para casos de coinfecção HIV-Leishmaniose (GUERIN et al., 2002)

A anfotericina B é uma droga utilizada para tratar micoses sistêmicas e Leishmania e seu mecanismo de ação é sobre o ergosterol, um lipídio de membrana presente nos fungos e em Leishmania (CROFT; YARDLEY, 2002; ZAIONCZ; KHALIL; MAINARDES, 2016).

A função do ergosterol é manter a integridade da membrana, sua permeabilidade e posicionamento proteico. Os triazóis, tal como a anfotericina $B$, age inibindo a síntese de ergosterol e pela ausência deste composto ocorre a morte 
celular por desequilíbrio iônico, soluto e metabólitos celular e pela sua auto oxidação gerando radicais livres (ZAIONCZ; KHALIL; MAINARDES, 2016; RYBAK; FORTWENDEL; ROGERS, 2019; TASLIMI; ZAHEDIFARD; RAFATI, 2018).

A anfotericina possui uma maior afinidade com o ergosterol, porém ele também pode se ligar a molécula de colesterol presente nas células dos mamíferos, e consequentemente expondo ao risco de toxicidade (ZAIONCZ; KHALIL; MAINARDES, 2016)

Este fármaco é utilizado como medicamento de segunda escolha em portadores de leishmaniose, possui duas apresentações, a anfotericina B simples e a anfotericina B liposomal e seu uso ocorre em situações de coinfecção com o HIV, na falha ao uso do antimonial (GUERIN et al., 2002), ou o pentosan e pentamidina em casos da forma visceral da doença (BERMAN, 1997).

A anfotericina B lipossomal possui um maior tempo de biodisponibilidade e devido ao seu baixo tamanho penetra com maior eficiência nos tecidos, além de que elas portam vesículas unilamelares, os lipossomos. Os lipossomos são compostos por fosfatidilcolina que é hidrogenada, diestearoilfosfatidilglicerol, que porta um ácido graxo, e o colesterol dando assim a sua característica lipofílica (GHORBANI; FARHOUDI, 2018).

Contudo sua infusão endovenosa deve ser lenta, levando cerca de 4 a 6 horas, necessitando de institucionalização hospitalar e nos casos de LC a sua escolha deve ser uma segunda ou terceira opção de esquema terapêutico após falha dos primeiros recursos devido à alta toxicidade (ULIANA; TRINCONI; COELHO, 2018).

Contudo, mesmo com estas restrições o fármaco é a alternativa mais segura, com baixo custo de uso combinado ou não, indicado para portadores da coinfecção HIV-Leishmaniose (ALVAR; CROFT; OLLIARO, 2006).

A miltefosina é um composto alquilfosfolipídeo e a primeira fármaco de uso oral com efeito anti-leishmania (SUNDAR; SINGH, 2018), ela foi desenvolvida primeiramente como um antineoplásico, porém possui benefícios em casos de leishmaniose visceral e cutânea (TASLIMI; ZAHEDIFARD; RAFATI, 2018). Sua dosagem é de 2 mg/kg (BRINDHA; BALAMURALI; CHANDA, 2021).

Sua formulação ocorreu nos anos de 1960's, contudo devido ao risco de teratogenicidade, mulheres em idade fértil devem possuir a garantia de 
contracepção (ALVAR; CROFT; OLLIARO, 2006) devido ao seu tempo de meia vida, além do risco de resistência parasitária (TASLIMI; ZAHEDIFARD; RAFATI, 2018).

O efeito terapêutico em parasitas tripanosomatídeos, consiste na indução de apoptose (morte celular programada) (MOHAPATRA, 2014). O mecanismo de ação é a inibição da via de sinalização da proteína $B$ quinase (AKt/PKB). A miltefosina possui maior tempo de meia vida plasmática quando comparado ao $\mathrm{Sb}^{5+}$, apresentando como efeito colateral o desconforto gastrointestinal (GHORBANI; FARHOUDI, 2018).

A pentoxifilina é um composto derivado da metilxantina e tem ação de inibidor competitivo não seletivo da fosfodiesterase, podendo aumentar o metabolismo cGMP e do cAMP, além de inibir a síntese de TNF e leucotrienos (RUAN et al., 2021).

Hoebe et al. (2001) avaliou in vitro os efeitos do uso da pentoxifilina em hepatócitos suínos incubados com LPS e sua correlação na expressão TNF - a e IL6. Como resultados as células ativadas com LPS houve produção de TNF - a nas primeira horas e o grupo tratado com LPS + pentoxifilina após 48 horas de incubação houve cessação de sua produção. Em relação a IL-6, após 8 horas de exposição houve a síntese de IL-6 e somente após 48 horas o grupo apresentou redução significativa da interleucina.

A pentoxifilina possui uma grande variedade de propriedades farmacológica, tais como, efeito anticoagulante, estimulação da fibrinólise, modificação da fisiologia do fibroblasto, melhoria da fluidez da membrana celular e imunomodulação (SAMLASKA; WINFIELD, 1994).

Na clínica é utilizado nas hemorragias ativas, doenças vasculares periféricas, defeitos regionais da microcirculação e na doença cerebrovascular (WARD; CLISSOLD, 1987).

De Sá Oliveira et al. (2000), utilizou um modelo murino e verificou que o uso da pentoxifilina ( $8 \mathrm{mg} / \mathrm{kg}$ por via intraperitoneal a de 12/12 horas) reduziu a carga parasitária, o processo inflamatório e o número de vacúolos nos macrófagos, com um alto número de neutrófilos e granulócitos no local da lesão.

O uso somado de Glucantime e pentoxifilina foi avaliado por Sadeghian e Nilforoushzadeh (2006), como resultados, após 3 meses de tratamento com Glucantime associado a pentoxifilina obteve maior eficácia quando comparado ao grupo tratado apenas com o Glucantime. 
A paromomicina, desenvolvida nos anos de 1960, também é utilizada em casos de leishmaniose visceral e cutânea (ALVAR; CROFT; OLLIARO, 2006). É administrada por via intramuscular ou endovenosa na dose de 15-20 mg/dia por 21 dias, sendo que seu uso como monoterapia é feita com sucesso na Índia, porém na Colômbia e no Brasil esta opção terapêutica não possui bom efeito terapêutico na infecção da forma cutânea com agente causal por $L$. (V) panamensis e L. (V) braziliensis (HERWALDT, 1999).

O mecanismo de ação da paromomicina é pela inibição da síntese proteica nos ribossomos (MOHAPATRA, 2014), seus efeitos adversos incluem dor no local da injeção, aumento da transaminase hepática sérica e ototoxicidade reversível (SUNDAR; SINGH, 2018).

O alopurinol é um fármaco utilizado para o tratamento de gota, seu mecanismo de ação é inibindo a xantina oxidase, sua absorção ocorre no trato gastrointestinal, sua eliminação ocorre principalmente pela via metabólica da aldeído oxidase para oxípurinol e seu tempo de meia vida é aproximadamente 1-2 horas (STAMP; CHAPMAN; PALMER, 2016).

Quando utilizado no tratamento da leishmaniose ele atua no metabolismo parasitário produzindo e inativando um análogo de inosina, exercendo uma falha na tradução de proteína do RNA protozoário (BANETH; SHAW, 2002). No padrão de terapia farmacológica, o alopurinol é utilizado como fármaco de primeira escolha, podendo ou não ser associado ao antimoniato de meglumina (MIRÓ et al., 2008).

Em um ensaio realizado em Thessaloniki, na Grécia por Koutinas et al. (2001), avaliou o efeito do alopurinol em 45 cães com sintomas de leishmaniose canina, em que um grupo com 37 cães receberam alopurinol $10 \mathrm{mg} / \mathrm{Kg}$ duas vezes ao dia e um grupo placebo com 8 cães, concluiu que 0 fármaco tem 0 efeito promover e restaurar o quadro clínico e patológico e diminui os parasitas, porém não os eliminam.

A pentamidina é um fármaco sintetizado nos anos de 1930's a partir de um grupo diamidina e um análogo da sintalina, composto que possui ação contra Trypanossoma (ULIANA; TRINCONI; COELHO, 2018). Seu uso se deve pela resistência clínica da leishmaniose visceral na Índia, com regime terapêutico de 4 $\mathrm{mg} / \mathrm{kg}$, três vezes por semana até que se observe a remissão da infecção (BERMAN, 1997). 
Seu efeito terapêutico é exercer uma ação de interferência na glicólise aeróbia do protozoário, ao inibir a topoisomerase II, devida a sua interação com o DNA do cinetoplasto (MOHAPATRA, 2014). No ensaio realizado por Kandpal et al. (1995) foi demonstrado que a pentamidina exerceu um mecanismo de inibição competitiva com os transportadores de arginina em promastigotas de L. donovani e possui valor de $\mathrm{IC}_{50} 40 \mu \mathrm{M}$.

Os antifúngicos "azóis" também são indicados para o tratamento das leishmanioses, pois esta classe de medicação atua na inibição da 14 a-desmetilação do lanosterol mediados pela esterol-14a-demetilase (citocromo P450 - CYP51), causando o acúmulo de 14-a-metil esterol-, causando o bloqueio da síntese de ergosterol na Leishmania (MINODIER; PAROLA, 2007) e, dessa forma, comprometem a função da membrana (MOHAPATRA, 2014).

A dosagem diária de cetoconazol é de $600 \mathrm{mg}$ por 28 dias nos casos da forma cutânea, causada pelas espécies L. mexicana, L. (V) panamensis e L. major. Itraconazol é administrado em duas doses diárias de 200 mg por 28 dias, não sendo indicado para casos em que a infecção foi provocada pelo subgênero Viannia (HERWALDT, 1999).

Alrajhi et al. (2002), utilizou uma dosagem diária por seis semanas, de fluconazol 200 mg em moradores de uma região de Al-Ahsaa e Riyadh na Arabia Saudita, onde a L. major é endêmica. Após o terceiro mês do término do tratamento, $79 \%$ dos pacientes do grupo fluconazol tiveram a cura da lesão, contra $34 \%$ do grupo placebo (Cl 95\%, 1.63-3.33) (ALRAJHI et al., 2002).

Nos Estados Unidos da América (EUA), segundo Aronson et al. (2017) a terapêutica utilizada para leishmaniose consiste no uso oral de miltefosina e uso de fármacos da classe dos "azois", como fluconazol e cetoconazol, para o uso parenteral foi indicado desoxicolato de anfotericina $B$, antimoniais pentavalentes, estibogluconato de sódio, antimoniato de meglumina, anfotericina B lipossomal e isetionato de pentamidina.

A terapia tópica com paromomicina é indicada para os casos das leishmanioses do Velho e do Novo Mundo, desde que não haja possibilidade para evolução clínica para a forma mucosa, como uso de terapia tópica e administração parenteral via lesão de antimoniais pentavalente, associada ou não com a crioterapia (ARONSON et al., 2017). 
Na figura 9 estão disponibilizadas o peso molar, a fórmula molecular e a estrutura molecular dos fármacos aqui abordados:<smiles>CNC[C@H](C)[C@@H](C)[C@H](C)C(Br)CO</smiles>

Antimoniato de meglumina Glucantime

P.M. $-365.98 \mathrm{~g} / \mathrm{Mol}$

$\mathrm{C}_{7} \mathrm{H}_{18} \mathrm{NO}_{8} \mathrm{Sb}$

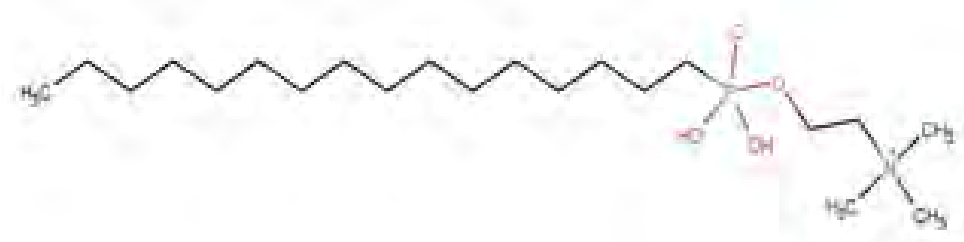

\section{Miltefosina}

P.M. $-407,6 \mathrm{~g} / \mathrm{Mol}$

$\mathrm{C}_{21} \mathrm{H}_{46} \mathrm{NO}_{4} \mathrm{P}$

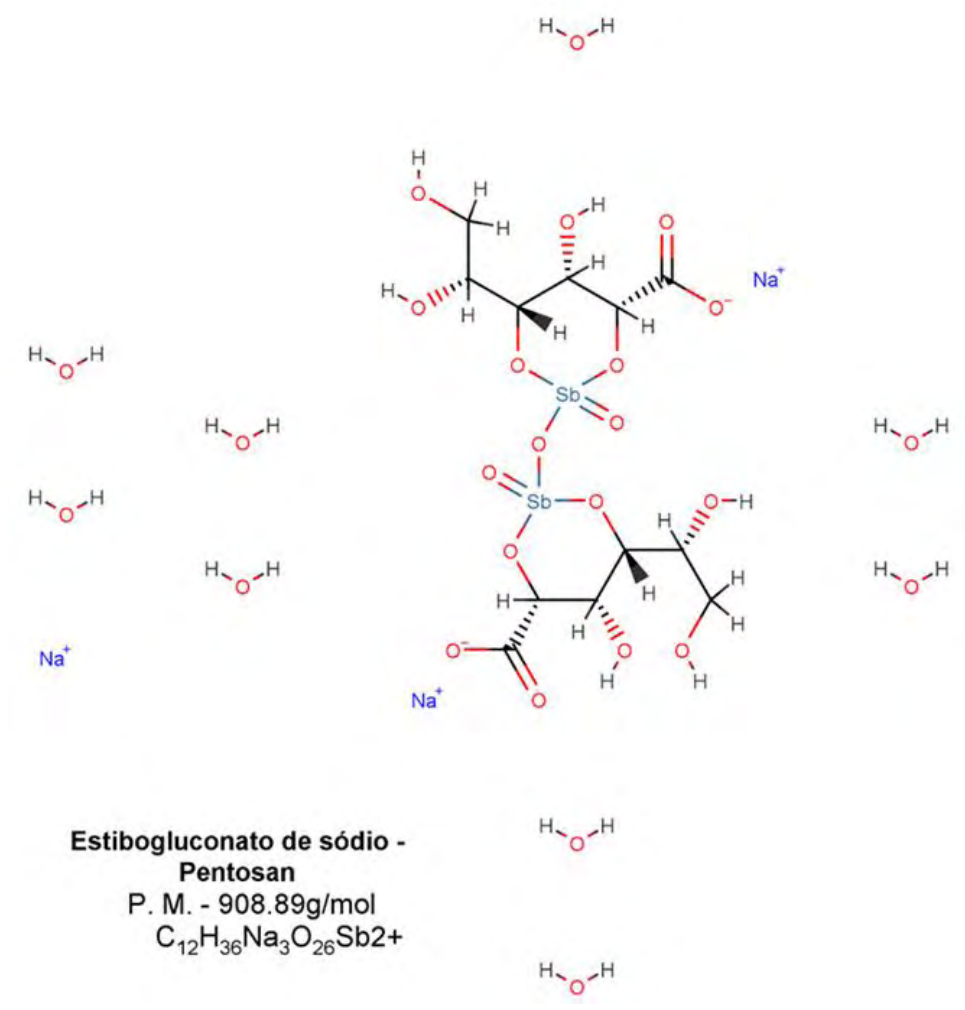


<smiles>O=c1[nH]cnc2[nH]ncc12</smiles>

Alopurinol

P.M. - $136.11 \mathrm{~g} / \mathrm{Mol}$

$\mathrm{C}_{5} \mathrm{H}_{4} \mathrm{~N}_{4} \mathrm{O}$<smiles>CC(=O)CCCCn1c(=O)c2c(ncn2C)n(C)c1=O</smiles>

Pentoxifilina

P.M. $-278.31 \mathrm{~g} / \mathrm{Mol}$

$\mathrm{C}_{13} \mathrm{H}_{18} \mathrm{~N}_{4} \mathrm{O}_{3}$

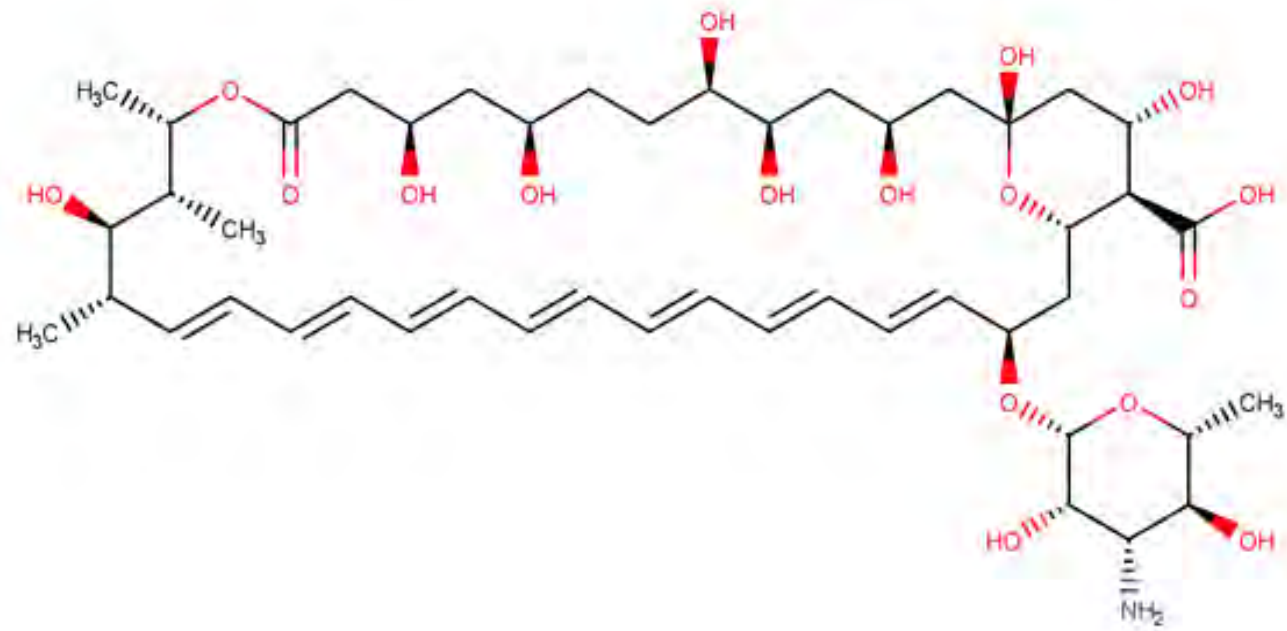

Anfotericina B

P.M. - $924.1 \mathrm{~g} / \mathrm{Mol}$

$\mathrm{C}_{47} \mathrm{H}_{13} \mathrm{NO}_{17}$ 


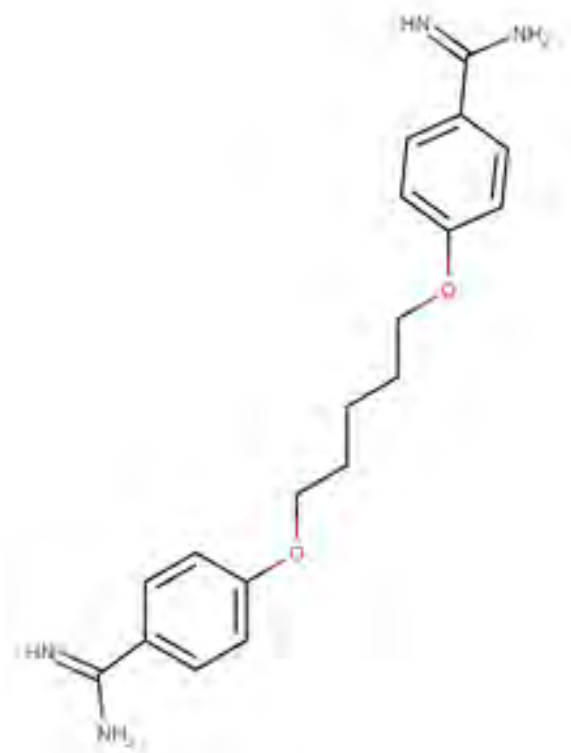

Pentamidina

P.M. $-340.4 \mathrm{~g} / \mathrm{Mol}$

$\mathrm{C}_{19} \mathrm{H}_{24} \mathrm{~N}_{4} \mathrm{O}_{2}$
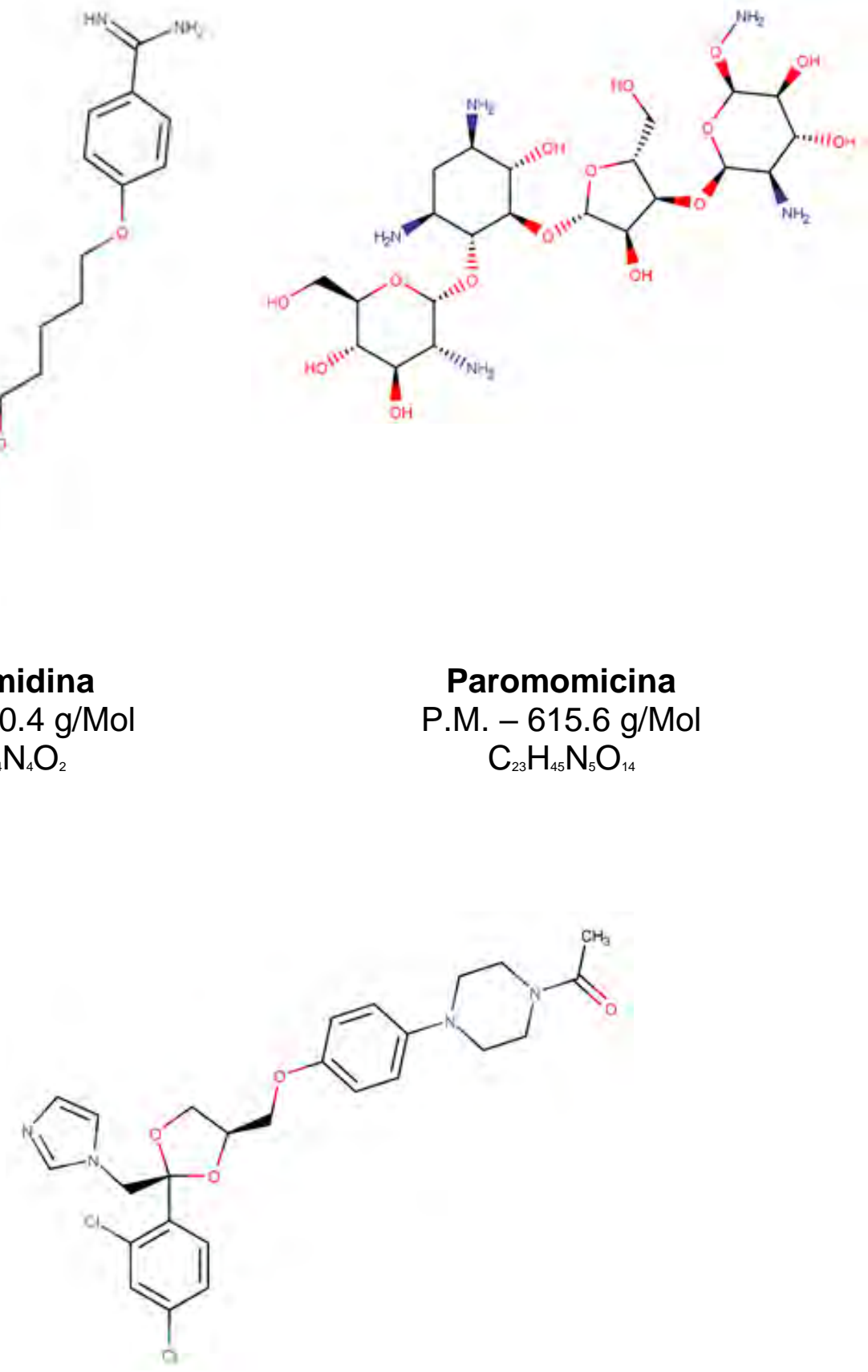

Cetoconazol

P. M. $-513.4 \mathrm{~g} / \mathrm{Mol}$

$\mathrm{C}_{26} \mathrm{H}_{28} \mathrm{Cl}_{2} \mathrm{~N}_{4} \mathrm{O}_{4}$

Paromomicina

P.M. $-615.6 \mathrm{~g} / \mathrm{Mol}$

$\mathrm{C}_{23} \mathrm{H}_{45} \mathrm{~N}_{5} \mathrm{O}_{14}$ 


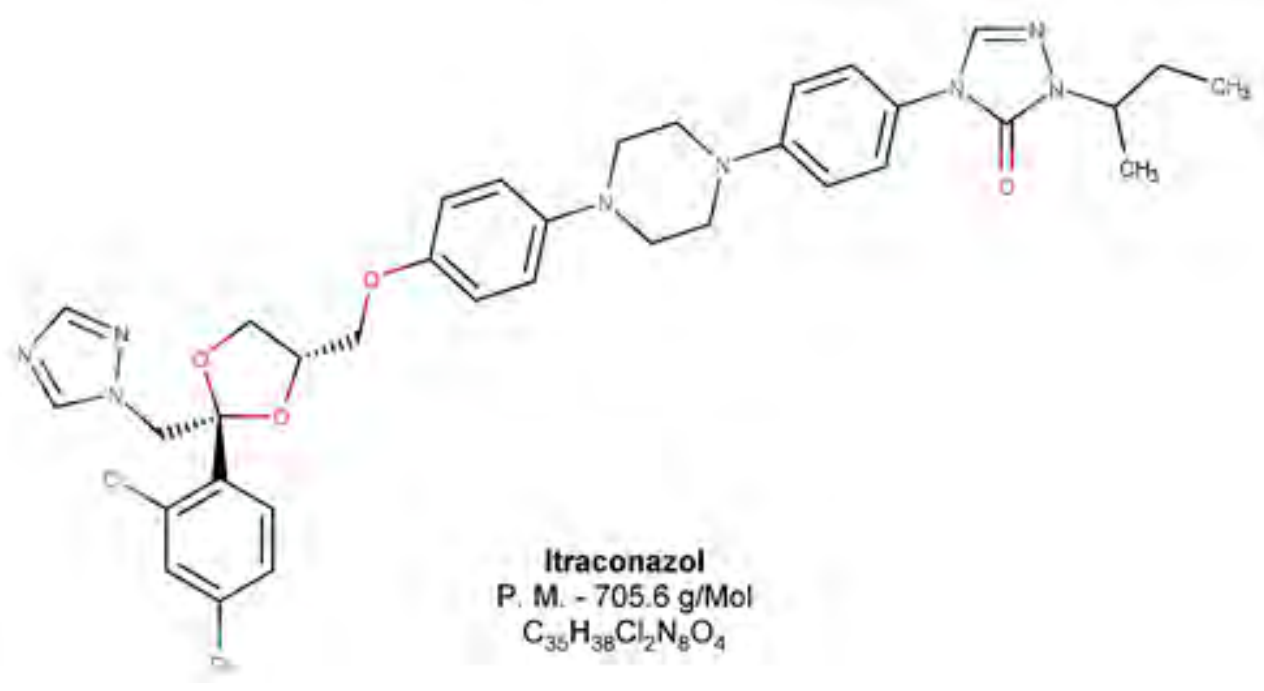

Figura 09 - Fármacos utilizados para terapêutica contra leishmaniose. Fonte: Própria autoria.

Os esquemas terapêuticos em situações de coinfecção de HIV-Leishmania dependem da política pública de saúde de cada país. Em geral, seguem-se duas linhas, a terapia antirretroviral associada aos agentes anti-leishmania e a e que proporciona uma terapêutica de manutenção, com o uso de anfotericina B (CROFT; OLLIARO, 2011).

No Brasil, na terapêutica farmacológica da leishmaniose cutânea disponibilizado pelo Ministério da Saúde pode-se utilizar o antimoniato de meglumina, desoxicolato de anfotericina $B$, anfotericina $B$ lipossomal, pentamidina $e$ a pentoxifilina, podendo seu uso ser sistêmico ou com injeção local, dependendo do caso (BRASIL, 2017).

$\mathrm{Na}$ terapêutica farmacológica para humanos da leishmaniose visceral, utilizase como primeira escolha o uso dos antimoniais pentavalentes, e na impossibilidade do uso desse fármaco, devido a situações de hipersensibilidade ou gestação, optase pela anfotericina B (BRASIL, 2016).

No Brasil, o Ministério da Agricultura, Pecuária e Abastecimento (MAPA, 2016), regulamentou o uso da miltefosina para tratamento de cães portadores de leishmaniose visceral, visto que, este medicamento não é utilizado no país para a terapêutica humana. A prevenção em cães pode ser feita com coleiras com repelentes do vetor sob responsabilidade dos tutores (REGUERA et al., 2016).

Mundialmente observam-se falhas no tratamento das leishmanioses, relacionadas à resistência parasitária aos antimoniais pentavalentes (CAPELA; 
MOREIRA; LOPES, 2019). Em Bihar, Índia, cerca de 30\% dos pacientes portadores de LV não apresentaram melhora após serem submetidos ao tratamento com um antimonial (DAVIDSON, 1998).

A falha terapêutica foi recentemente classificada por uma persistência da não resposta terapêutica ou reincidência da infecção no pós-tratamento, e ela advém de vários fatores, tais como: sexo, idade, imunidade, virulência do parasita, genes responsáveis pela resistência, dosagem, farmacocinética e farmacodinâmica do tratamento proposto (BARKATI; NDAO; LIBMAN, 2019).

É importante ressaltar, que a falha terapêutica não é sinônimo de resistência às drogas, pois outros fatores também podem influenciar na resposta terapêutica, tais como: imunidade, estado nutricional, a biodisponibilidade dos fármacos aos tecidos que estão infectados e as questões ambientais relacionadas a expansão geográfica da patologia (PONTE-SUCRE et al., 2017).

Por outro lado, na resistência parasitária, no caso das infecções antroponóticas, quando o flebotomíneo transfere o parasita de um humano para outro, há a possibilidade de o vetor infectar um novo paciente com uma cepa que já foi previamente exposto ao antimonial. Nesse caso, foi observado uma alta possibilidade de haver uma infecção com um agente que passou por uma seleção e se tornou resistentes ao fármaco (AÏT-OUDHIA et al., 2011).

O uso de antimoniais foi por muito tempo a primeira alternativa de tratamento da leishmaniose, porém a incidente resistência parasitária a este fármaco exige que sejam desenvolvidos novos medicamentos com maior eficácia (MACHADO-SILVA et al., 2015; SINGH; KUMAR; SINGH, 2012). A partir disto, esta tese é justificada devido ao fato dela buscar um novo agente que poderá evoluir para futuros candidatos a ensaios clínicos para a terapêutica antileishmania.

\subsection{Fenetil éster do ácido cafeico (CAPE)}

Os polifenóis e seus compostos estão presentes nos tecidos vegetais, participando da dieta humana e o aumento do interesse dessas substâncias ocorreu devido a sua repercussão na saúde humana devido ao seu potencial na eliminação de radicais livres (BRAVO, 1998).

Destes compostos, o fenetil éster do ácido cafeico (figura 10), é um composto polifenólico sintetizado pelas plantas (WANG et al., 2009), sendo o maior constituinte 
da própolis providas de regiões temperadas (HUANG et al., 2014), o nome químico desse composto é 2-feniletil (2E) -3- (3,4-di-hidroxifenil) acrilato, sendo que o CAPE possui massa molar de $284.31 \mathrm{~g} / \mathrm{mol}$ e fórmula química $\mathrm{C}_{17} \mathrm{H}_{16} \mathrm{O}_{4}$ (PITTALÀ et al., 2018).

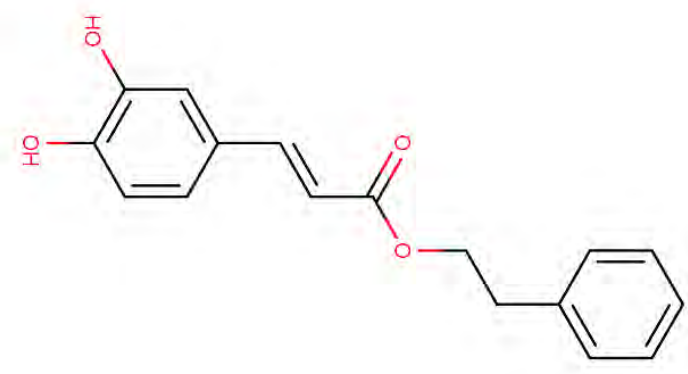

Figura 10 - Molécula do fenetil éster do ácido cafeico (CAPE). Fonte: autoria própria.

O CAPE foi identificado primeiramente em análise de cromatografia gasosa acoplada a espectrofotometria de massa (GC/MS) em constituintes fenólicos de diferentes amostras própolis búlgara realizada por Bankova et al. (1987), também publicada por Greenaway, Scaysbrook e Whatley (1987) ao realizar o mesmo teste em amostras de botões de Populus $x$ euramericana e própolis da região do Reino Unido e da Escócia.

Todavia este composto não foi unicamente encontrado em países supracitados, Kumazawa et al. (2010) analisou por cromatografia líquida de alta performance (HPLC) amostras de própolis das regiões argentinas de Mendoza, Rio Negro, La Pampa e Entre Rios, constatou que todas as amostras possuíam o CAPE dentre seus compostos.

Freires et al. (2016) buscou em seu experimento verificar a composição por meio de cromatografia gasosa acoplada à espectrometria de massa (CG-MS) e eficácia de duas amostras brasileiras, uma oriunda da região sudeste (extrato tipo 3) e outra da região nordeste (extrato tipo 3).

A fração de diclorometano da amostra tipo 3 apresentou um perfil de compostos fenólicos ácido cafeico, CAPE, ácido p-coumarico, kaempferol e quercetina, já a fração hexana do extrato tipo 13 apresentou os isoflavonóides medicarpina, vestitol e formononetina (FREIRES et al., 2016).

Sun et al. (2019) realizou uma análise de 14 amostras de própolis brasileiras coletadas no verão de 2017 utilizando o método de cromatografia acoplada a espectrometria de massas (UPLC-ESI-QTOF-MS) evidenciou que elas possuíam não somente o CAPE como um de seus compostos, mas também o ácido 
clorogênico, ácido cafeico, ácido isoclorogênico $A$, ácido isoclorogênico $B$, ácido isoclorogênico $\mathrm{C}$ e a artepilina $\mathrm{C}$.

Murtaza et al. (2014), descreveu que o composto é portador das propriedades biológicas de citotoxicidade, ação anti-inflamatória, antimicrobiana e antioxidante.

O CAPE possui potencial ação anticarcinogênica (BANSKOTA; TEZUKA; KADOTA, 2001), além da ação protetora dos tecidos hepático, cardíaco e nervoso (TOLBA et al., 2013), podendo ser um promissor agente terapêutico contra doenças cardiovasculares, neurodegenerativas e oncológicas (VAUZOUR et al., 2010).

Grosso (2018) referiu que o composto possui mecanismo anti-inflamatório e antioxidante. Também foi identificada ação antiviral contra o vírus tipo $A$ e do tipo $B$ da influenza na concentração de $8.8 \mu \mathrm{M}$, além de ação antioxidante e inibição da hialuronidase (KISHIMOTO et al., 2005).

Tolba et al. (2013) relatou que os alvos que a CAPE pode atuar como agente anti-inflamatória são sobre as enzimas pró-inflamatórias, tais como a COX-1, COX-2, LOX e iNOS), mediadores pró-inflamatórios (PGE2, TNF- $\alpha$, IL-1 $\beta$, IL-6, IL-10, NO, MCP-1), fatores de transcrição (NF-kB) e moléculas sinalizadoras (TLR4, C-jun e Ncinase).

Huang et al. (2014) observaram que o CAPE possui ampla atividade biológica, incluindo inibição do NF-kB, inibição da proliferação celular e indução da parada do ciclo celular e apoptose.

Wang et al. (2009) avaliou os níveis de IFN-y, IL-5, IL-10, IL-12 p40, IL-12 p70 e IP-10 secretados de células dendríticas derivados de monócitos de pacientes saudáveis e portadores de alergia a ácaros que receberam LPS e CAPE como tratamentos. Como resultados o composto inibiu a IL-12 p40, IL-12 p70 e IL-10 das células de pacientes saudáveis após ativação com LPS e para as células ativadas com extrato de ácaros a IL-12 p40, IL-10 e IP-10 foram inibidos.

O uso in vitro de nanopartículas de CAPE encapsulada com ácido poliláticoco-glicólico contra cepas de Leishmania infantum nas formas promastigotas e amastigotas apresentou inibição do crescimento dos parasitas. A formulação possui um grande potencial para tratamento da leishmaniose necessitando ser testada, in vivo (ABAMOR, 2017).

Borrelli et al. (2002), utilizou um modelo murino e demonstrou que o CAPE é uma substância com potencial anti-inflamatório, não havendo a necessidade de 
sinergismo com outro componente da própolis, como no caso a galangina, utilizada no experimento.

Em modelo murino, com indução da diabetes e lesão hepática por estreptomicina, Taslidere et al. (2015) verificou que no grupo diabético apresentou elevação dos níveis de malondialdeído (MDA) e diminuição da enzima superoxidase dismutase (SOD) e níveis de glutationa total (GSH) em relação ao grupo controle que não apresentava a indução do quadro patológico.

Porém no grupo diabético que recebeu o CAPE houve o oposto, os níveis de SOD e GSH foram elevados e os níveis de MDA estavam diminuídos em relação ao grupo diabético, demonstrando assim que o CAPE foi capaz de inibir a produção da MAD e consequentemente a peroxidação lipídica. Também foi descrito que o composto apresentou este mecanismo sem precisar do auxílio de antioxidantes e enzimas hepáticas (TASLIDERE et al., 2015).

Os efeitos farmacocinéticos do CAPE foram ensaiados por Wang et al. (2007), onde foi utilizado ratos Sprague-Dawley, onde demonstrou que a curva da concentração plasmática do CAPE nas dosagens de 5 para $20 \mathrm{mg} / \mathrm{Kg}$ era maior. A depuração total corporal do composto foi de 42.1 para $172 \mathrm{~mL} / \mathrm{min} / \mathrm{kg}$, o volume de distribuição foi cerca de 1555 para 5209 mL/Kg e o tempo de eliminação da meiavida, independente da dosagem, foi de 21,2 para 26,7 min.

Celli et al. (2007) em seu estudo comparou o efeito de hidrolisação no plasma humano e de ratos, seus resultados foram que o CAPE foi somente hidrolisado no plasma de rato gerando como produtos ácido cafeico e éster etílico de ácido cafeico.

\section{HIPÓTESE}

Espera-se que o CAPE iniba a atividade da enzima arginase de $L$. (Leishmania) amazonensis e elimine as formas promastigotas do protozoário. Também se espera que haja a diminuição do índice de infectividade dos macrófagos infectados ativados ou não com LPS + IFN - $\gamma$ e ocorra o crescimento parasitário após suplementação do meio de cultura com L-ornitina.

\section{OBJETIVOS}




\subsection{Objetivo geral}

Verificar se o composto CAPE tem potencial contra as formas promastigotas e amastigotas de L. (L.) amazonensis.

\subsection{Objetivos específicos}

- Verificar se o CAPE inibe a enzima arginase e identificar qual o seu mecanismo de inibição enzimática;

- Testar o composto in vitro contra promastigotas de L. (L.) amazonensis;

- Realizar a infecção de macrófagos peritoneais murinos com promastigotas metacíclicos e testar o composto sobre eles;

- Avaliar a ativação de macrófagos murinos infectados com LPS+IFN-ү;

- Quantificar os níveis de nitrito no sobrenadante do meio de cultura;

- Analisar o efeito da suplementação de L-ornitina nas grupos tratados com CAPE.

\section{MATERIAIS E MÉTODOS}

\subsection{Materiais}

Anfotericina B (Unianf) foi obtida da empresa União Química Farmacêutica Nacional, Embu-Guaçu, SP, Brasil. Meio 199 contendo L-glutamina, Sal de Hanks, HEPES, RPMI 1640, penicilina/ estreptomicina, lipopolissacarídeos (LPS) e interferon gama (IFN- $\gamma$ ) (Life Technologies Corporation, Frederick MD, EUA). Giemsa, MTT (3-(4,5-dimethyltiazol-2y-I)-2,5 diphenyl bromide tetrazolium), DMSO (dimetilsulfóxido), hemina, soro fetal bovino, L-arginina , CHES (Ácido 2(ciclohexilamino) etanossulfônico), cloranfenicol, ampicilina, anfotericina, glicerol e o fenetil éster do ácido cafeico (CAPE), foram adquiridos da Sigma-Aldrich, St. Louis, MO, EUA.

As cepas dos parasitas L. (Leishmania) amazonensis (MHOM/BR/1973/M2269) foram gentilmente cedidas pela Dra. Lucile M. FloeterWinter (Instituto de Biociências IB - USP).

\subsection{Aquisição de macrófagos peritoneais murino}


Utilizando a metodologia adaptada de Layoun, Samba e Santos (2015), os macrófagos murinos foram coletados de aspirado de lavado abdominal. $O$ procedimento obteve a aprovação do Comitê de Ética de Uso De Animais da FZEAUSP (CEUA nํ 3086190918).

Brevemente, camundongos Swiss machos com peso médio de 35 a 45 gr., foram encaminhados ao Centro de Pesquisa em Toxicologia Veterinária (CEPTOX USP), Campus Pirassununga-SP e após período de adaptação os animais foram mantidos no biotério em caixas de polipropileno (30X19X13 cm), autoclavadas, sem bordas, com o número máximo de 3 animais por caixa, em condições ideais de temperatura, tipo de ração para a espécie, com dieta e água ad libitum.

Para mobilizar a migração de macrófagos maduros, três dias antes do procedimento de coleta foi realizada a administração por via intraperitoneal $0,5 \mathrm{~mL}$ de PBS, pH 7.4, com 3\% de tioglicolato, utilizando seringa de $1 \mathrm{~mL}$ e agulha $24 \mathrm{G} \mathrm{3/4}$ (ou $20 \times 5.5$ ).

Para a coleta os animais foram anestesiados com halotano e submetidos a eutanásia por deslocamento cervical e fazendo uso seringa de $5 \mathrm{~mL}$ e agulha $26 \mathrm{G} 1 / 2$ (ou 13 x 4.5) se aspirou o conteúdo líquido do abdômen. O líquido aspirado passou por contagem celular na câmara de Neubauer.

\subsection{Determinação da $\mathrm{EC}_{50}$ do CAPE}

Utilizando reagentes comerciais foi realizado o ensaio colorimétrico de Berthelot (FAWCETT \& SCOTT, 1960), realizou-se a triagem do CAPE para verificar sua capacidade de inibir a enzima arginase recombinante de L. (L.) amazonensis, expressão e purificação realizada conforme descrito previamente por Da Silva, Maquiaveli e Magalhães (2012), utilizando o inibidor nas concentrações de 100 $0,01 \mu \mathrm{M}$. A reação ocorreu em tampão CHES $50 \mathrm{mM}$ e $50 \mathrm{mM}$ de L-arginina, ambas com pH 9,5 seguidos de incubação em banho-Maria à $37^{\circ} \mathrm{C}$ por 30 min.

Brevemente, a atividade catalítica da reação da arginase foi cessada transferindo $10 \mu \mathrm{L}$ da reação da mistura em $750 \mu \mathrm{L}$ do reagente $\mathrm{A}$ (20 mM tampão fosfato, $\mathrm{pH} 7$, contendo $60 \mathrm{mM}$ salicilato, $1 \mathrm{mM}$ nitroprussiato de sódio e $>500 \mathrm{IU}$ de urease). A mistura foi incubada por $5 \mathrm{~min}$ à $37^{\circ} \mathrm{C}$. Após, $750 \mu \mathrm{L}$ do reagente $\mathrm{B}$ (hipoclorito de sódio $100 \mathrm{mM}$ e $150 \mathrm{mM} \mathrm{NaOH}$ ) foi adicionado, e estas amostras foram incubadas à $37^{\circ} \mathrm{C}$ por 10 min (FAWCET; SCOTT, 1960). A mensuração da 
absorbância foi realizada em espectrofotômetro Epoch 2 da empresa Biotek, com feixe de luz $600 \mathrm{~nm}$.

Os controles negativos e positivos se fizeram nas mesmas condições e na ausência do inibidor. Determinação da concentração que inibe $50 \%$ da atividade catalítica da enzima foi realizada pela variação da concentração do inibidor com um fator de diluição 1:10. Os experimentos foram realizados em triplicatas em pelo menos 2 experimentos independentes até que fosse obtido um coeficiente de regressão não-linear $R^{2} \geq 0,95$.

As diferentes concentrações do inibidor foram obtidas pelo preparo de uma solução mãe contendo como solvente o DMSO e a partir desta se realizou uma diluição seriada do CAPE em água e tampão CHES com concentração final de 50 mM. As reações foram realizadas em pH 9.5 utilizando tampão CHES $50 \mathrm{mM}$ na presença do substrato L-arginina $50 \mathrm{mM}(\mathrm{pH}$ 9.5). As amostras foram incubadas em banho maria à $37^{\circ} \mathrm{C}$ por 15 min e a ureia formada foi analisada como descrito acima. Utilizando um modelo matemático sigmoidal ( $\log \mathrm{EC}_{50}$ ) para determinar a EC50, utilizando o software GraphPad Prism 8.0.

\subsection{Determinações do mecanismo de inibição enzimática e elaboração das constantes de CORNISH-BOWDEN e DIXON}

Para determinar o mecanismo de inibição também foi realizado o ensaio colorimétrico Berthelot com algumas adaptações (FAWCETT \& SCOTT, 1960). O

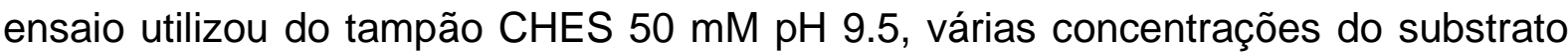
L-arginina (25, 50 e $100 \mathrm{mM})$ com pH 9.5. A partir da $\mathrm{EC}_{50}$ o inibidor foi utilizado em diferentes concentrações, sendo elas 4 x EC50, 2 x EC50 e a EC50.

Foi preparado uma mistura substrato, contendo o dobro da concentração do substrato L-arginina ( $\mathrm{pH} \mathrm{9,5)} \mathrm{Mix} \mathrm{1,} \mathrm{e} \mathrm{outra} \mathrm{mistura,} \mathrm{Mix} \mathrm{2,} \mathrm{contendo} \mathrm{a} \mathrm{enzima} \mathrm{(2000}$ U de arginase) ambas diluídas em 500 mM de tampão CHES (pH 9,5). O volume do experimento continha $100 \mu \mathrm{L}$, sendo $45 \mu \mathrm{L}$ do Mix 1, $10 \mu \mathrm{L}$ de inibidor e $45 \mu \mathrm{L}$ da Mix 2 e seu preparo ocorreu em gelo até a finalização do preparo, após se fez incubação em banho-Maria por 30 min à $37^{\circ} \mathrm{C}$. A análise da ureia utilizou como a metodologia descrita na etapa anterior e todas as reações foram realizadas em triplicata e no mínimo dois experimentos independentes. 
Para determinar o mecanismo de inibição, se fez o uso da evidência de Cornish-Bowden (1974), em que a constante Ki foi determinada para inibidores que apresentam mecanismo de inibição mista ou competitiva, enquanto K'i foi determinada para inibidores que apresentaram inibição mista ou não competitiva.

Cada constante foi determinada pelo cálculo do ponto de intersecção do ponto $x$ entre duas linhas obtidas pela regressão linear. Para inibição não competitiva, $y=0$ foi utilizado para a equação para encontrar os valores das constantes Ki e K'i (CORNISH-BOWDEN, 1974). Na elaboração dos gráficos, foi utilizado outra planilha do software MS-Excel.

\subsection{Determinação da $\mathrm{EC}_{50}$ do CAPE em meio de cultura com promastigotas de L. (L.) amazonensis}

Os promastigotas foram incubados em meio 199 suplementado com 10\% de soro fetal bovino, $5 \mathrm{ppm}$ de hemina, estreptomicina $50 \mu \mathrm{g} / \mathrm{mL}$ e $100 \mathrm{U}$ penicilina até a sua fase estacionária. Os protozoários foram transferidos para $1400 \mu \mathrm{L}$ de meio de cultura na razão de $5 \times 10^{5}$ células $/ \mathrm{mL}$ e incubadas com 2,8 $\mu \mathrm{L}$ do inibidor CAPE nas concentrações de $100 \mu \mathrm{M}$ à 1,5625 $\mu \mathrm{M}$ dissolvidos em DMSO. Para o controle positivo $(\mathrm{C}+)$ do crescimento dos promastigotas se utilizou DMSO à $0,2 \%$. A anfotericina B foi utilizada como um controle negativo (C-) da inibição do crescimento celular com variadas concentrações de $10 \mu \mathrm{M}$ à 0,001 $\mu \mathrm{M}$.

Os testes foram realizados em microtubos cônicos de 1,5 mL. Após 72 horas de incubação a 25ํㅡ, uma nova centrifugação 2.300 rpm por 10 minutos, drenagem do sobrenadante e novamente uma dupla lavagem com HBSS foi realizada nos microtubos. As células foram suspendidas em $200 \mu \mathrm{L}$ de RPMI sem vermelho fenol e $20 \mu \mathrm{L}$ de MTT a $5 \mathrm{mg} / \mathrm{mL}$. A mistura foi incubada à 34ํㅡ "overnight".

Transcorrido a incubação, os tubos foram centrifugados por 5 min à 5.000 rpm, drenado o sobrenadante, adicionado $500 \mu \mathrm{L}$ de DMSO para dissolução dos cristais de formazan e transferido $200 \mu \mathrm{L}$ para placa de 96 poços para leitura em espectrofotômetro com absorbância a $570 \mathrm{~nm}$. Foram realizados pelo menos dois experimentos independentes em triplicata. Os valores da $\mathrm{EC}_{50}$ foram calculados com um modelo sigmoidal ( $\log \mathrm{IC}_{50}$ ) utilizando o software GraphPad Prism 8.0 (San Diego, CA, USA). 


\subsection{Avaliação infecção dos macrófagos murinos pelos parasitos tratados com o CAPE}

Para este experimento foi utilizado a metodologia adaptada de Maquiaveli et al. (2017), os macrófagos peritoneais murinos foram inoculados junto ao meio de cultura RPMI 1640 enriquecido com soro fetal bovino à $10 \%, 10 \mu \mathrm{g} / \mathrm{mL}$ de estreptomicina e $10 \mathrm{U} / \mathrm{mL}$ penicilina, à $34^{\circ} \mathrm{C}$ em atmosfera controlado com $5 \% \mathrm{CO}_{2}$ por 6 horas em câmara de cultura de 8 poços (Lab-Tek Chamber Slide, Nunc) e lavados com HBSS para remoção das células não aderidas. Promastigotas em fase estacionária foram adicionados na razão de 10 parasitas para 1 macrófago. Após 24h de exposição os promastigotas não fagocitados foram removidos do meio por dupla lavagem com HBSS. As células infectadas foram expostas aos tratamentos com CAPE nas concentrações de $3,1 \mu \mathrm{M}$ à $100 \mu \mathrm{M}$ diluídas em meio de cultura; a anfotericina foi utilizada como droga padrão para a inibição do crescimento parasitário.

Para o controle positivo do crescimento parasitário intracelular foi adicionado no meio $0,2 \%$ DMSO. O período de tratamento das células foi de $24 \mathrm{~h}$ e as células foram lavadas com meio fresco, fixadas com metanol $100 \%$ e corados com Giemsa.

O índice de infectividade (razão dos macrófagos infectados multiplicado pela média do número de amastigotas em macrófagos) foi calculado pela contagem aleatória de 100 macrófagos em cada lâmina. O efeito leishmanicida dos tratamentos foi expresso pela $\mathrm{EC}_{50}$ que corresponde a concentração que reduz $50 \%$ do índice de infectividade comparado com o controle do índice de infectividade dos macrófagos expostos ao meio RPMI somente com DMSO.

\subsection{Ativação dos macrófagos com LPS e IFN- $\gamma$ e tratados com CAPE}

Os macrófagos murinos foram semeados em lâminas de 8 poços (Lab Tek Chamber Slide, Nunc) e cultivados por $6 \mathrm{~h}$ à $34^{\circ} \mathrm{O}$ em $\mathrm{CO}_{2} 5 \%$. Neste meio os promastigotas em fase estacionária foram adicionados na razão de 1 macrófago:10 parasitas. Após 24 horas de incubação a $34^{\circ} \mathrm{C}$ em $\mathrm{CO}_{2} 5 \%$, os protozoários não fagocitados foram lavados com HBSS.

Os macrófagos infectados e não infectados foram semeados em placa de 8 poços e tratados isoladamente ou associada com $20 \mu \mathrm{M}$ CAPE a $5 \mathrm{ng} / \mathrm{mL}$ INF- $\gamma+$ $0,1 \mu \mathrm{g} / \mathrm{mL}$ LPS dissolvidos em meio RPMI 1640 contendo 0,2\% DMSO. Após 
transcorrido $24 \mathrm{~h}$, as células foram lavadas com HBSS, seguido de fixação com metanol $100 \%$ e corados com Giemsa.

O índice de infectividade (razão dos macrófagos infectados multiplicado pela média do número de amastigotas em macrófagos) foi calculado pela contagem aleatória de 100 macrófagos em cada tratamento. Todos os experimentos foram realizados em triplicatas em dois experimentos independentes.

O efeito leishmanicida dos tratamentos foram expressos em $\mathrm{EC}_{50}$ dos tratamentos que reduz $50 \%$ do índice de infectividade quando comparados com o controle dos macrófagos infectados expostos ao meio RPMI 1640 que somente continha DMSO (MAQUIAVELI et al., 2017).

\subsection{Concentração de nitrito na cultura macrófagos infectados com amastigotas de L. (L.) amazonensis}

Utilizando a metodologia de Maquiaveli et al. (2017) os níveis de nitritos foram determinados nos sobrenadantes dos meios de cultura infectados em dois grupos, um primeiro grupo que era composto por macrófagos infectados, macrófagos infectados tratados com $20 \mu \mathrm{M}$ CAPE e macrófagos infectados ativados com 5 $\mathrm{ng} / \mathrm{mL}$ INF- $\gamma+0,1 \mu \mathrm{g} / \mathrm{mL}$ LPS, oriundos de um experimento de reação de cadeia da polimerase (PCR) não apresentados nesta dissertação, e o segundo grupo vindo dos meios de cultura de macrófagos infectados da etapa anterior que foram tratados com $5 \mathrm{ng} / \mathrm{mL}$ INF- $\gamma+0,1 \mu \mathrm{g} / \mathrm{mL}$ LPS, $20 \mu \mathrm{M}$ CAPE e $5 \mathrm{ng} / \mathrm{mL}$ INF- $\gamma+0,1 \mu \mathrm{g} / \mathrm{mL}$ LPS + $20 \mu \mathrm{M}$ CAPE dissolvidos em meio RPMI 1640 contendo 0,2\% DMSO, utilizando o reagente de Griess. Brevemente, $50 \mu \mathrm{L}$ do sobrenadante foi adicionado em $43 \mu \mathrm{L}$ de água Milli $\mathrm{Q}$ e $7 \mu \mathrm{L}$ do reagente de Griess (diluição de 1:1 da solução dicloridrato de $\mathrm{N}$ - (1-naftil) etilenodiamina $1 \mathrm{mg} / \mathrm{mL}$ com ácido sulfanílico $10 \mathrm{mg} / \mathrm{mL}$ em solução de ácido fosfórico a 5\%), resultando um volume final de $100 \mu \mathrm{L}$. Após 30 minutos em temperatura ambiente e abrigada da luz foi realizada a leitura da absorbância das amostras em espectrofotômetro Epoch 2 (Biotek), com absorbância de $548 \mathrm{~nm}$. A concentração de $\mathrm{NaNO}_{2}$ foi calculada em comparação com uma curva padrão de nitrito 0 a $100 \mu \mathrm{M}$ de $\mathrm{NaNO}_{2}$ associado ou não com o $20 \mu \mathrm{M}$ CAPE nas amostras que possuíam o composto como tratamento. Todos os experimentos foram realizados em triplicata e conduzidos 2 experimentos independentes.

\subsection{Suplementação com L-ornitina}


Para verificar se o CAPE reduzia o crescimento parasitário pela inibição da via da arginase em cultura de macrófagos infectados o seu cultivo foi suplementado o meio com L-ornitina. Brevemente, os macrófagos infectados com promastigotas metacíclicos de L. L. amazonensis em lâmina de 8 poços e foram tratados com 20 $\mu \mathrm{M}$ de CAPE, dissolvidos em meio de cultura RPMI 1640 contendo 0.2\% DMSO, suplementado ou não com $5 \mathrm{mM}$ L-ornitina. Após 72 horas de tratamento, os macrófagos infectados foram lavados com meio fresco e as lâminas foram fixadas com metanol $100 \%$ e corados com Giemsa. O índice de infectividade foi calculado pela contagem randomizada de 100 macrófagos por tratamento. Todos os experimentos foram realizados em duplicata e conduzidos 3 experimentos independentes (MAQUIAVELI et al., 2017).

\subsection{Análise estatística}

Para comparações múltiplas de dados não paramétricos foi utilizado o teste de KrusKal-Walis, com pós-teste de Dunn, sendo os dados expressos em mediana e percentis (25-75\%). Os demais dados foram submetidos à Análise de Variância (ANOVA), com comparações múltiplas pelo teste de Newman-Keuls, sendo os resultados expressos em média \pm SEM. As análises estatísticas foram realizadas utilizando-se o programa GraphPad Prisma versão 8.0 para Windows, GraphPad Software, San Diego, California, USA. O nível de significância adotado foi de $p<0,05$. 


\section{RESULTADOS}

\subsection{Determinação da $\mathrm{IC}_{50}$ de inibição da arginase pelo CAPE e mecanismo de inibição enzimática}

O CAPE apresentou uma $\mathrm{EC}_{50}$ de 1,947 $\mu \mathrm{M}$ (intervalo de confiança 95\% 1,4 a 2,6 $\mu \mathrm{M}$ ) na inibição da arginase de L. (L.) amazonensis (figura 11). A constante da inibição da arginase foi determinada pela análise dos gráficos de Dixon, resultado no valor de Ki de 1,5 $\mu \mathrm{M}$. A cinética de inibição enzimática demonstrou que o CAPE tem um mecanismo de inibição não competitiva da arginase do parasito (figura 12).

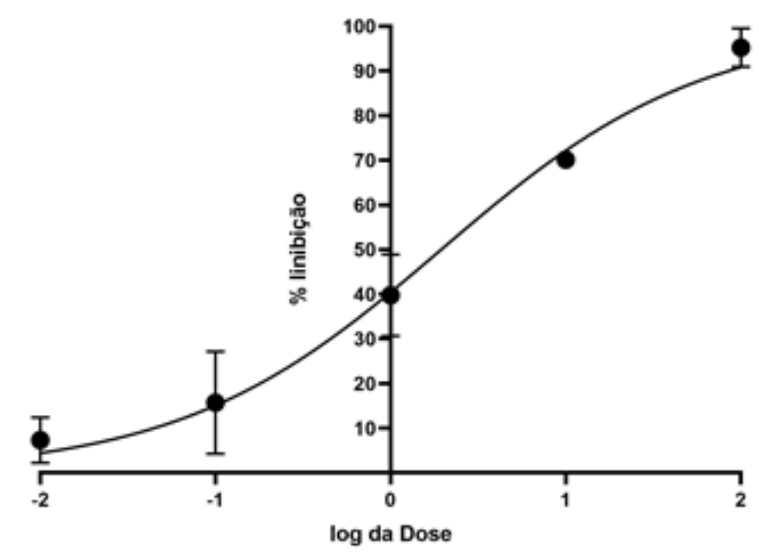

Figura 11. Gráfico da curva dose versus resposta de inibição arginase após serem tratadas com diferentes concentrações do CAPE (100-0,01 $\mu \mathrm{M})$. Graficamente se infere que o CAPE exerce sob a enzima arginase de $L$. (L) amazonensis uma $\mathrm{EC}_{50}$ de 1,947 $\mu \mathrm{M}$ com $95 \% \mathrm{Cl}$ de 1,4 - 2,6 $\mu \mathrm{M}$. Os dados representam a média de três experimentos realizados em duplicata. $O r^{2}=0,9557, I_{50}$ de 1,947 $\mu \mathrm{M}$ com 95\% Cl de 1,4 - 2,6 $\mu \mathrm{M}$. Fonte: Própria autoria.
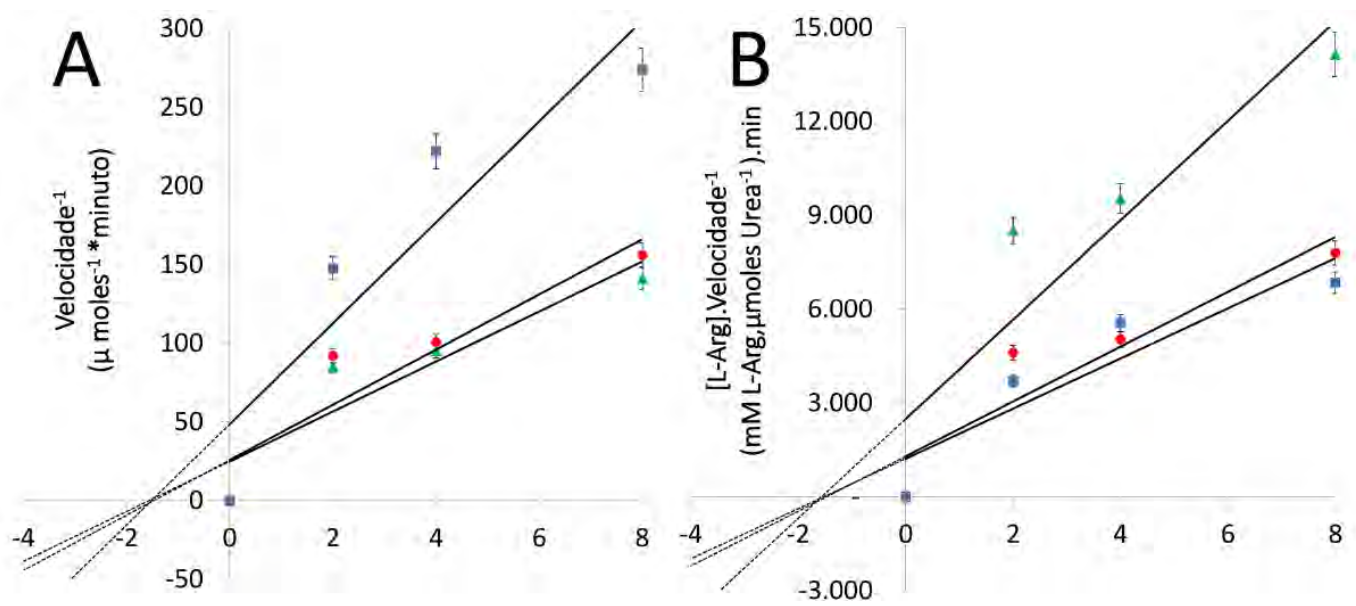

Figura 12. Mecanismo de inibição da arginase. Gráficos de Dixon (A) e de Cornish-Bowden (B) foram usados para determinar os valores das constantes $\mathrm{Ki}$ e Kis respectivamente. Graficamente se infere que o mecanismo de inibição da arginase de $L$. (L.) amazonensis é não competitivo ( $\mathrm{Ki}=\mathrm{Kis})$. As concentrações de L-arginina foram de $25 \mathrm{mM}(\bullet), 50 \mathrm{mM}(\bullet)$ e $100 \mathrm{mM}(\Delta)$. Os dados representam a média de três experimentos realizados em duplicata. As barras de erro indicam o desvio padrão da média. $R^{2} 0,85$. Fonte: Própria autoria. 


\subsection{Determinação da $\mathrm{IC}_{50}$ do CAPE em promastigotas de $L$. amazonensis}

Os efeitos biológicos do CAPE foram avaliados em promastigotas de L. (L.) amazonensis e a anfotericina $\mathrm{B}$ foi utilizada como controle negativo de crescimento. O CAPE (a) apresentou uma $\mathrm{EC}_{50}$ de 8,666 $\mu \mathrm{M}$, com intervalo de confiança de 95\% (Cl 95\%) entre $7,281 \mu \mathrm{M}$ à $10,41 \mu \mathrm{M}\left(\mathrm{r}^{2}=0,8527\right)$, enquanto a anfotericina $\mathrm{B}$ apresentou uma $\mathrm{EC}_{50}$ de 0,02 $\mu \mathrm{M}$ (Figura 13).

a

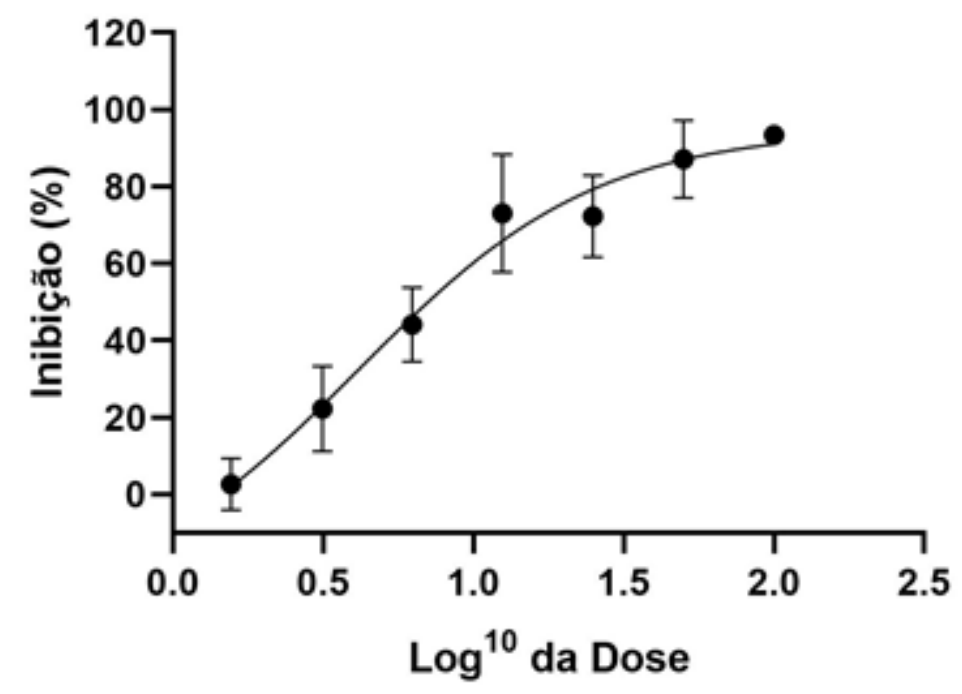

b

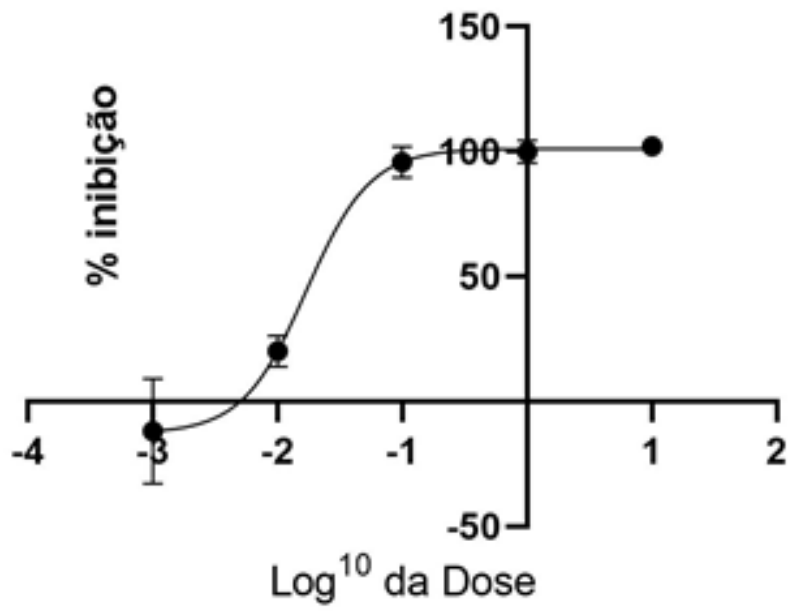

Figura 13. Gráfico da curva dose versus resposta em promastigotas de $L$. $(L)$ amazonensis após $72 h$ de tratamento com (a) CAPE nas concentrações de 100-1,56 $\mu \mathrm{M}$ e (b) anfotericina nas concentrações de $10-0,01 \mu \mathrm{M}$. Graficamente se infere que o CAPE exerce sob os protozoários uma $\mathrm{EC}_{50}$ de 8,666 $\mu \mathrm{M}$ com $95 \% \mathrm{Cl}$ de 7,281-10,41 $\mu \mathrm{M}$ e a anfotericina $\mathrm{EC}_{50}$ de $0,02 \mu \mathrm{M}$. Os dados representam a média de três experimentos realizados em duplicata. $O \mathrm{r}^{2}=0,8527$. Fonte: Própria autoria. 


\subsection{Avaliação do efeito do composto CAPE em macrófagos peritoneais de murino infectados por $L$. (L.) amazonensis}

O efeito antileishmania do CAPE contra macrófagos infectados com amastigotas de $L$. (L.) amazonensis reduziu significativamente o Índice de infectividade (IF) nas concentrações de 25 e $50 \mu \mathrm{M}$, quando comparado com o grupo controle após 72 horas de tratamento. O composto apresentou uma EC50 de 16,28 $\mu \mathrm{M}$ e intervalo de confiança de $95 \%$ (Cl 95\%) entre 9,05 $\mu \mathrm{M}$ a 31,51 $\mu \mathrm{M}$ (Figura 14).

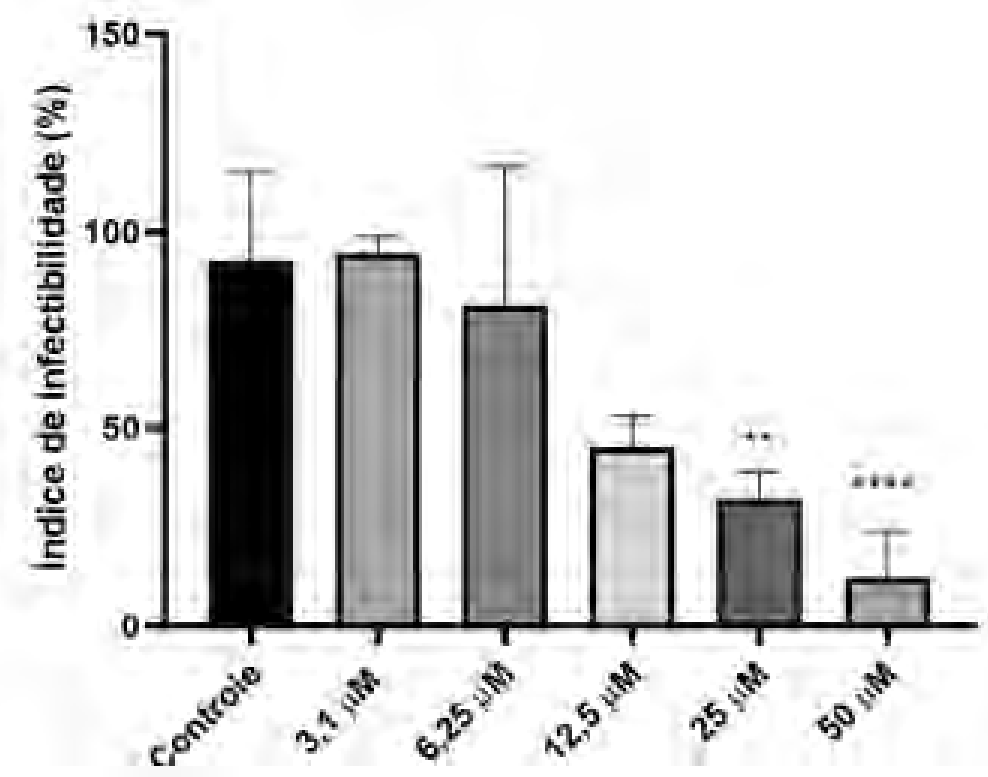

Figura 14. Índice de Infectividade de culturas de macrófagos peritoneais infectados com L. (L.) amazonensis após 72 horas do início do tratamento, grupo não tratado (Controle) e grupos tratados com diferentes concentrações de CAPE Os dados foram expressos como média e erro padrão da média (SEM). ${ }^{* *} p, 0,023 .{ }^{* * * *} p<0,0001$. Teste Anova de uma via seguido por um teste de múltiplas comparações de Kruskal-Wallis.

\subsection{Efeito da CAPE em macrófagos ativados com LPS, IFN-Y}

O tratamento dos macrófagos infectados com $5 \mathrm{ng} / \mathrm{mL}$ de IFN- $\gamma$ mais 0,1 $\mu \mathrm{g} / \mathrm{mL}$ de LPS teve como objetivo de desviar a ativação dos macrófagos para a resposta Th1 para o aumento da produção de óxido nítrico (NO). A concentração do composto CAPE a $20 \mu \mathrm{M}$ foi escolhida para o tratamento por estar próximo ao valor da EC50.

Os macrófagos tratados com $5 \mathrm{ng} / \mathrm{mL}$ de IFN- $\gamma$ mais $0,1 \mu \mathrm{g} / \mathrm{mL}$ de LPS apresentaram o mesmo índice de infectividade que o controle. Esse resultado demonstrou que a cepa de $L$. (L.) amazonensis era resistente ao NO. O tratamento com o composto CAPE foi estatisticamente relevante em relação ao grupo controle e ao grupo tratado com INF- $\gamma$ e LPS e capaz de reduzir o índice de infectividade dos 
macrófagos murinos infectados pelo parasito, em ambos os grupos tratado e não tratado com INF- $\gamma$ e LPS (Figura 15).

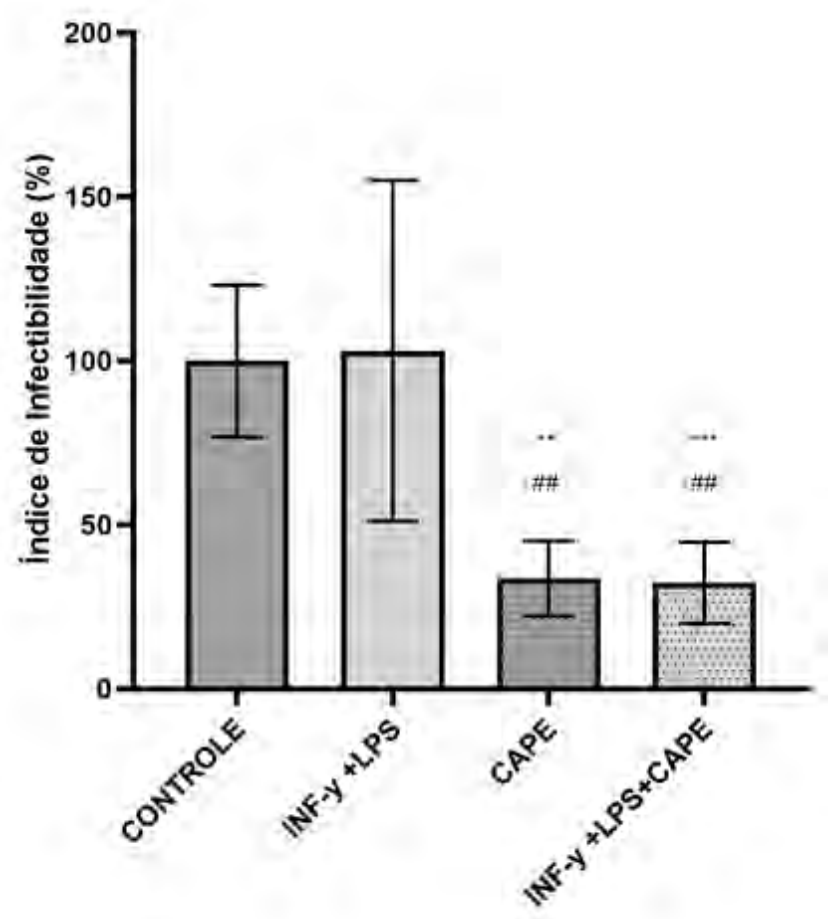

Figura 15. Índice de Infectividade de culturas macrófagos peritoneais de Swiss infectados com $L$. (L.) amazonensis por um período de 72 horas dos grupos não foi tratado (Controle), tratado com $5 \mathrm{ng} / \mathrm{mL}$ de IFN- $\gamma$ mais $0.1 \mu \mathrm{M}$ de LPS (IFN- $\gamma+$ LPS), $20 \mu \mathrm{M}$ de CAPE (CAPE), $5 \mathrm{ng} / \mathrm{mL}$ de INF- $\gamma$ mais $0.1 \mu \mathrm{M}$ de LPS associados com $20 \mu \mathrm{M}$ de CAPE (INF- $\gamma+\mathrm{LPS}+\mathrm{CAPE}$ ), dissolvidos em meio RPMI $1640 \mathrm{e}$ $0,02 \%$ DMSO. Os dados foram expressos em média e erro padrão da média (SEM). ${ }^{* *} p<0,01$. ${ }^{* * *} p<0,001$ vs control. \#\#p<0,01 vs INF+LPS. Anova de uma via seguido por um pós-teste de Newman Keuls.

\subsection{Concentração de nitrito da cultura macrófagos infectados com amastigotas de $L$. (L.) amazonensis}

O tratamento com LPS associado ao IFN- $\gamma$ resultou na produção de nitrito na cultura de macrófagos infectados com $L$. (L.) amazonensis, enquanto os macrófagos infectados tratados com CAPE, houve redução da produção de nitrito (figura 16). Todavia, na figura 17 ambos os grupos, macrófagos infectados tratados com CAPE, apresentavam diferenças significativas em relação aos macrófagos ativados. $\mathrm{Na}$ figura 16 a somente o grupo tratado com CAPE tinha diferença estatística em relação ao grupo de macrófagos ativados. 


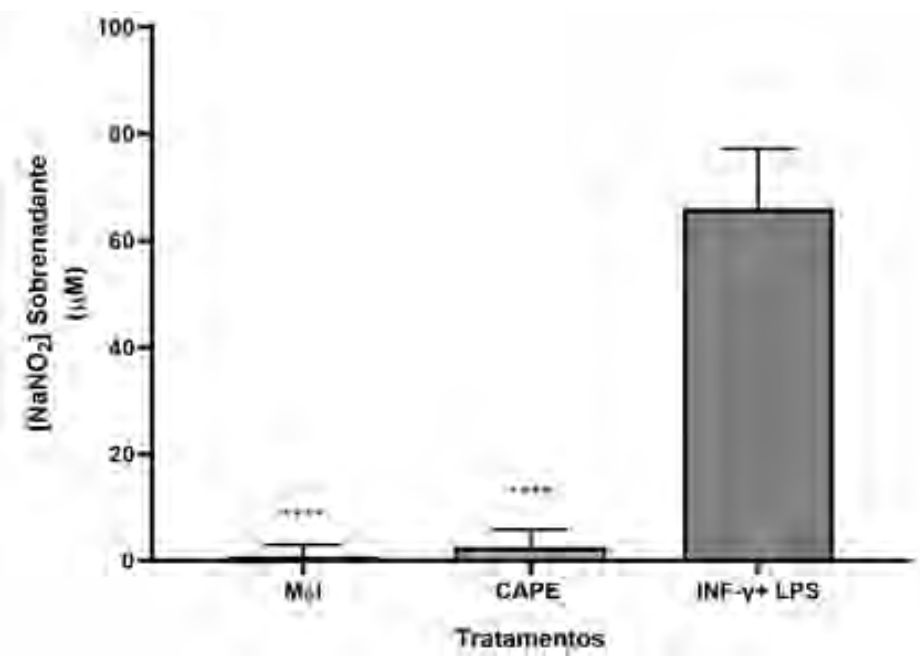

Figura 16. Concentração de nitrito no sobrenadante de cultura de macrófagos infectados (MØI) com L. (L.) amazonensis tratados por um período de 72 horas com $0.1 \mu \mathrm{g} / \mathrm{mL}$ INF- $\gamma+5 \mathrm{ng} / \mathrm{mL}$ LPS (IFN$\gamma^{+}$LPS) e CAPE $20 \mu \mathrm{M}$ (CAPE) dissolvido em meio de cultura RPMI. Os dados são expressos em média e diferença da média. ${ }^{* * * *} p<0.0001$ vs. INF- $\gamma+$ LPS pelo teste de Anova de uma via seguido por teste Tukey de múltiplas comparações.

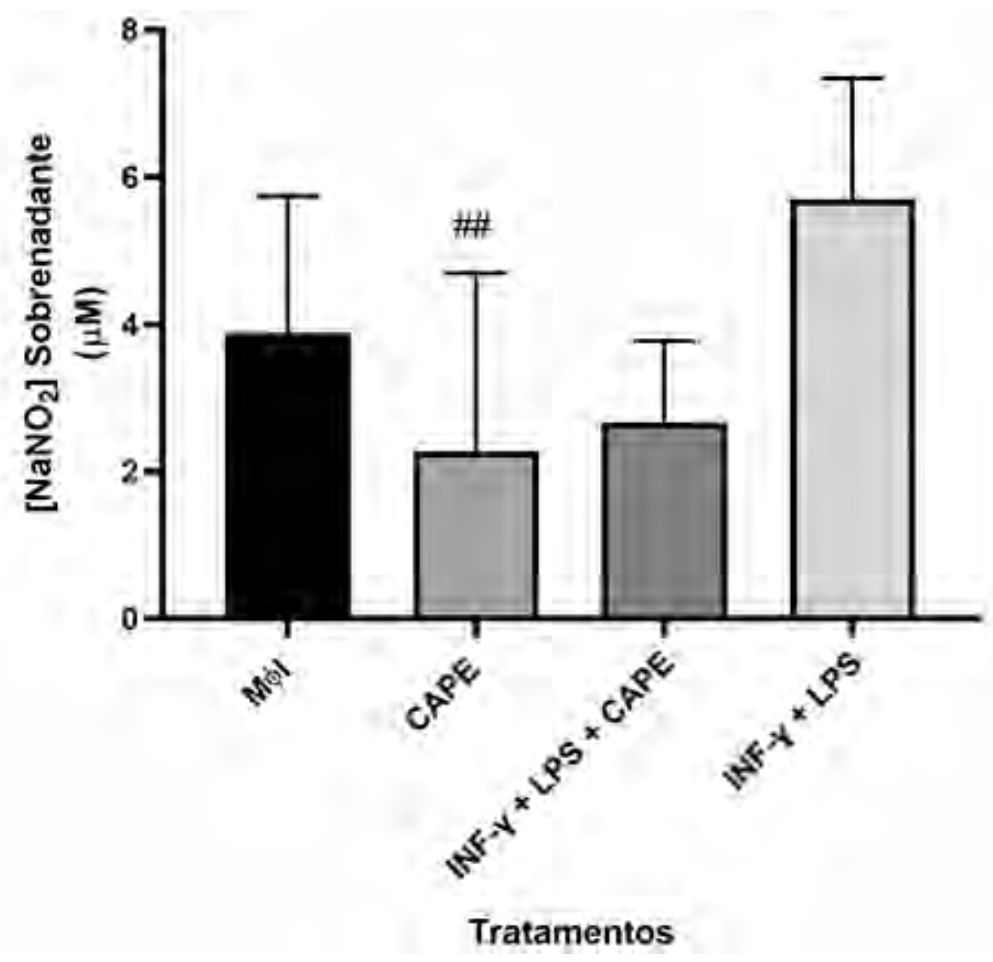

Figura 17. Concentração de nitrito no sobrenadante de cultura de macrófagos infectados (MØI) com L. (L.) amazonensis tratados por um período de $72 \mathrm{~h}$ com $0.1 \mu \mathrm{g} / \mathrm{mL}$ INF- $\gamma+5 \mathrm{ng} / \mathrm{mL}$ LPS (INF- $\gamma+$ LPS) associado ou não com CAPE $20 \mu \mathrm{M}$ (INF-y + LPS + CAPE) e CAPE $20 \mu \mathrm{M}$ (CAPE) dissolvido em meio de cultura RPMI. Os dados são expressos em média e diferença da média. \#\# $p<0.0276$ vs. INF-y + LPS pelo teste de Anova de uma via seguido por teste Tukey de múltiplas comparações.

\subsection{Suplementação com L-ornitina}

Para ensaio in vitro da inibição da arginase pelo CAPE, cultura com macrófagos infectados foi suplementada com L-ornitina, um produto da reação da 
catálise da L-arginina pela arginase, deste modo criando um desvio para a catálise da arginase na via da poliaminas. A figura 18 foi demonstrado que a inibição do

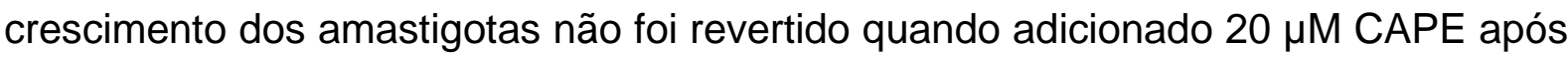
adição de 5 mM L-ornitina após 72 horas de incubação.

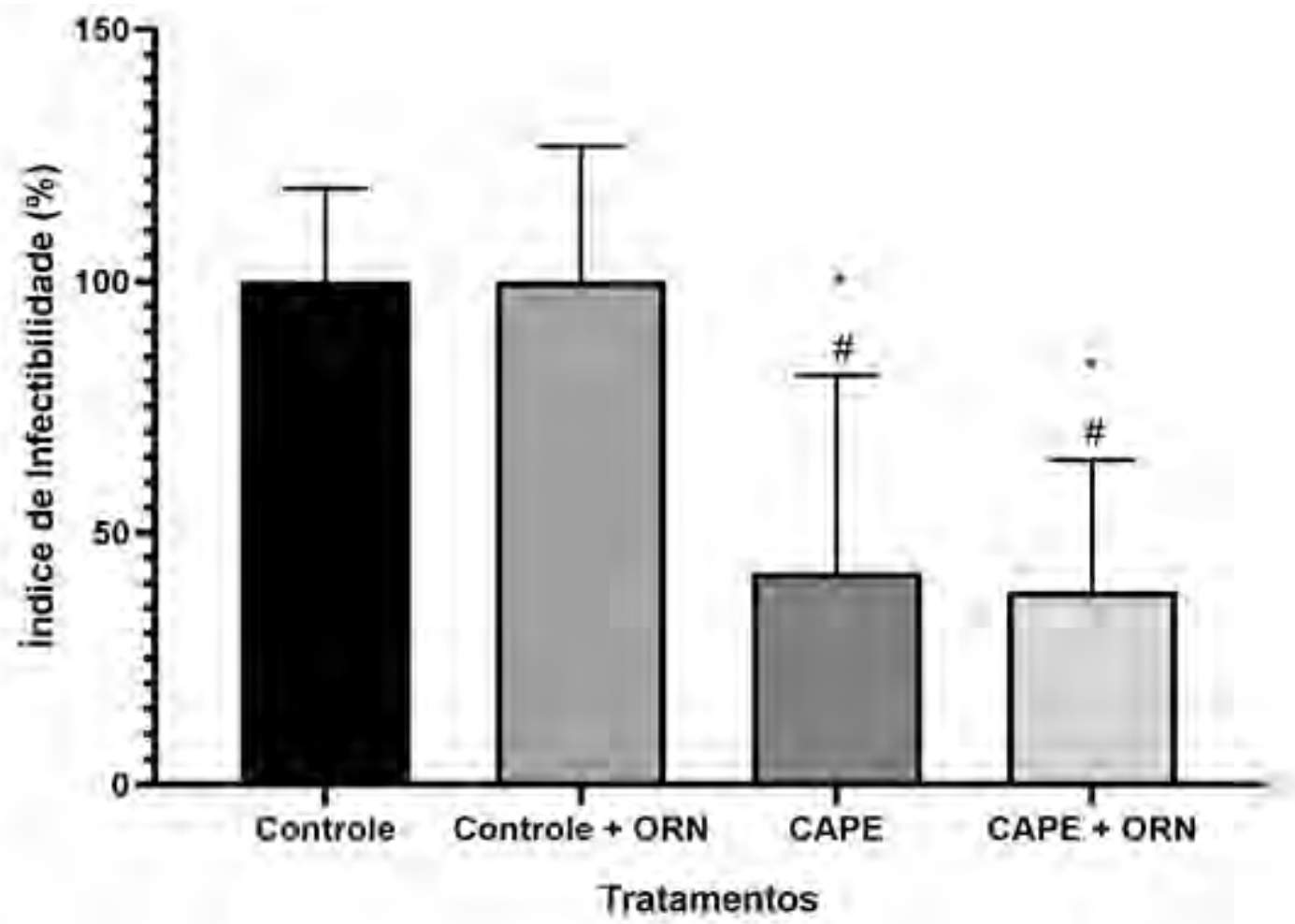

Figura 18. Gráfico da suplementação de L-ornitina de cultura de macrófagos infectados com $L$. ( $L$.) amazonensis tratados por um período de $72 \mathrm{~h}$ com $0.2 \%$ DMSO (Controle), $5 \mathrm{mM}$ L-ornitina (Controle + ORN), $20 \mu \mathrm{M}$ CAPE (CAPE) e $20 \mu \mathrm{M}$ CAPE + 5 mM L-ornitina (CAPE + ORN) dissolvidos em meio RPMI 1640. Dados foram expressos em média e erro padrão das médias (SEM). ${ }^{*} p<0.0202$ vs Controle e \# $p<0.0081$ vs Controle + ORN pelo teste de Anova de uma via seguido por teste Tukey de múltiplas comparações. 


\section{DISCUSSÃO}

$\mathrm{Na}$ presente dissertação foi avaliado o potencial leishmanicida da molécula fenetil éster do ácido cafeico (CAPE), através da verificação bioquímica do mecanismo da inibição enzimática da arginase de $L$. (L) amazonensis e nos promastigotas cultivados in vitro.

Também foi verificado quais eram seus efeitos sobre o índice de infectividade em macrófagos de lavado peritoneal murino ativados ou não com LPS+IFN- $\gamma$ tratados ou não com o CAPE. Além do mais, foi analisado seus efeitos em meio suplementado com L-ornitina associada ao composto e a avaliação dos níveis de nitrito do sobrenadante no meio de cultura dos macrófagos infectados.

$O$ uso de inibidores da arginase são potenciais alvos terapêuticos para o tratamento da leishmaniose, seguindo esta linha de pesquisa, Guo, Chen e Seto (2018) desenvolveram em seu ensaio dois inibidores irreversíveis do sítio ativo da arginase 1 e 2 podendo tanto servir como base terapêutica para tratamento de infecções parasitárias quanto para explorar a biologia das arginases.

Esta dissertação evidenciou que o composto CAPE apresentou uma inibição da enzima arginase de L. (L.) amazonensis com uma $E_{50}$ estimada em 1,9 $\mu \mathrm{M}$ (intervalo de confiança 95\% 1,4 - 2,6 $\mu \mathrm{M}$ ) e possuindo um mecanismo de inibição enzimática não-competitiva $(\mathrm{Ki}=1,51 \mu \mathrm{M})$.

O polissacarídeo fucogalactan, um biopolímero heterogalactan isolado do fungo Agrocybe aegerita, apresentou uma $\mathrm{IC}_{50}=5.82 \pm 0.57$ e mecanismo de inibição de inibição competitiva da arginase de L. (L.) amazonenesis e Ki 1,54 $\pm 0,15 \mu \mathrm{M}$ (MOTOSHIMA et al., 2018), ao comparar com os resultados do CAPE, o composto polifenol apresentou uma $\mathrm{EC}_{50}$ menor $(1,9 \mu \mathrm{M})$, uma Ki semelhante, porém outro mecanismo de inibição enzimática.

Utilizar a enzima arginase como alvo terapêutico para tratar a leishmaniose não contempla somente a infecção causada pela espécie $L$. amazonensis, visto que, no ensaio realizado por Riley, Roberts e Ullman (2011) buscaram comparar um perfil bioquímico entre a arginase de L. mexicana com a arginase humana e com isso foi verificado em ambas as enzimas alguns inibidores e seus respectivos mecanismos de inibição.

Os compostos na concentração de $40 \mathrm{mM}$ que bloquearam as enzimas de ambas as espécies foram o ácido 2(S)-amino-6-boronohaxanoico $(\mathrm{ABH})$, S-(2- 
boronoetil)-L-cisteína (BEC), Nwhidroxi-nor-L-arginina (nor-NOHA) e N-hidroxi-Larginina (NOHA) (RILEY; ROBERTES; ULLMAN, 2011).

Diferentemente com o que houve com o CAPE, os compostos $\mathrm{ABH}$, BEC norNOHA e NOHA apresentaram sob a enzima arginase de L. mexicana o mecanismo competitivo, com Ki de 1.3, 10, 50 e $85 \mu \mathrm{M}$, respectivamente. Contudo, em relação ao $\mathrm{Ki}$, somente o composto $\mathrm{ABH}$ apresentou um valor semelhante ao do composto utilizado na dissertação diferentemente o que houve com o CAPE (RILEY; ROBERTES; ULLMAN, 2011).

Garcia et al. (2019) verificou que os compostos fenólicos apigenina-7-Oglucosídeo, catequina, diidroquercetina, isorhamnetina, naringenina, quercetina, ramnetina, raponticina, ácido clorogênico, eugenol, ácido o-cumárico, ácido rosmarínico e cumarina, exerciam efeito inibitório da enzima arginase de L. infantum.

Os maiores resultados de inibição foram apresentados pelo ácido cafeico e o ácido rosmarínico, que à $100 \mu \mathrm{M}$ inibiu $71.48 \pm 0.85 \%$ e $56.98 \pm 5.51 \%$ da enzima arginase de L. infantum, respectivamente (GARCIA et al., 2019), e ao comparar com o CAPE, na mesma concentração houve a média de inibição da enzima arginase de L. (L.) amazonensis de 95,22\% (dados não apresentados).

$\mathrm{Na}$ presente dissertação foi avaliado in vitro os efeitos do CAPE sob os promastigotas metacíclicos e em macrófagos peritoneais murinos infectados. Como resultados o CAPE apresentou sobre os promastigotas uma $\mathrm{EC}_{50}$ de 8,6 $\mu \mathrm{M}$, com intervalo de confiança de 95\% (Cl 95\%) entre 7,281 e 10,41 $\mu \mathrm{M}$ e como controle negativo foi utilizado a anfotericina apresentando uma $\mathrm{EC}_{50}$ de 0,02 $\mu \mathrm{M}$.

Os macrófagos murinos infectados com L. (L.) amazonensis e tratados com CAPE, apresentaram uma redução significativa do Índice de infectividade (IF) quando comparado ao grupo controle, com uma $\mathrm{EC}_{50}$ de 16,28 $\mu \mathrm{M}$ e intervalo de confiança de $95 \%$ entre 9,05 $\mu \mathrm{M}$ à 31,51 $\mu \mathrm{M}$.

Maquiaveli et al. (2016b) mostraram o efeito da fração n-butanólica de $S$. cayennensis, um composto rico em verbascosídeo e isoverbascosídeo, sob a enzima arginase e em L. (L.) amazonensis. $\mathrm{O}$ extrato inibiu a enzima arginase $\left(\mathrm{IC}_{50}\right.$ $1.2 \mu \mathrm{g} / \mathrm{mL}$ com Cl $95 \%$ da $\mathrm{IC}_{50} 0.9$ - $1.6 \mu \mathrm{g} / \mathrm{mL}$ ), inibiu o crescimento de promastigotas após 72 horas de tratamento ( $\mathrm{IC}_{50}$ foi de $51 \mu \mathrm{g} / \mathrm{mL}$ ) reduziu o índice de infectividade em macrófagos após 24 horas de tratamento ( $\mathrm{EC}_{50}$ foi de $32 \mu \mathrm{g} / \mathrm{mL}$ ).

Diversamente ao CAPE, o composto verbascosídeo isolado inibiu a arginase do parasito através de outro mecanismo de inibição, sendo ela a competitiva e com 
uma Ki menor (Ki $0.7 \pm 0.1 \mu \mathrm{M})$. Todavia ambos os compostos apresentaram ação leishmanicida aos promastigotas de L. amazonensis, sendo que a EC50 do verbascosídeo maior que a do CAPE (EC5019 $\mu \mathrm{M})$ (MAQUIAVELI et al., 2016; MAQUIAVELI et al., 2017).

Aos macrófagos infectados, o verbascosídeo reduziu o índice de infecção em macrófagos infectados $\left(\mathrm{EC}_{50}=32 \mu \mathrm{M}\right)$ no prazo de 24 horas, com um citotoxicidade em macrófagos cerca de 7 vezes maior $\left(C_{50}=222 \mu \mathrm{M}\right)$, já o composto apresentou uma $\mathrm{EC}_{50}=16,28 \mu \mathrm{M}$ com a metade da concentração, todavia com um prazo maior de exposição ao tratamento (MAQUIAVELI et al., 2017).

Os compostos fenólicos ácido rosmarínico e apigenina foram avaliados por Antwi et al. (2019) em promastigotas de L. donovani e apresentou valores de $I_{50}$ $16,34 \pm 0,1 \mu \mathrm{M}$ e $22,77 \pm 0,01 \mu \mathrm{M}$, respectivamente, e os valores dos controles positivos foram $\mathrm{IC}_{50} 6,56 \pm 0,06 \mu \mathrm{M}$ para a anfotericina e $\mathrm{IC}_{50} 10.35 \pm 0.01 \mu \mathrm{M}$ para deferoxamina.

Nos macrófagos infectados houve efeito inibitório da infecção com IC 50 19,21 \pm 0,1 $\mu \mathrm{M}$ para o ácido rosmarínico e $\mathrm{IC}_{50} 45,66 \pm 0,01 \mu \mathrm{M}$ para a apigenina e ao ser comparados com os controles os valores da $\mathrm{IC}_{50} 6,49 \pm 0,03 \mu \mathrm{M}$ e $\mathrm{IC}_{50}$ 36,74 0,01 $\mu \mathrm{M}$, respectivamente para a anfotericina e deferoxamina (ANTWI et al., 2019). Em ambas as formas, nos promastigotas e nos macrófagos infectados, o CAPE apresentou valores de $\mathrm{EC}_{50}$ menores.

Assim como na inibição da enzima arginase, outros compostos polifenólicos também foram utilizados para eliminar os promastigotas de Leishmania ssp. Khademvatan et al. (2019) mostraram que o uso dos componentes de chá verde, a epigalocatequina 3-O-galato (EGCG) com $\mathrm{IC}_{50} 27,71 \mu \mathrm{M}$ e o galato de epicatequina (ECG) $\mathrm{IC}_{50} 75 \mu \mathrm{M}$, foram tóxicos aos promastigotas de $L$. infantum após exposição de 72 horas enquanto o controle positivo realizado com pentamidina apresentou $\mathrm{IC}_{50}$ de 10,5 $\mu \mathrm{M}$. O composto EGCG foi descrito anteriormente como inibidor competitivo da arginase de L. amazonensis com $\mathrm{Ki}=3,0 \pm 0,4 \mu \mathrm{M}$ (DOS REIS et al. 2013).

Das et al. (2013) avaliou o efeito de nanopartículas de ouro funcionalizadas com quercetina (QAunp) in vitro sob amastigotas selvagem de L. donovani isoladas de uma paciente portador da forma visceral e a partir destes parasitas foi realizado a indução em meio de cultura a resistência ao Estibogluconato de sódio (SSG) ou paromomicina (PMN). 
Ao comparar os dados com o macrófagos infectados com L. (L.) amazonensis tratados com CAPE (EC50 de 16,28 $\mu \mathrm{M}$ ) abordados na dissertação com os dados apresentados por Das et al. (2013), somente o grupo de macrófagos infectados com L. donovani $\left(\mathrm{IC}_{50} 10 \pm 2 \mu \mathrm{M}\right)$ da forma selvagem tratados com QAunp tiveram dados semelhantes, enquanto as formas resistentes a SSG e ao PMN tiveram valores de $I_{50}$ mais elevados, $I C_{50} 35 \pm 6$ e $18 \pm 3$ respectivamente.

Antinarelli et al. (2019) utilizou o composto análogo resveratrol AR26 macrófagos infectados com L. braziliensis o composto apresentou inibição $96.95 \%$ na concentração de $50 \mu \mathrm{g} / \mathrm{mL}, 63.71 \%$ na concentração de $25 \mu \mathrm{g} / \mathrm{mL}, 31.75 \%$ com $12.5 \mu \mathrm{g} / \mathrm{mL}, 25.43 \%$ com $6.25 \mu \mathrm{g} / \mathrm{mL}, 19.30 \%$ com $3.12 \mu \mathrm{g} / \mathrm{mL}$. Além de que, ele não apresentou efeito citotóxico sobre macrófagos $\left(\mathrm{CC}_{50}>150 \mu \mathrm{g} / \mathrm{mL}\right)$.

Foi evidenciado neste trabalho que a avaliação do índice de infectividade dos macrófagos tratados com $5 \mathrm{ng} / \mathrm{mL}$ de IFN- $\gamma$ mais $0,1 \mu \mathrm{g} / \mathrm{mL}$ de LPS não houve diferença entre o grupo controle, demonstrando que a cepa utilizada era resistente ao NO.

A presença de cepas resistentes ao NO já foram registradas por Giudice et al. (2007), a partir de cepas de L. (V.) braziliensis e L. (L.) amazonensis isoladas de pacientes humanos portadores de diferentes formas clínicas de leishmaniose oriundos de um hospital público localizado no estado da Bahia. Elas apresentaram resistência ao óxido nítrico, por meio de avaliação in vitro, sendo capazes de se multiplicarem diferente dos isolados suscetíveis.

Porém, o grupo tratado com o composto foi capaz de reduzir o índice de infectividade dos macrófagos murinos infectados pelo parasito, em ambos os grupos tratado e não tratado com INF-Y e LPS, estes dados corroboram com os apresentados por Maquiaveli et al. (2017), em que ao utilizar o verbascosídeo associado ou não com $5 \mathrm{ng} / \mathrm{mL}$ de IFN- $\gamma+0,1 \mu \mathrm{g} / \mathrm{mL}$ de LPS em macrófagos RAW infectados com L. amazonensis, houve diminuição do IF.

Do experimento de macrófagos ativados também foi avaliado os níveis de nitrito $\left(\mathrm{NaNO}_{2}\right)$ do sobrenadante do meio de cultura. $\mathrm{O}$ cultivo em que estavam os macrófagos ativados com LPS + IFN - $\gamma$ apresentou elevação dos níveis de $\mathrm{NaNO}_{2}$ e elevação do IF. Contudo, ao tratar os macrófagos com CAPE houve tanto a diminuição da IF quanto da produção de $\mathrm{NaNO}_{2}$. Maquiaveli et al. (2017) descreveu o mesmo efeito: ao ativar os macrófagos Raw 264.7 infectados com L. amazonensis com LPS + IFN- $\gamma$ observou aumento da produção de nitrito no sobrenadante. 
A reversão parcial de índice de infectividade foi descrita para o tratamento com verbascosídeo, inibidor da arginase de L. amazonensis, com meio de cultura suplementado com 5 mM de L-ornitina (MAQUIAVELI et al., 2017). Neste trabalho, ao tratar os macrófagos infectados com o CAPE ocorreu a diminuição do índice de infectividade, mas não foi observado o aumento, mesmo que parcial, do índice de infecção para o tratamento com CAPE na presença de suplemento de L-ornitina a 5 mM. Este resultado mostra que o CAPE, mesmo apresentando inibição da enzima arginase de L. (L.) amazonensis in vitro, age por mecanismo ainda desconhecido.

\section{CONCLUSÕES}

O composto CAPE possui ação contra as formas promastigotas e amastigotas intracelulares in vitro. O composto foi caracterizado como inibidor da enzima arginase de $L$. (L.) amazonensis em ensaio in vitro, inibindo a enzima de forma não competitiva. A suplementação do meio de cultura com L-ornitina não foi capaz de elevar os índices de infectividade dos macrófagos tratados como o composto e devido a estes resultados do CAPE na forma amastigota do parasito outros estudos deverão ser realizados para entender sua ação no parasito e contribuir para o desenvolvimento de um novo fármaco para o tratamento de leishmaniose.

\section{REFERÊNCIAS}

ABAMOR, E. S. Antileishmanial activities of caffeic acid phenethyl ester loaded PLGA nanoparticles against Leishmania infantum promastigotes and amastigotes in vitro. Asian Pacific Journal of Tropical Medicine, v. 10, n. 1, p. 25-34, 2017.

ABEBE, T. et al. Local increase of arginase activity in lesions of patients with cutaneous leishmaniasis in Ethiopia. PLoS Neglected Tropical Diseases, v. 6, n. 6, p. 1-10, 2012.

AïT-OUDHIA, K. et al. Leishmania antimony resistance: What we know what we can learn from the field. Parasitology Research, v. 109, n. 5, p. 1225-1232, 2011.

ALBUQUERQUE, P. L. M. M. et al. Urbanization of visceral leishmaniasis (kala-azar) in Fortaleza, Ceará, Brazil. Revista Panamericana de Salud Publica/Pan American Journal of Public Health, v. 26, n. 4, p. 330-333, 2009.

ALCÁZAR, R.; TUBURCIO, A. F. Determination of Arginine and Ornithine Decarboxylase Activities in Plants. Methods Mol Biol, v. 1694, p. 117-122, 2018. 
ALRAJHI, A. A. et al. Fluconazole for the Treatment of Cutaneous Leishmaniasis Caused by Leishmania major. New England Journal of Medicine, v. 346, n. 12, p. 891-895, 2002.

ALVAR, J.; CROFT, S.; OLLIARO, P. Chemotherapy in the Treatment and Control of Leishmaniasis. Advances in Parasitology, v. 61, n. 05, p. 223-274, 2006.

ANVERSA, L. S. et al. Human leishmaniasis in Brazil: A general review. Revista da Associação Médica Brasileira, v. 64, n. 3, p. 281-289, 2018.

ANTINARELLI, L. M. R. et al. Resveratrol analogues present effective antileishmanial activity against promastigotes and amastigotes from distinct Leishmania species by multitarget action in the parasites. Journal of Pharmacy and Pharmacology, v. 71, n. 12, p. 1854-1863, 2019.

ANTWI, C. A. et al. In vitro activity and mode of action of phenolic compounds on leishmania donovani. PLoS Neglected Tropical Diseases, v. 13, n. 2, p. 1-22, 2019.

AOKI, J. I. et al. RNA-seq transcriptional profiling of Leishmania amazonensis reveals an arginase-dependent gene expression regulation. PLoS Neglected Tropical Diseases, v. 11, n. 10, p. 1-22, 2017.

ARONSON, N. et al. Diagnosis and treatment of leishmaniasis: Clinical practice guidelines by the infectious diseases society of America (IDSA) and the American Society of tropical medicine and hygiene (ASTMH). American Journal of Tropical Medicine and Hygiene, v. 96, n. 1, p. 24-45, 2017.

BAE, D. H. et al. The old and new biochemistry of polyamines. Biochimica et Biophysica Acta - General Subjects, v. 1862, n. 9, p. 2053-2068, 2018.

BANETH, G.; SHAW, S. E. Chemotherapy of canine leishmaniosis. Veterinary Parasitology, v. 106, n. 4, p. 315-324, 2002.

BANKOVA, V. et al. A GC/MS study of the propolis phenolic constituents. Zeitschrift fur Naturforschung - Section C Journal of Biosciences, v. 42, n. 1-2, p. 147-151, 1987.

BANSKOTA, A. H.; TEZUKA, Y.; KADOTA, S. Recent progress in pharmacological research of propolis. Phytotherapy Research, v. 15, n. 7, p. 561-571, 2001.

BARKATI, S.; NDAO, M.; LIBMAN, M. Cutaneous leishmaniasis in the 21st century: From the laboratory to the bedside. Current Opinion in Infectious Diseases, v. 32, n. 5, p. 419-425, 2019.

BATES, P. A. The Developmental Biology of Leishmania Promastigotes. Experimental Parasitology, v. 79, n.2, p. 215-218, 1994.

BATES, P. A. Transmission of Leishmania metacyclic promastigotes by phlebotomine sand flies. International Journal for Parasitology, v. 37, n. 10, p. 1097-1106, 2007. 
BERMAN, J. D. Human leishmaniasis: Clinical, diagnostic, and chemotherapeutic developments in the last 10 years. Clinical Infectious Diseases, v. 24, n. 4, p. 684703, 1997.

BRAVO, L. Polyphenols: Chemistry, dietary sources, metabolism, and nutritional significance. Nutrition Reviews, v. 56, n. 11, p. 317-333, 1998.

BORRELLI, F. et al. Phytochemical compounds involved in the anti-inflammatory effect of propolis extract. Fitoterapia, v. 73, n. SUPPL. 1, 2002.

BRASIL. Guia de Vigilância em Saúde: Leishmaniose visceral. 1. ed. Brasília: Ministério da Saúde, 2016.

BRASIL. Manual de vigilância da leishmaniose tegumentar. Brasília: Ministério da Saúde, 2017.

BRASIL. Ministério da Saúde. Sistema de Informação de Agravos de Notificação (SVS) - Sinan Net. Acesso em: 01 out 2020.

BRINDHA, J.; BALAMURALI, M. M.; CHANDA, K. An Overview on the Therapeutics of Neglected Infectious Diseases - Leishmaniasis and Chagas Diseases. Frontiers in Chemistry, v. 9, n. March, p. 1-19, 2021.

BURZA, S.; CROFT, S. L.; BOELAERT, M. Leishmaniasis. The Lancet, v. 392, n. 10151, p. 951-970, 2018.

CALDWELL, R. B. et al. Arginase: An old enzyme with new tricks. Trends in Pharmacological Sciences, v. 36, n. 6, p. 395-405, 2015.

CAPELA, R.; MOREIRA, R.; LOPES, F. An overview of drug resistance in protozoal diseases. International Journal of Molecular Sciences, v. 20, n. 22, 2019

CDC, Centers For Diases Crontrol And Preventiol. Parasites - Leishmaniasis. 2018. Disponível em: <https://www.cdc.gov/parasites/leishmaniasis/gen_info/faqs.html>. Acesso em: 21 jun. 2019.

CELLI, N. et al. In vitro and in vivo stability of caffeic acid phenethyl ester, a bioactive compound of propolis. Journal of Agricultural and Food Chemistry, v. 55, n. 9, p. 3398-3407, 2007.

CHAPPUIS, F. et al. Visceral leishmaniasis: What are the needs for diagnosis, treatment and control? Nature Reviews Microbiology, v. 5, n. 11, p. 873-882, 2007.

CHAUDHURI, A. C. A Study of Arginase Content in the Fowl with Special Reference to Sex. Journal of Experimental Biology, v. 5, n. 2, p. 97-101, 1927.

CLEMENTE, G. S. et al. Arginase as a potential biomarker of disease progression: A molecular imaging perspective. International Journal of Molecular Sciences, v. 21, n. 15, p. 1-36, 2020.

COLEMAN, C. S.; HU, G.; PEGG, A. E. Putrescine biosynthesis in mammalian tissues. Biochemical Journal, v. 379, n. 3, p. 849-855, 2004.

COLOTTI, G.; ILARI, A. Polyamine metabolism in Leishmania: From arginine to trypanothione. Amino Acids, v. 40, n. 2, p. 269-285, 2011. 
CORNISH-BOWDEN, A. A simple graphical method for determining the inhibition constants of mixed, uncompetitive and non-competitive inhibitors. Biochemical Journal, v.137(1), p.143-144, 1974.

COURRET, N. et al. Biogenesis of Leishmania-harbouring parasitophorous vacuoles following phagocytosis of the metacyclic promastigote or amastigote stages of the parasites. Journal of cell science, v. 115, n. Pt 11, p. 2303-16, 2002.

CROFT, S. L.; YARDLEY, V. Chemotherapy of leishmaniasis. Current Pharmaceutical Design, v. 8, p. 319-342, 2002.

CROFT, S. L.; OLLIARO, P. Leishmaniasis chemotherapy-challenges and opportunities. Clinical Microbiology and Infection, v. 17, n. 10, p. 1478-1483, 2011.

DANTAS-TORRES, F. The role of dogs as reservoirs of Leishmania parasites, with emphasis on Leishmania (Leishmania) infantum and Leishmania (Viannia) braziliensis. Veterinary Parasitology, v. 149, n. 3-4, p. 139-146, 2007.

DAS, S. et al. Colloids and Surfaces B: Biointerfaces One pot synthesis of gold nanoparticles and application in chemotherapy of wild and resistant type visceral leishmaniasis. Colloids and Surfaces B: Biointerfaces, v. 107, p. 27-34, 2013.

DA SILVA, E. R. et al. Dietary polyphenols rutin, taxifolin and quercetin related compounds target: Leishmania amazonensis arginase. Food and Function, v. 10, n. 6, p. 3172-3180, 2019.

DA SILVA, E. R.; MAQUIAVELI, C. DO C.; MAGALHÃES, P. P. The leishmanicidal flavonols quercetin and quercitrin target Leishmania (Leishmania) amazonensis arginase. Experimental Parasitology, v. 130, n. 3, p. 183-188, 2012.

DA SILVA, E. R. et al. Cinnamides Target Leishmania amazonensis Arginase Selectively. Molecules (Basel, Switzerland), v. 25, n. 22, 2020.

DAVIDSON, R. N. Practical Guide for the Treatment of Leishmaniasis. Drugs, v. 56, n. 6, p. 1009-1018, 1998.

DAVIS, R. H. Management of Polyamine. Journal of Cellular Biochemistry, v. 205, n. 44, p. 199-205, 1990.

DEANE, L. M. Gaspar Vianna, on the centenary of his birth. Mem Inst Oswaldo Cruz, v. 80, n. 2, p. 253-5, 1985.

DE AZEVEDO, T. S.; LORENZ, C.; CHIARAVALLOTI-NETO, F. Risk mapping of visceral leishmaniasis in Brazil. Revista da Sociedade Brasileira de Medicina Tropical, v. 52, n. May, p. 0-3, 2019.

DE SÁ OLIVEIRA, T. et al. Action of Pentoxifylline on Experimental Cutaneous Leishmaniasis Due to Leishmania (Leishmania) amazonensis. Memórias do Instituto Oswaldo Cruz, v. 95, n. 4, p. 477-482, 2000.

DE VRIES, H. J. C.; REEDIJK, S. H.; SCHALLIG, H. D. F. H. Cutaneous Leishmaniasis: Recent Developments in Diagnosis and Management. American Journal of Clinical Dermatology, v. 16, n. 2, p. 99-109, 2015. 
DOS REIS, M. B. G. et al. Inhibition of Leishmania (Leishmania) amazonensis and rat arginases by green tea EGCG, (+)-catechin and (-)-epicatechin: A comparative structural analysis of enzyme-inhibitor interactions. PLoS ONE, v. 8, n. 11, 2013.

FAWCETT, J. K.; SCOTT, J. E. A rapid and Precise Method for the Determination of Urea. J. clin. Path., v. 13, p. 156-159, 1960.

FREIRES, I. A. et al. Chemical composition and antifungal potential of Brazilian propolis against Candida spp. Journal de Mycologie Medicale, v. 26, n. 2, p. 122132, 2016.

FRÉZARD, F.; DEMICHELI, C.; RIBEIRO, R. R. Pentavalent antimonials: New perspectives for old drugs. Molecules, v. 14, n. 7, p. 2317-2336, 2009.

FUELL, C. et al. Plant Physiology and Biochemistry Polyamine biosynthetic diversity in plants and algae decarboxylase SpdSyn AdoMetDC TSpmSyn SpmSyn.

Plant Physiology et Biochemistry, v. 48, n. 7, p. 513-520, 2010.

GABRIEL, Á. et al. Cutaneous Leishmaniasis: The Complexity of Host's Effective Immune Response against a Polymorphic Parasitic Disease. Journal of Immunology Research, v. 2019, p. 1-16, 2019.

GARCIA, A. R. et al. Leishmania infantum arginase: biochemical characterization and inhibition by naturally occurring phenolic substances. Journal of Enzyme Inhibition and Medicinal Chemistry, v. 34, n. 1, p. 1100-1109, 2019.

GHORBANI, M.; FARHOUDI, R. Leishmaniasis in humans: Drug or vaccine therapy? Drug Design, Development and Therapy, v. 12, p. 25-40, 2018.

GIUDICE, A. et al. Resistance of Leishmania (Leishmania) amazonensis and Leishmania (Viannia) braziliensis to nitric oxide correlates with disease severity in Tegumentary Leishmaniasis. BMC Infectious Diseases, v. 7, p. 1-12, 2007.

GOGOI, M. et al. Dual role of arginine metabolism in establishing pathogenesis. Current Opinion in Microbiology, v. 29, n. November 2015, p. 43-48, 2016.

GOTO, H.; LAULETTA LINDOSO, J. A. Cutaneous and Mucocutaneous Leishmaniasis. Infectious Disease Clinics of North America, v. 26, n. 2, p. 293307, 2012.

GREENAWAY, W.; SCAYSBROOK, T.; WHATLEY, F. R. The analysis of bud exudate of Populus $x$ euramericana, and of propolis, by gas chromatography-mass spectrometry . Proceedings of the Royal Society of London. Series B. Biological Sciences, v. 232, n. 1268, p. 249-272, 1987.

GROSSO, G. Effects of polyphenol-rich foods on human health. Nutrients, v. 10, n. 8, 2018.

GUERRA, J. A. O. et al. Tegumentary leishmaniasis in the state of amazonas: What have we learned and what do we need? Revista da Sociedade Brasileira de Medicina Tropical, v. 48, n. July 2014, p. 12-19, 2015.

GUERIN, P. J. et al. Visceral leishmaniasis: current status of control, diagnosis, and treatment, and a proposed research and development agenda. The Lancet

Infectious Diseases, v. 2, n. August, p. 494-501, 2002. 
GUO, X.; CHEN, Y.; SETO, C. T. Rational design of novel irreversible inhibitors for human arginase. Bioorganic and Medicinal Chemistry, v. 26, n. 14, p. 3939-3946, 2018.

HALARIS, A.; PLIETZ, J. Agmatine: Metabolic pathway and spectrum of activity in brain. CNS Drugs, v. 21, n. 11, p. 885-900, 2007.

HELLERMAN, LESLIE PERKINS, M. E. Activation Of Enzymes. III. The role of metal ions in the activation of arginase the hydrolysis of arginine induced by certain metal ions with urease. J. Biol. Chem, n. 112, p. 175-194, 1935.

HERWALDT, B. L. Leishmaniasis. Lancet, v. 354, n. 9185, p. 1191-1199, 1999.

HOEBE, K. H. N. et al. Differential effects of pentoxifylline on the hepatic inflammatory response in porcine liver cell cultures increase in inducible nitric oxide synthase expression. Biochemical Pharmacology, v. 61, n. 9, p. 1137-1144, 2001.

HOLZMULLER, P. et al. Trypanosomatid infections: How do parasites and their excreted-secreted factors modulate the inducible metabolism of I-arginine in macrophages? Frontiers in Immunology, v. 9, n. APR, p. 1-14, 2018.

HUANG, S. et al. Recent advances in the chemical composition of propolis. Molecules, v. 19, n. 12, p. 19610-19632, 2014.

ILARI, A. et al. Targeting Polyamine Metabolism for Finding New Drugs Against Leishmaniasis: A Review. Mini-Reviews in Medicinal Chemistry, v. 15, n. 3, p. 243-252, 2015.

ISLAM, A. et al. Sero-prevalence of visceral leishmaniasis (VL) among dogs in VL endemic areas of Mymensingh distict, Bangladesh. Journal of Advanced Veterinary and Animal Research, v. 4, n. 3, p. 241-248, 2017.

JENKINSON, C. P.; GRODY, W. W.; CEDERBAUM, S. D. Comparative properties of arginases. Comparative Biochemistry and Physiology - B Biochemistry and Molecular Biology, v. 114, n. 1, p. 107-132, 1996.

KANDPAL, M. et al. Kinetics and molecular characteristics of arginine transport by Leishmania donovani promastigotes. Molecular and Biochemical Parasitology, v. 71, n. 2, p. 193-201, 1995.

KAYE, P.; SCOTT, P. Leishmaniasis: Complexity at the host-pathogen interface. Nature Reviews Microbiology, v. 9, n. 8, p. 604-615, 2011.

KHADEMVATAN, S. et al. In silico and in vitro comparative activity of green tea components against Leishmania infantum. Journal of Global Antimicrobial Resistance, v. 18, p. 187-194, 2019.

KISHIMOTO, N. et al. In vitro antibacterial, antimutagenic and anti-influenza virus activity of caffeic acid phenethyl esters. Biocontrol Science, v. 10, n. 4, p. 155-161, 2005.

KRAUTH-SIEGEL, R. L.; MEIERING, S. K.; SCHMIDT, H. The parasite-specific trypanothione metabolism of trypanosoma and leishmania. Biological Chemistry, v. 384, n. 4, p. 539-549, 2003. 
KOUTINAS, A. F. et al. A randomised, blinded, placebo-controlled clinical trial with allopurinol in canine leishmaniosis. Veterinary Parasitology, v. 98, n. 4, p. 247-261, 2001.

KUMAR, A. Transmission of leishmaniasis from human to other vertebrates: a rapid zooanthroponotic evolution. International Microbiology, v. 22, n. 3, p. 399-401, 2019.

KUMAZAWA, S. et al. Radical-scavenging activity and phenolic constituents of propolis from different regions of Argentina. Natural Product Research, v. 24, n. 9, p. 804-812, 2010.

LAINSON, R.; SHAW, J. J. Epidemiology and ecology of leishmaniasis in LatinAmerica. Nature, v. 273, n. 5664, p. 595-600, 1978.

LAYOUN A, SAMBA M, SANTOS MM. Isolation of murine peritoneal macrophages to carry out gene expression analysis upon Toll-like receptors stimulation. J Vis Exp. 2015 Apr 29;(98):e52749. doi: 10.3791/52749. PMID: 25993651 ; PMCID: PMC4541597.

LEZAMA-DAVILA, C. M. et al. Sex-associated susceptibility in humans with chiclero's ulcer: Resistance in females is associated with increased serum-levels of GM-CSF. Scandinavian Journal of Immunology, v. 65, n. 2, p. 210-211, 2007.

LIMA-JUNIOR, D. S. et al. Inflammasome-derived IL-1 $\beta$ production induces nitric oxide-mediated resistance to Leishmania. Nature Medicine, v. 19, n. 7, p. 909-915, 2013.

LOCKSLEY, R. M. et al. Murine cutaneous leishmaniasis : Susceptibility correlates with differential expansion of helper T-cell subsets. Annales de I'Institut Pasteur Immunology, v. 138, n. 5, p. 744-749, 1987.

LOISEAU, P.; BORIES, C. Mechanisms of Drug Action and Drug Resistance in Leishmania as Basis for Therapeutic Target Identification and Design of Antileishmanial Modulators. Current Topics in Medicinal Chemistry, v. 6, n. 5, p. 539-550, 2006.

MACHADO-SILVA, A. et al. New perspectives for leishmaniasis chemotherapy over current anti-leishmanial drugs: A patent landscape. Expert Opinion on Therapeutic Patents, v. 25, n. 3, p. 247-260, 2015.

MALAFAIA, G. Leishmaniose visceral e desnutrição: uma relação ainda muito negligenciada Visceral leishmaniasis and malnutrition : a relation much neglected. Revista da Sociedade Brasileira de Medicina Tropical, v. 43, n. 4, p. 478-479, 2010.

MAQUIAVELI, C. C. et al. Verbascoside Inhibits Promastigote Growth and Arginase Activity of Leishmania amazonensis. Journal of Natural Products, v. 79, n. 5, p. 1459-1463, 2016.

MAQUIAVELI, C. DO C. et al. Stachytarpheta cayennensis extract inhibits promastigote and amastigote growth in Leishmania amazonensis via parasite arginase inhibition. Journal of Ethnopharmacology, v. 192, p. 108-113, 2016b. 
MAQUIAVELI, C. DO C. et al. Antileishmanial activity of verbascoside: Selective arginase inhibition of intracellular amastigotes of Leishmania (Leishmania) amazonensis with resistance induced by LPS plus IFN-y. Biochemical

Pharmacology, v. 127, p. 28-33, 2017.

MARSDEN, P. D. Pentavalent antimonials: old drugs for new diseases. Revista da Sociedade Brasileira de Medicina Tropical, v. 18, n. 3, p. 187-198, 1985.

MARTINEZ, F. O. et al. Macrophage activation and polarization. BioScience, v. 13, n. 4, p. 453-461, 2008.

MCGWIRE, B. S.; CHANG, K.; ENGMAN, D. M. Migration through the Extracellular Matrix by the Parasitic Protozoan. Infection and Immunity, v. 71, n. 2, p. 10081010, 2003.

MCGWIRE, B. S.; SATOSKAR, A. R. Leishmaniasis: Clinical syndromes and treatment. Qjm, v. 107, n. 1, p. 7-14, 2014.

MEDEIROS, A. et al. Mechanistic and biological characterisation of novel N5substituted paullones targeting the biosynthesis of trypanothione in Leishmania.

Journal of Enzyme Inhibition and Medicinal Chemistry, v. 35, n. 1, p. 1345-1358, 2020.

MEDKOUR, $\mathrm{H}$. et al. Potential animal reservoirs (Dogs and bats) of human visceral leishmaniasis due to Leishmania infantum in French Guiana. PLoS Neglected Tropical Diseases, v. 13, n. 6, p. 1-15, 2019.

MENGESHA, B. et al. Prevalence of malnutrition and associated risk factors among adult visceral leishmaniasis patients in Northwest Ethiopia: A cross sectional study. BMC Research Notes, v. 7, n. 1, p. 1-6, 2014.

MINISTÉRIO DA AGRICULTURA, PECUÁRIA E ABASTECIMENTO (MAPA). NOTA TÉCNICA № 11/2016/CPV/DFIP/SDA/GM/MAPA. Distrito Federal, p.01, 2016. Disponível em: https://www.sbmt.org.br/portal/wp-content/uploads/2016/09/notatecnica.pdf. Acesso em: 20 dez 2020.

MINISTÉRIO DA SAÚDE. Secretaria de Vigilância em Saúde. Departamento de Vigilância das Doenças Transmissíveis. Manual de vigilância da leishmaniose tegumentar [recurso eletrônico]. Brasília-DF, p.72, 2017.

MINISTÉRIO DA SAÚDE. Serviço de Vigilância em saúde. Gráfico do Casos de leishmaniose cutânea no Brasil 1980 a 2020. Publicado em 17 nov 2021. Disponível em: https://www.gov.br/saude/pt-br/media/pdf/2021/novembro/17/lt-graficos-emapas.pdf. Acesso em 25 nov 2021.

MINODIER, P.; PAROLA, P. Cutaneous leishmaniasis treatment. Travel Medicine and Infectious Disease, v. 5, n. 3, p. 150-158, 2007.

MIRÓ, G. et al. Canine leishmaniosis - new concepts and insights on an expanding zoonosis: part two. Trends in Parasitology, v. 24, n. 8, p. 371-377, 2008.

MOHAPATRA, S. Drug resistance in leishmaniasis: Newer developments. Tropical Parasitology, v. 4, n. 1, p. 4, 2014. 
MOODY, S. F. Molecular variation in Leishmania. Acta Tropica, v. 53, n. 3-4, p. 185-204, 1993.

MORRIS JR, S. M. Arginine: beyond protein. Am J Clin Nutr, v. 83, n. April, p. 508512, 2018.

MOTOSHIMA, R. A. et al. Inhibition of Leishmania amazonensis arginase by fucogalactan isolated from Agrocybe aegerita mushroom. Carbohydrate Polymers, v. 201, n. August, p. 532-538, 2018.

MOUGNEAU, E.; BIHL, F.; GLAICHENHAUS, N. Cell biology and immunology of Leishmania. Immunological Reviews, v. 240, n. 1, p. 286-296, 2011.

MUNDER, M. Arginase: An emerging key player in the mammalian immune system: REVIEW. British Journal of Pharmacology, v. 158, n. 3, p. 638-651, 2009.

MURTAZA, G. et al. Caffeic acid phenethyl ester and therapeutic potentials. BioMed Research International, v. 2014, 2014.

MUXEL, S. M. et al. Arginine and polyamines fate in leishmania infection. Frontiers in Microbiology, v. 8, n. JAN, p. 1-15, 2018.

NADÈGE MINOIS; DIDAC CARMONA-GUTIERREZ; FRANK MADEO. Polyamines in aging and disease. Aging, v. 3, n. 8, p. 1-17, 2011.

NAHIDI, S. et al. The outcome of arginase activity inhibition in BALB/c mice hosting Leishmania tropica. Parasite Immunology, v. 42, n. 3, p. 1-10, 2020.

NEUBER, H. Leishmaniasen. JDDG - Journal of the German Society of Dermatology, v. 6, n. 9, p. 754-765, 2008.

NETO, J. C.; WERNECK, G. L.; COSTA, C. H. N. Factors associated with the incidence of urban visceral leishmaniasis: An ecological study in Teresina, Piauí State, Brazil. Cadernos de Saúde Publica, v. 25, n. 7, p. 1543-1551, 2009.

NWEZE, J. A.; NWEZE, E. I.; ONOJA, U. S. Nutrition, malnutrition, and leishmaniasis. Nutrition, v. 73, p. 110712, 2020.

OKWOR, I.; UZONNA, J. Review Article : Social and Economic Burden of Human Leishmaniasis. Am J Trop Med Hyg, v. 94, n. 3, p. 489-93, 2016.

OLIVEIRA, J. M. DE et al. Mortalidade por leishmaniose visceral: aspectos clínicos e laboratoriais. Revista da Sociedade Brasileira de Medicina Tropical, v. 43, n. 2, p. 188-193, 2010.

ORGANIAÇÃO PANAMERICANA DE SAÚDE (OPAS). LEISHMANIOSES. Informe epidemiológico das Américas. Núm. 9, dezembro de 2020. Disponível em:

https://iris.paho.org/bitstream/handle/10665.2/53091/OPASCDEVT200041_por.pdf?s equence=6\&isAllowed=y. Acesso em: 01 dez 2021.

ORGANIZACIÓN PANAMERICANA DE LA SALUD (OPS). Leishmaniasis en las Américas Recomendaciones para el tratamento. Washington, DC, 2013.

PACE, D. Leishmaniasis. Journal of Infection, v. 69, n. S1, p. S10-S18, 2014. 
PEGG, A. E. Spermidine/spermine-N1-acetyltransferase: A key metabolic regulator. American Journal of Physiology - Endocrinology and Metabolism, v. 294, n. 6, 2008.

PEGG, A. E. Mammalian polyamine metabolism and function. IUBMB Life, v. 61, n. 9, p. 880-894, 2009.

PEGG, A. E.; CASERO, R. A. Current Status of the Polyamine Research Field. Methods Mol. Biol, v. 720, p. 3-35, 2011.

PERDEH, J. et al. Critical functions of the polyamine putrescine for proliferation and viability of Leishmania donovani parasites. Amino Acids, p. 1-14, 2019.

PESSENDA, G.; DA SILVA, J. S. Arginase and its mechanisms in Leishmania persistence. Parasite Immunology, v. 42, n. 7, p. 1-12, 2020.

PETROPOLIS, D. B. et al. Leishmania amazonensis promastigotes in $3 \mathrm{~d}$ collagen I culture: An in vitro physiological environment for the study of extracellular matrix and host cell interactions. PeerJ, v. 2014, n. 1, 2014.

PHILLIPS, M. A. Polyamines in protozoan pathogens. Journal of Biological Chemistry, v. 293, n. 48, p. 18746-18756, 2018.

PISCOPO, T. V.; AZZOPARDI, C. M. Leishmaniasis. Postgraduate medical journal, v. 83, n. 976, p. 649-657, 2007.

PITTALÀ, V. et al. Therapeutic Potential of Caffeic Acid Phenethyl Ester (CAPE) in Diabetes. Current Medicinal Chemistry, v. 25, n. 37, p. 4827-4836, 2018.

PONTE-SUCRE, A. et al. Drug resistance and treatment failure in leishmaniasis: A 21st century challenge. PLoS Neglected Tropical Diseases, v. 11, n. 12, p. 1-24, 2017.

RECZKOWSKIT, ROBERT S. ASH, D. E. EPR Evidence for Binuclear Mn(I1) Centers in Rat Liver Arginase. American Chemical Society, v. 114, n. 3, p. 1099210994, 1992.

REGUERA, R. M. et al. Current status on prevention and treatment of canine leishmaniasis. Veterinary Parasitology, v. 227, p. 98-114, 2016.

REINHARD, K. et al. International Journal of Medical Microbiology The role of NF-kB activation during protection against Leishmania infection. International Journal of Medical Microbiology, v. 302, n. 4-5, p. 230-235, 2012.

REZENDE, J. M. DE. Gaspar Vianna, mártir da ciência e benfeitor da humanidade. Ética Revista, v. 5, p. 359-362, 2008.

RIBEIRO, J. M. C. et al. A novel vasodilatory peptide from the salivary glands of the sand fly Lutzomyia longipalpis. Science, v. 243, n. 4888, p. 212-214, 1989.

RIBEIRO, J. M. C.; ROSSIGNOL, P. A.; SPIELMAN, A. Blood-finding strategy of a capillary-feeding sandfly, Lutzomyia longipalpis. Comparative Biochemistry and Physiology -- Part A: Physiology, v. 83, n. 4, p. 683-686, 1986. 
RILEY, E.; ROBERTS, S. C.; ULLMAN, B. Inhibition profile of Leishmania mexicana arginase reveals differences with human arginase I. International Journal for

Parasitology, v. 41, n. 5, p. 545-552, 2011.

ROQUE, A. L. R.; JANSEN, A. M. Wild and synanthropic reservoirs of Leishmania species in the Americas. International Journal for Parasitology: Parasites and Wildlife, v. 3, n. 3, p. 251-262, 2014.

RUAN, D. et al. Pentoxifylline Can Reduce the Inflammation Caused by LPS after Inhibiting Autophagy in RAW264.7 Macrophage Cells. BioMed Research International, v. 2021, 2021.

RUIZ-POSTIGO, J. A. et al. Global leishmaniasis surveillance: 2019-2020, a baseline for the 2030 roadmap. World Health Organization - Control of Neglected Tropical Diseases, v. 35, n. 96, p. 401-419, 2021.

RYBAK, J. M.; FORTWENDEL, J. R.; ROGERS, P. D. Emerging threat of triazoleresistant Aspergillus fumigatus. Journal of Antimicrobial Chemotherapy, v. 74, n. 4, p. 835-842, 2019.

SADEGHIAN, G.; NILFOROUSHZADEH, M. A. Effect of combination therapy with systemic glucantime and pentoxifylline in the treatment of cutaneous leishmaniasis. International Journal of Dermatology, v. 45, n. 7, p. 819-821, 2006.

SANDOVAL, C. et al. In situ cellular immune response in non-ulcerated skin lesions due to Leishmania (L.) infantum chagasi infection. Journal of Venomous Animals and Toxins Including Tropical Diseases, v. 27, n. February 2021, p. 1-8, 2021.

SAMLASKA, C. P.; WINFIELD, E. A. Pentoxifylline. Journal of the American Academy of Dermatology, v. 30, n. 4, p. 603-621, 1994.

SAMUELSON, J. et al. A mouse model of Leishmania braziliensis braziliensis infection produced by coinjection with sand fly saliva. Journal of Experimental Medicine, v. 173, n. 1, p. 49-54, 1991.

SANTOS-PEREIRA, S. et al. Leishmania amazonensis resistance in murine macrophages: Analysis of possible mechanisms. PLoS ONE, v. 14, n. 12, p. 1-16, 2019.

SINGH, N.; KUMAR, M.; SINGH, R. K. Leishmaniasis: Current status of available drugs and new potential drug targets. Asian Pacific Journal of Tropical Medicine, v. 5, n. 6, p. 485-497, 2012.

SNIDER, $\mathrm{H}$. et al. Sex hormones and modulation of immunity against leishmaniasis. NeurolmmunoModulation, v. 16, n. 2, p. 106-113, 2009.

SOUSA-PAULA, L. C. DE; OTRANTO, D.; DANTAS-TORRES, F. Lutzomyia longipalpis (Sand Fly). Trends in Parasitology, v. 36, n. 9, p. 796-797, 2020.

STAMP, L. K.; CHAPMAN, P. T.; PALMER, S. C. Allopurinol and kidney function: An update. Joint Bone Spine, v. 83, n. 1, p. 19-24, 2016. 
STEVERDING, D. The history of leishmaniasis. Parasites and Vectors, v. 10, n. 1, p. 1-10, 2017.

SUN, S. et al. Identification and determination of seven phenolic acids in brazilian green propolis by UPLC-ESI-QTOF-MS and HPLC. Molecules, v. 24, n. 9, p. 1-13, 2019.

SUNDAR, S.; SINGH, A. Chemotherapeutics of visceral leishmaniasis: Present and future developments. Parasitology, v. 145, n. 4, p. 481-489, 2018.

TABBABI, A. Review of leishmaniasis in the middle east and North Africa. African Health Sciences, v. 19, n. 1, p. 1329-1337, 2019.

TASLIDERE, E. et al. The effects of caffeic acid phenethyl ester on streptozotocininduced diabetic liver injury. Bratisl Lek Listy., v. 116, n. 5, p. 296-301, 2015.

TASLIMI, Y.; ZAHEDIFARD, F.; RAFATI, S. Leishmaniasis and various immunotherapeutic approaches. Parasitology, v. 145, n. 4, p. 497-507, 2018.

TELES, G. DA C.; FONSECA, F. R.; GONÇALVES, M. J. F. American tegumentary Leishmaniasis in the Brazilian Amazon from 2010 to 2014. Revista do Instituto de Medicina Tropical de São Paulo, v. 61, n. March, p. 1-8, 2019.

TOLBA, M. F. et al. Caffeic acid phenethyl ester, a promising component of propolis with a plethora of biological activities: A review on its anti-inflammatory, neuroprotective, hepatoprotective, and cardioprotective effects. IUBMB Life, v. 65, n. 8, p. 699-709, 2013.

TOLEDO, C. R. S. DE et al. Vulnerabilidade à transmissão da leishmaniose visceral humana em área urbana brasileira. Revista de Saúde Pública, v. 51, p. 1-11, 2017.

ULIANA, S. R. B.; TRINCONI, C. T.; COELHO, A. C. Chemotherapy of leishmaniasis: Present challenges. Parasitology, v. 145, n. 4, p. 464-480, 2018.

URDIALES, J. L.; MEDINA, M.; SÁNCHEZ-JIMÉNEZ, F. Polyamine metabolism revisited. European Journal of Gastroenterology and Hepatology, v. 13, n. 9, p. 1015-1019, 2001

VAN DEN BERG, M. P.; MEURS, H.; GOSENS, R. Targeting arginase and nitric oxide metabolism in chronic airway diseases and their co-morbidities. Current Opinion in Pharmacology, v. 40, p. 126-133, 2018.

VARIN, A.; GORDON, S. Alternative activation of macrophages: Immune function and cellular biology. Immunobiology, v. 214, n. 7, p. 630-641, 2009.

VAUZOUR, D. et al. Polyphenols and human health: Prevention of disease and mechanisms of action. Nutrients, v. 2, n. 11, p. 1106-1131, 2010.

WALLACE, H. M. The polyamines: past, present and future. Essays In Biochemistry, v. 46, p. 1-10, 2009.

WALLACE, H. M.; FRASER, A. V.; HUGHES, A. A perspective of polyamine metabolism. Biochemical Journal, v. 376, n. 1, p. 1-14, 2003. 
WANG, X. et al. Pharmacokinetics of Caffeic Acid Phenethyl Ester and its Catecholring Fluorinated Derivative Following Intravenous Administration to Rats.

Biopharmaceutics \& drug disposition, v. 28, n. 3, p. 135-143, 2007.

WANG, L. C. et al. The effect of caffeic acid phenethyl ester on the functions of human monocyte-derived dendritic cells. BMC Immunology, v. 10, p. 1-13, 2009.

WARD, A.; CLISSOLD, S. P. Pentoxifylline A Review of its Pharmacodynamic and Pharmacokinetic Properties, and its Therapeutic Efficacy. Drugs, v. 34, n. 1, p. 5097, 1987.

WORLD HEALTH ORGANIZATION - WHO. Control of the leishmaniasis: report of a meeting of the WHO Expert Committee on the Control of Leishmaniases, Geneva, 22-26 March 2010.

WORLD HEALTH ORGANIZATION - WHO. LEISHMANIASIS IN THE AMERICAS TREATMENT RECOMMENDATIONS. Washington, DC, 2015.

WORLD HEALTH ORGANIZATION - WHO. Leishmaniasis. 2021. Disponível em: https://www.who.int/health-topics/leishmaniasis\#tab=tab_1. Acesso em: 10 set. 2021.

WU, G.; MORRIS JR., S. Arginine metabolism: nitric oxide and beyond.

Biochem. J., v. 17, n. 366, p. 1 - 17, 1998.

ZAIONCZ, S.; KHALIL, N. M.; MAINARDES, R. M. Exploring the Role of Nanoparticles in Amphotericin B Delivery. Current Pharmaceutical Design, v. 23, n. 3, p. 509-521, 2016. 